\title{
STRUCTURAL BEHAVIOUR OF REINFORCED HIGH PERFORMANCE CONCRETE FRAMES SUBJECTED TO MONOTONIC LATERAL LOADING
}

\author{
By: \\ Ali Ehsani Yeganeh \\ BEng, Ryerson University, Toronto, Ontario, 2013
}

\begin{abstract}
A Thesis
Presented to Ryerson University

In partial fulfillment of the Requirements for the

Master of Applied Science In the program of Civil Engineering
\end{abstract}

Toronto, Ontario, Canada, 2015

(C) Ali Ehsani Yeganeh 2015 


\begin{abstract}
AUTHOR'S DECLARATION
I hereby declare that I am the sole author of this thesis. This is a true copy of the thesis, including any required final revisions, as accepted by my examiners.

I authorize Ryerson University to lend this thesis to other institutions or individuals for the purpose of scholarly research.

I further authorize Ryerson University to reproduce this thesis by photocopying or by other means, in total or in part, at the request of other institutions or individuals for the purpose of scholarly research.

I understand that my thesis may be made electronically available to the public.
\end{abstract}




\title{
STRUCTURAL BEHAVIOUR OF REINFORCED HIGH PERFORMANCE CONCRETE FRAMES SUBJECTED TO MONOTONIC LATERAL LOADING
}

\author{
Ali Ehsani Yeganeh \\ Masters of Applied Science, 2015 \\ Department of Civil Engineering \\ Ryerson University, Toronto, Canada
}

\begin{abstract}
This thesis describes the structural performance of reinforced one storey flexural and shear-critical frames made of high performance concretes (HPCs) such as: self-consolidating concrete (SCC), engineered cementitious composite (ECC) and ultra-high performance concrete (UHPC) subjected to monotonic lateral loading. The performance of SCC/ECC/ UHPC frames are described based on load-deformation/moment-rotation responses, stiffness, strain developments, crack characterization, failure modes, ductility and energy absorbing capacity. The experimentally obtained moment and shear capacities of the frames are compared with those obtained from Codes and other existing design specifications. Overall, ECC frames showed better performance in terms of higher energy absorbing capacity and ductility compared to SCC/UHPC frames. ECC/UHPC frames showed higher load carrying capacity compared to SCC frames. ECC and UHPC shearcritical frames without shear reinforcement were able to prevent shear failure due to fiber bridging and crack control characteristics contributing to the enhanced shear resistance of the matrix.
\end{abstract}




\section{ACKNOWLEDGEMENT}

I wish to express my deepest gratitude to my supervisor Professor Dr. Khandaker. M. Anwar Hossain whose insight, guidance, meticulous review, and criticism of the work had a significant impact on this thesis. Without his time and countless efforts, this thesis would not have been completed. His inspirational attitude toward research, trust in his graduate students, and insight into the problems left a significant impression on this work. I cannot thank him enough as my life will always bear an imprint of his teachings and vision.

I would also like to thank the committee for their revisions and suggestions. I also wish to thank all my colleagues in the Civil Engineering Department at Ryerson University; especially PhD Candidate Mohammed Sherir for his help and support.

Finally, I am forever indebted to my parents for giving me the support throughout my life. Also deep gratitude is expressed to my wife Mehrnoush for her strong support and encouragement. 


\section{Dedications}

To my parents

That sacrifice their life for my greatest success 


\section{Table of Contents}

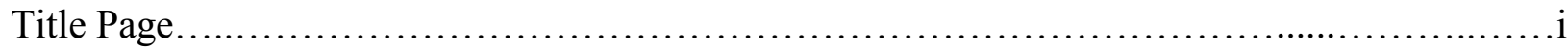

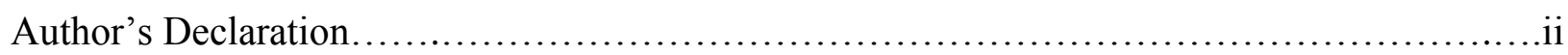

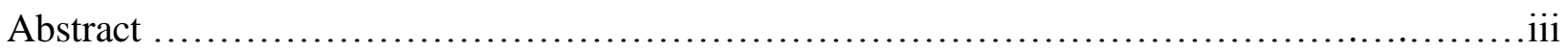

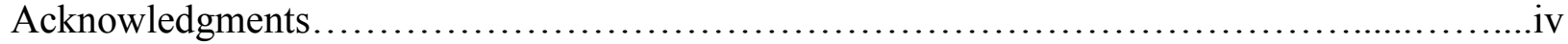

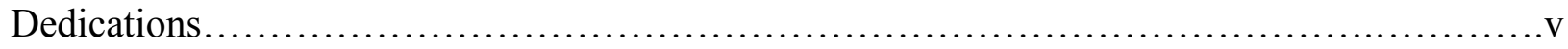

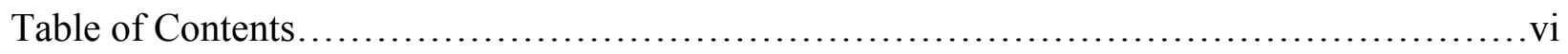

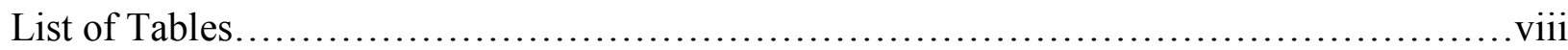

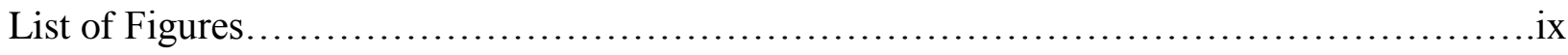

List of Symbols and Abbreviations.........................................................

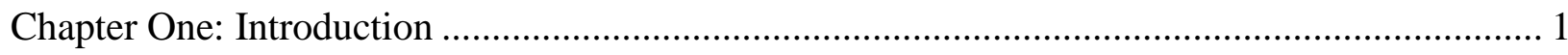

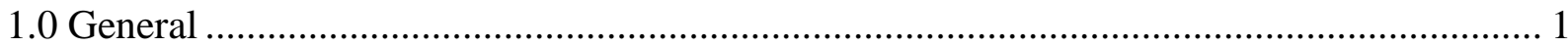

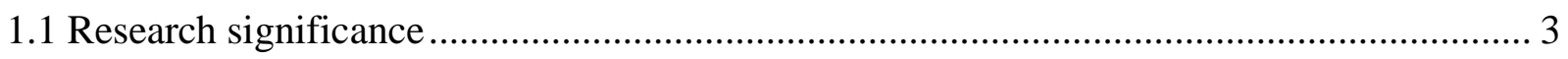

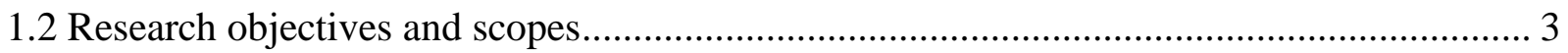

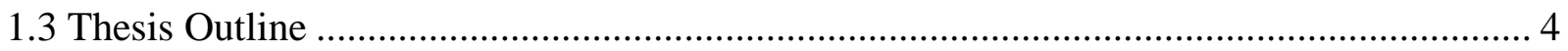

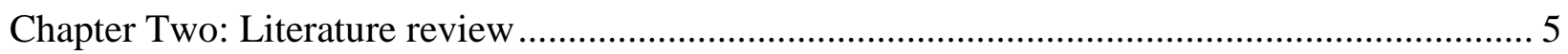

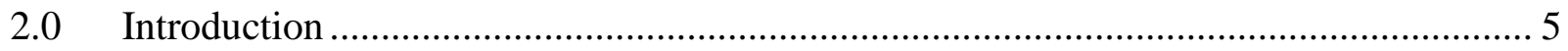

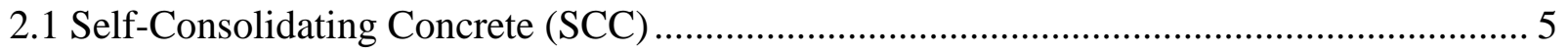

2.2 Engineered Cementitious Composite (ECC)............................................................... 6

2.3 Ultra-high performance concrete (UHPC) ……….................................................... 10

2.4 ECC/UHPC structural applications and Research on structural performance ..................... 13

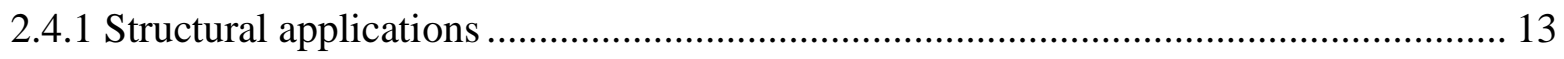

2.4.2 Research on structural performance research ..................................................... 18

2.5 Design aspects of high performance concrete members .................................................... 23

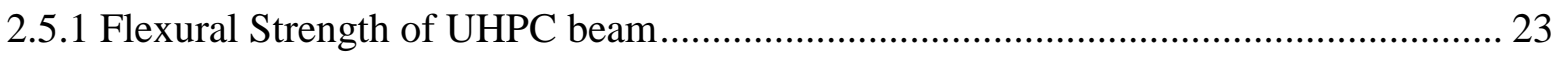

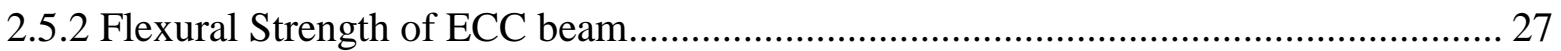

2.5.3 Shear Strength of UHPC and ECC beams without stirrups........................................ 29

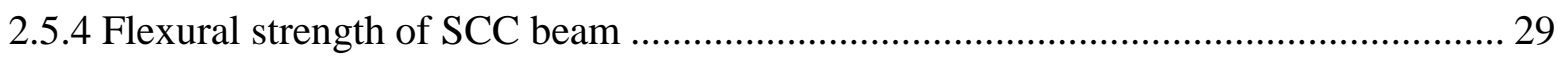

2.5.5 Shear strength of UHPC and ECC beams with stirrups ............................................... 32 


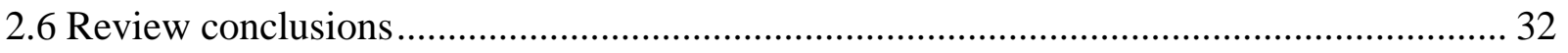

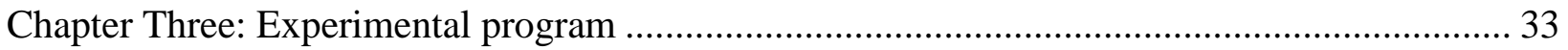

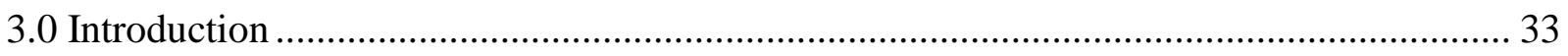

3.1 Geometric dimensions of frame specimens and reinforcement details .............................. 33

3.2 Material properties and construction model frame …………………………………...... 38

3.2.1 Mix design and mixing sequences for SCC, ECC and UHPC …………................... 38

3.2.2 Fabrication and construction of model frame specimens ............................................ 40

3.3 Frame instrumentation, test set-up and testing ............................................................... 45

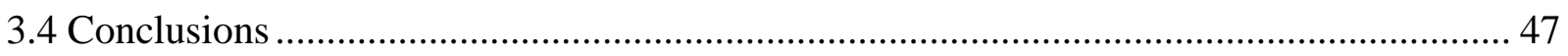

Chapter Four: Structural performance of reinforced ECC/UHPC frames - Results and Discussion

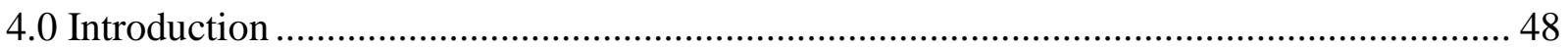

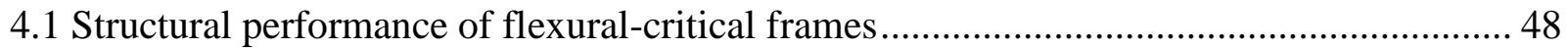

4.1.1 Experimental load-deflection/moment-rotation responses and strength/stiffness........ 48

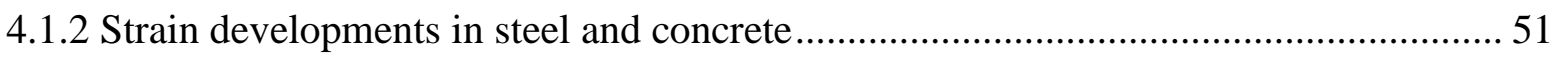

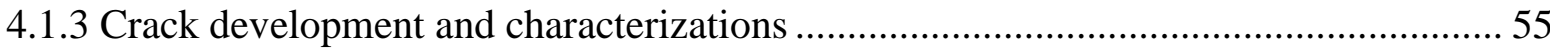

4.1.4 Initial stiffness, energy absorption capacity and ductility of RC frames....................... 59

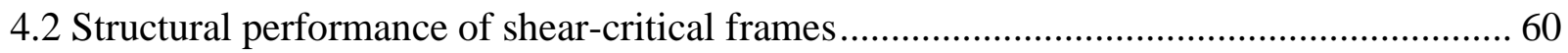

4.2.1 Experimental load-deflection/moment-rotation responses and strength ...................... 60

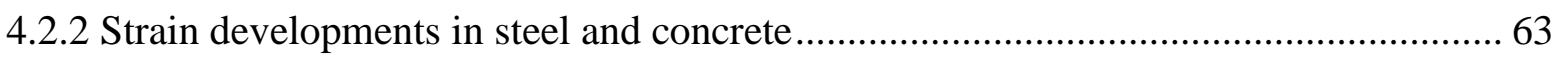

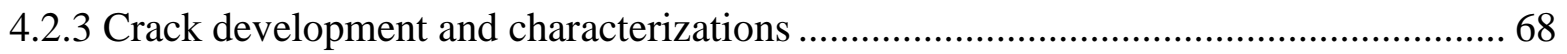

4.2.4 Initial stiffness, energy absorption capacity and ductility of shear critical RC frames 70

4.3 Comparison of performance of flexure and shear critical frames ...................................... 71

4.4 Comparison of experimental results with Codes/existing design equations ........................ 72

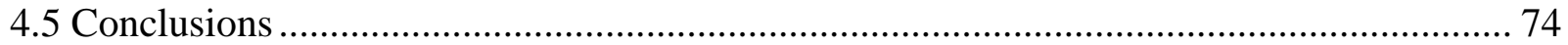

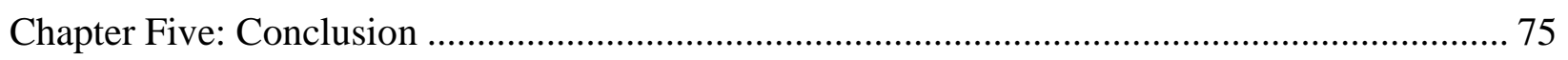

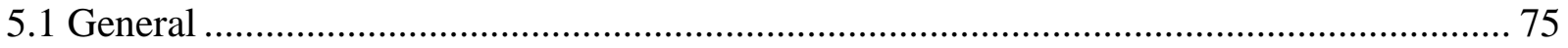

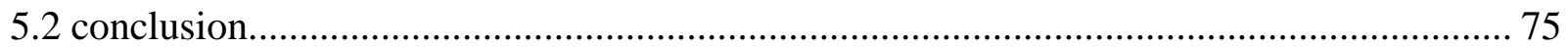

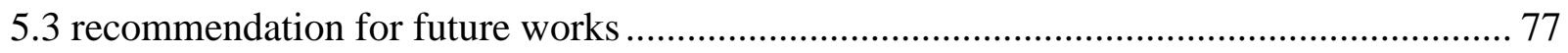

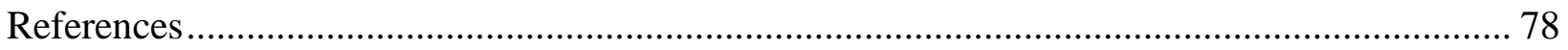

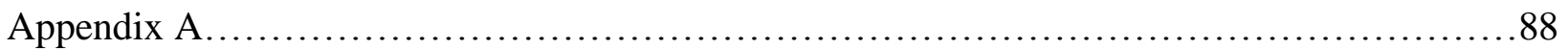




\section{List of Tables}

Table 3.1 Geometric dimensions and reinforcement details of frames.......................38

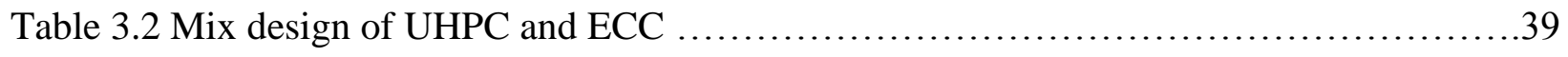

Table 3.3 Concrete compressive and flexural/tensile strength $\ldots \ldots \ldots \ldots \ldots \ldots \ldots \ldots \ldots \ldots \ldots \ldots \ldots$

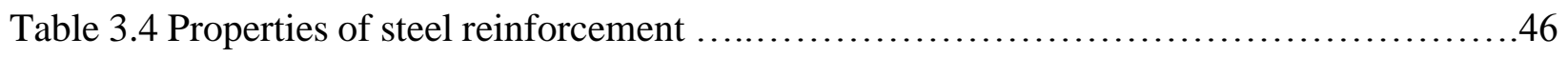

Table 4.1 Summary of load-deflection and moment rotation responses ......................50

Table 4.2 Summary of strain developments and yield load .............................56

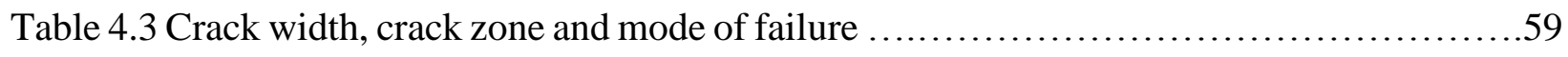

Table 4.4 Initial stiffness, energy absorption capacity and ductility of RC frames ............60

Table 4.5 Summary of load-deflection and moment rotation responses ....................64

Table 4.6 Summary of strain developments and yield load ...........................69

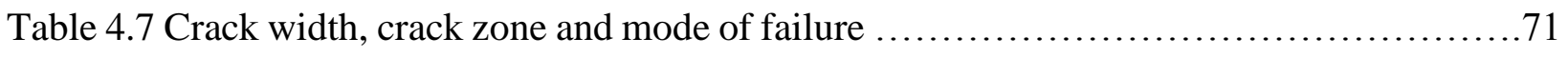

Table 4.8 Initial stiffness, energy absorption capacity and ductility of RC frames .............71

Table 4.9 Performance evaluation of shear critical and flexure critical frames .................72

Table 4.10 Theoretical and experimental values for shear and moment capacities .............73 


\section{List of Figures}

Figure 2.1 Tensile Stress-Strain Curve and Crack Width Development $\ldots \ldots \ldots \ldots \ldots \ldots \ldots \ldots \ldots \ldots$

Figure 2.2 Ductile response of ECC under flexural .....................................

Figure 2.3 Overview of Mihara Bridge ...............................................

Figure 2.4 Spray repair of the Mitaka Dam with ECC for water-proofing $\ldots \ldots \ldots \ldots \ldots \ldots \ldots \ldots \ldots 14$

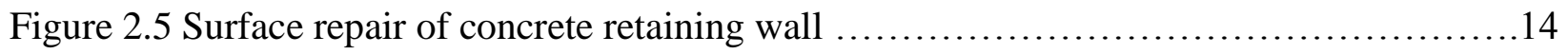

Figure 2.6(a) Patch repair on a bridge deck ......................................... 15

Figure 2.6(b) Crack width development in concrete patch and ECC patch over time ..............15

Figure 2.7 ECC link slab on Grove Street Bridge, Michigan, USA $\ldots \ldots \ldots \ldots \ldots \ldots \ldots \ldots \ldots \ldots$

Figure 2.8 The Nabeaure Tower in Yokohoma, Japan under construction and schematics.......17

Figure 2.9 Stress-force-strain distribution of reinforced UHPC beam ......................23

Figure 2.10 Modified strain- stress-force distribution of reinforced UHPC beam ...............24

Figure 2.11 Stress-strain distribution of reinforced ECC member .........................27

Figure 2.12 Stress-strain and force distribution for rectangular SCC beam ...................30

Figure 3.1 Typical beam-column frame fixed to the based beam with instrumentation ............34

Figure 3.2 Geometric dimensions and reinforcement details for flexural critical frame............36

Figure 3.3 Geometric dimensions and reinforcement details for shear critical frame ............37

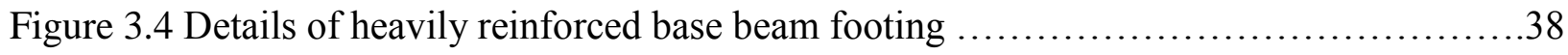

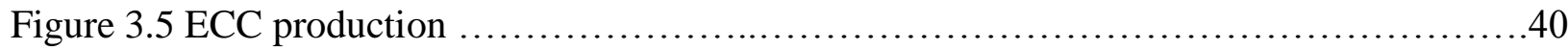

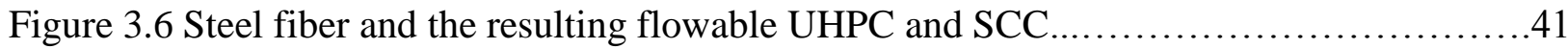

Figure 3.7 Typical formwork showing reinforcement and strain gauges for flexural critical

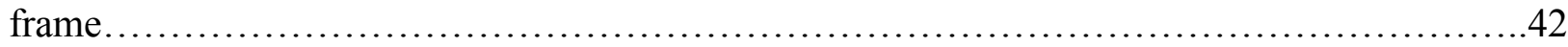

Figure 3.8(a) Typical model frame and formwork after casting with control specimens ........42

Figure 3.8(b) Typical model frame and formwork after casting with control specimens ........43

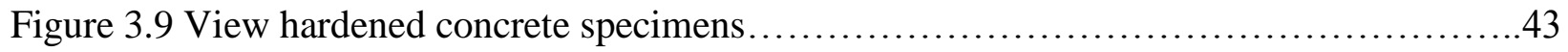

Figure 3.10 Flexural stress-displacement responses of UHPC, ECC and SCC ...............44 
Figure 3.12 Stress-strain/deformation responses of steel bars.................................45

Figure 3.13 Locations of concrete and steel strain gauges in flexural critical frames...............47

Figure 3.14 Locations of concrete and steel strain gauges in shear critical frames................47

Figure 3.15 Test set-up Locations of concrete and steel strain gauges in shear critical frames.....48

Figure 4.1(a) Lateral load-top deflection responses of SCC/ECC/UHPC frame/column..........51

Figure 4.1(b) Moment-rotation response of SCC/ECC/UHPC frame/column.....................51

Figure 4.1(c) Lateral load-vertical central deflection response of beam in SCC/ECC/UHPC

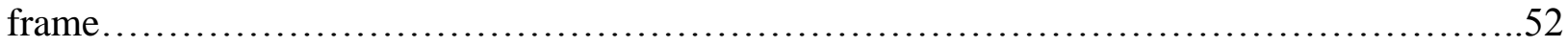

Figure 4.1(d) SCC/ECC/UHPC frame lateral load-displacement responses at LVDT

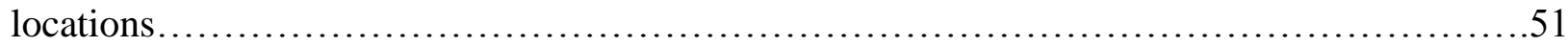

Figure 4.2(a) Concrete flexural strain development in SCC/ECC/UHPC frames ...............53

Figure 4.2(b) Comparative concrete strain development in SCC/ECC/UHPC frames ............54

Figure 4.3(a) Rebar strain development for SCC/ECC/UHPC frame............................55

Figure 4.3(b) Comparative rebar strain development at typical strain gauge locations ............55

Figure 4.4(a) Crack development and failure mode of SCC frame............................57

Figure 4.4(b) Crack development and failure modes of ECC/UHPC frames...................58

Figure 4.5 Crack zones on flexural-critical frames.......................................5

Figure 4.6 SCC/ECC/UHPC frame lateral load-displacement responses at LVDT locations.......62

Figure 4.7(a) Lateral load-top deflection responses of SCC/ECC/UHPC frame/column..........63

Figure 4.7(b) Moment-rotation response of SCC/ECC/UHPC frame/column ...................63

Figure 4.7(c) Lateral load-vertical central deflection response of beam in SCC/ECC/UHPC

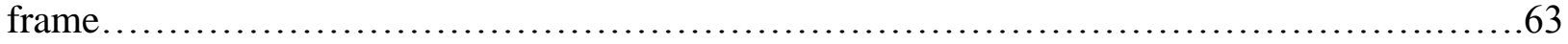

Figure 4.8(a) Concrete flexural strain development in SCC/ECC/UHPC frames ...............65

Figure 4.8(b) Comparative concrete strain development in SCC/ECC/UHPC frames ...........66

Figure 4.9(a) Strain development in longitudinal and shear reinforcement- SCC/ECC/UHPC

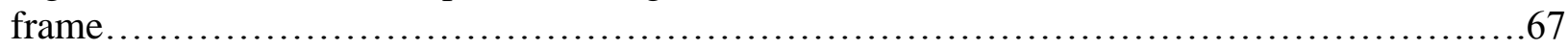

Figure 4.9(b) Comparative rebar strain development at typical strain gauge locations............68

Figure4.10 Crack development and failure modes of shear-critical SCC/ECC/UHPC frames 


\section{List of Symbols and Abbreviations}

a: Depth of the equivalent compressive block

$a_{b}$ : The balance depth of the compression zone

$A_{f}$ : Cross-sectional area of steel fibers

$\mathrm{A}_{\mathrm{s}}$ : Area of tensile steel bars

$a_{s}:$ Shear span

$A_{s, \min }$ : Minimum of tensile reinforcement

$A_{v}:$ Area of shear reinforcement

$A_{v, \min }$ : Minimum area of shear reinforcement

b: Width of the beam

$b_{t}$ : The width of tension zone

c: The distance of natural arises from the top fiber

$\mathrm{C}$ : Concrete compressive force

$C_{E C C}$ : ECC Concrete compressive force

$d_{a}$ : Maximum aggregate size

$d_{f}$. Diameter of fibers

$\mathrm{D}_{\mathrm{f}}$ : Lateral displacement at $80 \%$ of ultimate load at the descending part of the curve

DI: Ductility Index

$d_{v}$ : Effective depth of concrete block

$\mathrm{D}_{\mathrm{y}}$ : Lateral displacement at $80 \%$ of ultimate load at the ascending part of the curve

$E_{f}$ : Modulus of elasticity of steel fibers

F: Average pullout stress of fiber

$f_{c}^{\prime}$ : Compressive strength of normal strength concrete

$\mathrm{f}_{\mathrm{cf}}$ : Compressive strength of fibrous concrete

fy: Yield strength of tensile reinforcement bar

$f_{m c}$ : UHPC limiting compressive strength

$f_{m t}$ : UHPC tensile stress

$G_{m}$ : Shear modulus of concrete matrix 
$h$ : The overall height of the beam

$l_{f}$ : Length of fibers

$M_{f}$ : Moment resisting capacity of normal concrete

$M_{n}$ : Nominal moment capacity of UHPC beam

$M_{r}$ : Resisting moment capacity

$n_{\varepsilon}:$ represent the strain modular ratio

$r_{f}$ : Radius of steel fibers

$s$ : Spacing between shear reinforcement

$\mathrm{T}_{\mathrm{c}:}$ UHPC tensile force based on fiber contribution

$T_{E C C-1}$ : ECC concrete tensile force

$T_{E C C-2}:$ ECC concrete tensile force

$\mathrm{T}_{\mathrm{ps}}$ : UHPC steel reinforcement force

$T_{\text {Steel }}$ : ECC tensile force of steel

$\mathrm{V}_{\mathrm{c}}$ : Concrete shear capacity

$V_{f}:$ : Volume fraction of fibers

$V_{m}$ : Volume fraction of the matrix

$\mathrm{Vp}$ : shear resistance capacity of pre-stress reinforcement

Vs: shear resistance of stirrups

$\mathrm{V}_{\text {shear: }}$ Resisting shear capacity

$\alpha_{1}$ : Concrete stress block parameter

$\beta_{1}$ : Concrete stress block parameter

$\varepsilon_{c}$ : Concrete Strain

$\varepsilon_{f}$ : Fiber tensile strain

$\varepsilon_{m c}$ : UHP Concrete compressive strain at the top fiber

$\varepsilon_{m t}$ : UHP Concrete tensile strain

$\varepsilon_{p s}:$ UHPC reinforcement strain

$\varepsilon_{y}:$ Reinforcement strain

$\varepsilon_{y-E C C}:$ Yield strain of ECC

$\varepsilon_{y-\text { steel }}$ : ECC yield strain of steel

$\rho_{s}$ : Longitudinal reinforcement ratio 
$\sigma_{c}$ : Ultimate tensile strength of steel fiber reinforced composite prior to cracking $\sigma_{f}$ : Ultimate pull out strength of steel fiber

$\sigma_{m}$ : Ultimate tensile strength of un-cracked concrete matrix

$\varphi_{c}$ : Concrete Reduction factor

$\varphi_{s}:$ Steel reduction factor

$\lambda$ : Concrete stress block parameter

$\eta_{b}$ : Fiber bond efficiency factor

$\eta_{l}$ : Fiber length efficiency factor

$\eta_{o}$ : Fiber orientation factor

$\theta$ : Cracks angle

$\tau_{f}$ : Bond strength between the fiber and matrix 


\section{Chapter One: Introduction}

\subsection{General}

Civil infrastructure constitutes a major proportion of Canada's wealth and thus, it behooves the scientific community and relevant industries to develop new, cost-effective construction materials with superior qualities that exceed the performance of currently available materials. During the last decades, tremendous progress has been made on the high performance concretes (HPCs). Such HPC technology involves the family of highly durable fibre reinforced engineered cementitious composite (ECC) and ultra-high strength/performance concrete (UHSC/UHPC).

Compared to traditional concrete, UHPC demonstrated advantages such as outstanding mechanical properties, ductility and durability (Acker and Behloul 2004, Tafraoui et al. 2009, Hossain et al. 2011, Hossain et al. 2014; Mak et al. 2011). Incorporation of high volume of steel fibers and homogenized microstructure lead to UHPC's higher compressive strength, improved toughness and increased damage tolerance and high strain capacity. Such properties make UHPC material very attractive to use in heavily loaded components and civil infrastructures (Doo et al. 2013, Tawfik et al, 2013, Hosinieh et al, 2015, Blais and Couture 1999, Hajar et al. 2004, Bierwagen and Abu-Hawash 2005, Hossain et al. 2012).

UHPC is characterized by high strength with moderate ductility while ECC materials commonly have high ductility, tight crack width and low to high strength. Micromechanical design allows optimization of ECC for high performance. Poly-vinyl alcohol (PVA) fiber is successfully in the production of moderate strength ECC while PVA/polyethylene (PE) fibers can also be used for high strength. ECC strain hardens after first cracking, like a ductile metal, and demonstrates a strain capacity 300 to 500 times greater than conventional concrete. Even at large deformation, crack widths of EC remain less than $60 \mu \mathrm{m}$ (Li, 2003; Li \& Kanda, 1998; Li et al. 2002). The multiple micro-cracking behavior and high strain hardening characteristic of ECC components under tension and flexure with relatively low reinforcing fibers contents (less than $2 \%$ by volume) makes it an ideal material for structural applications (Fischer and Li, 2003; Sahmaran et al. 2010; Shahman and Li 2010; Li 1998; Li et al.2001).

During the last 10 years, research at Ryerson University have been devoted to developing sustainable HPCs (including self-consolidating concrete 'SCC', fiber reinforced SCC, ECC and 
UHPC) and innovative structural systems/construction technologies. Ryerson's research team has developed a UHPC through evaluation of mechanical/durability properties and structural performance in bridge deck joints (Sherir et al. 2015, Hossain et al. 2011, 2012, 2014). Team has also pioneered the development of green cost-effective ECC incorporating locally available aggregates/industrial wastes (Sahmaran 2009, Ozbay et al. 2011, Sherir 2012) and their potential applications in 'joint-free bridge deck with link slab', 'composite framed shear wall system' and 'coupling slab in shear wall structures' (Issani and Hossain 2013, Rafiei et al. 2013, Hossain and Taormina 2012). In addition, team has incorporated local sands into ECC instead of relatively expensive and difficult to obtain micro-silica sand. Extensive research studies have been conduct on material properties of the ECC by incorporating different supplementary cementitious material (SCM), sand aggregates and different types and configuration of fibers. ECC mixtures have been developed by incorporating supplementary cementitious materials such as fly ash, volcanic ash, blast furnace slag and metakaolin as replacement of cement as well as different type, size and volume of fibers (Hossain \& Anwar, 2014; Sherir, 2012; Maulin, 2012; Sahmaran et al. 2010, Ozbay et al. 2011, 2012). Research at Ryerson also lead to the development of a UHPC having a compressive strength of over $140 \mathrm{MPa}$. Fresh, mechanical and durability properties including bond strength of developed UHPC (known as Ryerson mix) as well as its structure performance as closure strip material in bridge deck have been investigated (Ametrano 2010, Mak et al. 2011, Hossain et al. 2010, 2011, 2012, 2014).

With superior mechanical and durability properties, UHPC and ECC are the materials of future which offer significant potential to resolve durability problems of RC structures. Given the worldwide demand for infrastructure systems, the potential application of ECC and UHPC either in new construction or as repair/retrofitting material is enormous. The combination of greener material, deterioration resistance, decreased maintenance and extended life cycle suggests that the sustainability of ECC/UHPC based infrastructure will be far superior to those with conventional concrete. 


\subsection{Research significance}

The use of ECC and UHPC in construction of building and bridge structures have been a new emerging technology. Although research to lead to the development of ECC and UHPC mixes, their performance in such structural elements has not been optimized and performance criteria have not been defined. Design guidelines/performance-based design procedures incorporating structural performance and serviceability of ECC/UHPC based structural elements are not available in Codes. The lack of research studies specifically in Canada requires a detailed investigation on performance of ECC and UHPC mixes in infrastructure to understand structural behavior and to develop design guidelines and specifications. The proposed research on the lateral load resistance of reinforced ECC/UHPC/SCC moment and shear critical frame is an important step towards the development and construction of robust and sustainable high-performance structural systems (with enhanced strength, ductility, durability, service life and economy) for the 21 st century. The findings of this research will surely benefit engineers, builders and local authorities when designing and constructing civil infrastructures.

\subsection{Research objectives and scopes}

The main objectives of this research program are to:

- Evaluate the structural performance of one-storey flexural-critical (using both flexural and shear reinforcement) and shear-critical (using only flexural reinforcement) beam-column frame specimens of $1 / 3^{\text {rd }}$ scale by conducting experimental tests under lateral monotonic loading to failure by incorporating ECC (a green cost-effective mix with high volume fly ash) and UHPC materials. Analyze the performance based on through loaddeformation/moment-rotation responses, stiffness, strain developments, crack characterization, crack widths, ductility, energy absorbing capacity of the frames and stiffness.

- Compare the performance of ECC and UHPC flexural/shear critical frames with their SCC counterparts based on the above mentioned criteria. Also compare the performance flexural and shear-critical frame and discuss the influence of concrete materials.

- Compare the experimentally obtained moment and shear capacity of flexural and shearcritical frames with those obtained from Code based equations and other existing design specifications. 


\subsection{Thesis Outline}

This thesis consists of 5 chapters presenting experimental and theoretical investigations on the structural performance of flexural and shear-critical frames made with SCC, ECC and UHPC materials.

Chapter 1 introduces ECC and UHPC materials and summary of advancement of ECC/UHPC technology. It also describes the objectives and scopes of this research with a thesis outline.

Chapter 2 presents the comprehensive literature review on materials, mix design and properties of SCC, ECC and UHPC including practical construction applications. It also presents research conducted on SCC/ECC/UHPC structural elements including building frames and design flexural/shear design procedures ECC/ECC/UHPC beams based on Codes and other existing design specifications.

Chapter 3 describes the experimental program including material properties, geometric dimensioning of flexural and shear-critical frames models, casting/curing of specimens, test setup, instrumentation and testing procedures.

Chapter 4 presents the results of the experimental investigation on $1 / 3^{\text {rd }}$ scale frame specimens subjected to monotonic lateral loading. The performance is described based on the loaddeflection/moment-rotation response, strain developments, crack characterization, ductility, energy absorption, stiffness and failure modes. The influence of different materials (ECC and UHPC) on the structural performance of flexural and shear-critical frame is described and compared with those made with SCC. In addition experimentally obtained moment and shear resisting capacity of the members of different frames are compared with those obtained from theoretical analysis based on Codes and other existing design specifications.

Chapter 5 summarizes the findings of the research and provides recommendation for future research studies. 


\section{Chapter Two: Literature review}

\subsection{Introduction}

The use of new generation of high performance concretes (HPCs) such as self-consolidating concrete (SCC), engineered cementitious composite (ECC) and ultra-high strength/performance concrete (UHSC/UHPC) can significantly improve the process of casting through selfconsolidation as well as improve the strength, ductility and durability of structures. The chapter presents the following: (a) mix design and properties of SCC, ECC and UHPC, (b) research studies conducted on SCC/ECC/UHPC structural elements, (c) practical construction applications of SCC/ECC/UHPC, (d) design aspects of SCC/ECC/UHPC beams and (e) summary to illustrate the need for proposed research study in the context of current state of the technology.

\subsection{Self-Consolidating Concrete (SCC)}

Self-Consolidating Concrete (SCC) is a highly flowable concrete that can flow into place under its own weight. SCC achieves good consolidation without external or internal vibration and also without defects due to bleeding or segregation (Ozawa et al. 1989; Li 1995; Yurugi 1998; Petersson 1998; Khayat et al. 2001; Lachemi et al. 2003; Poon and Ho 2004b; Khatib 2008). SCC typically has a higher content of fine particles and improved flow properties compared to the conventional concrete. SCC can be used to improve the productivity of casting congested sections and also to insure the proper filling of restricted areas with minimum or no consolidation (Khayat 1999). SCC showed greater homogeneity of distribution of in-place compressive strength than conventionally vibration-compacted concrete. SCC can improve the working environment by eliminating the noise and pollution caused by vibrators and also reduces labour cost. SCC was developed in Japan in the early 1980's (Hayakawa et al. 1993; Hossain and Lachemi 2010).

High-strength SCC usually has a low water/cementitious material ratio which requires high binder content, but results in the addition of high range water reducers or superplastizer (Behnood and Ziari 2008). But it is important to do mix proportioning in a manner that prevents segregation of the concrete. Previous investigation by Yahia et al. (1999) has shown that the amount of superplastizer can be reduced by the addition of fly ash and blast furnace slag to have the similar slump flow compared to concrete made with Portland cement only. 
Several different approaches can be used to develop SCC. One approach is to replace the coarse aggregates by sand at a ratio of $5 \%$ to $4 \%$, which in turn requires a high volume of cement (Lachemi et al. 2003). Another method is to design SCC by incorporating viscosity modifying admixture (VMA) to improve the stability. Commercial VMA currently available in the market is costly and may increase the price of such a concrete (Lachemi et al. 2003). VMAs are water soluble polymers which enhance the ability of cement paste to retain its constituents in suspension and also increase the viscosity of the mixture. Using VMA with super-plasticizers can ensure adequate workability without segregation. The last technique is to increase significantly the amount of fine materials such as fly ash, volcanic ash and slag cement without changing the water content compared to common concrete. This method is the least expensive of the three mentioned above and these supplementary cementing materials help create highly flowable cohesive mixtures at a lower cost with high durability (Lachemi et al. 2003; Hossain and Lachemi 2010).

\subsection{Engineered Cementitious Composite (ECC)}

Engineered Cementitious Composite (ECC) is a class of ultra-ductile fiber reinforced composites originally invented at the University of Michigan in the early 1990s ( $\mathrm{Li} \mathrm{1993).} \mathrm{ECC} \mathrm{is}$ characterized by high ductility under uniaxial tensile loading in the range of 3-7\%. It has a tight crack width of around 60-100 $\mu \mathrm{m}$, which improves durability (Wang and Li 2007; Sahmaran and Li 2010; Sahmaran et al. 2011). The sequential development of multiple cracks, instead of continuous increase of crack opening contributes to larger tensile strength capacity in the range of 3 to 5\% (Wang and Li 2007). When cracking begins in ECC, it undergoes strain-hardening and has a 300-500 times higher strain capacity than normal concrete. Cracks in ECC do not widen any further after the initial cracks are formed, which allow for additional tensile deformation to occur through the propagation of micro cracks, with spacing about 1-2 mm (Sahmaran et al. 2011). Under compressive loads, ECC exhibits compressive strength of 60MPa, similar to high strength concretes. Under compressive loading, ECC reaches its compressive strength at higher strain due to the exclusion of aggregates and as a consequence has a lower modulus of elasticity than conventional concrete (Fischer and Li 2003). It has relatively low fiber content of $2 \%$ or less by volume (Li 1998; Li et al. 2001; Li 2003; Sahmaran and Li 2010; Sahmaran et al. 2011). 
The addition of fibers in ECC increases tensile strength, ductility and toughness and improves durability. The efficiency of the fiber reinforcement is affected by the properties of the concrete mix, as well as the fiber geometry, size, type, volume and dispersion. The typical fibres used in ECC are polypropylene (PP), glass (GF), carbon (CF) and polyvinyl alcoholic (PVA) (Cavdar 2012). The most common fiber used in ECC is the polyvinyl alcohol (PVA) fiber with a diameter of $39 \mu \mathrm{m}$ and a length of 6-12 mm (Li et al. 2001; Kunieda and Rokugo 2006).

ECC contains higher cement content, when compared with conventional concrete. This high cement content is used to promote better fiber dispersion, rheology control or workability, and most importantly to promote strain hardening behavior. The exclusion of aggregates in ECC explains the increased cement content. In order to reduce the amount of cement used in ECC, supplementary cementing materials such as fly ash or blast furnace slag can be incorporated into the mix design. In order to have adequate workability, while maintaining a water-to-cementitious material ratio of around 0.25 to 0.3 , a high range water reducer or superplastizer must be employed (Wang and $\mathrm{Li}$ 2007). In general the aggregates in ECC are either silica sand (usually with an average particle size of a 100-200 micrometres), crushed sand or gravel sand of nominal sizes of around one or two millimetres.

It was observed that ECC with silica sand yielded slightly higher compressive strength than those with gravel sand and crushed sand, with crushed sand having higher compressive strength than gravel sand (Sahmaran and Li 2009). Large aggregates are not used in ECC because the large aggregates would hinder micro-scale interactions between fiber and the concrete matrix. These interactions are important for promoting the strain-hardening behavior of ECC. Eliminating large aggregates also promotes low matrix fracture toughness (Lepech et al. 2008).

In order to have tight micro crack width and high tensile ductility while keeping the fiber content low (2\% or less by volume), ECC has been optimized through the use of micromechanics (Li 1993, Sahmaran and Li 2009). Micromechanics is a branch of mechanics applied at the material constituent level that captures the mechanical interactions among the fiber, mortar matrix, and fiber matrix interface. Usually, fibers are of the order of millimeters in length and tens of microns in diameter, and they may have a surface coating on the nanometer scale (Nawy 2008). 
Different types of fibers have been incorporated into ECC mixtures, but PVA fibers were found to be most effective and efficient for achieving the strain hardening characteristic after the first crack formation (Weimann \& Li 2003). The typical uniaxial tensile stress-strain curve and cracking development of the ECC at 2\% PVA fiber is presented in Figure 2.1.

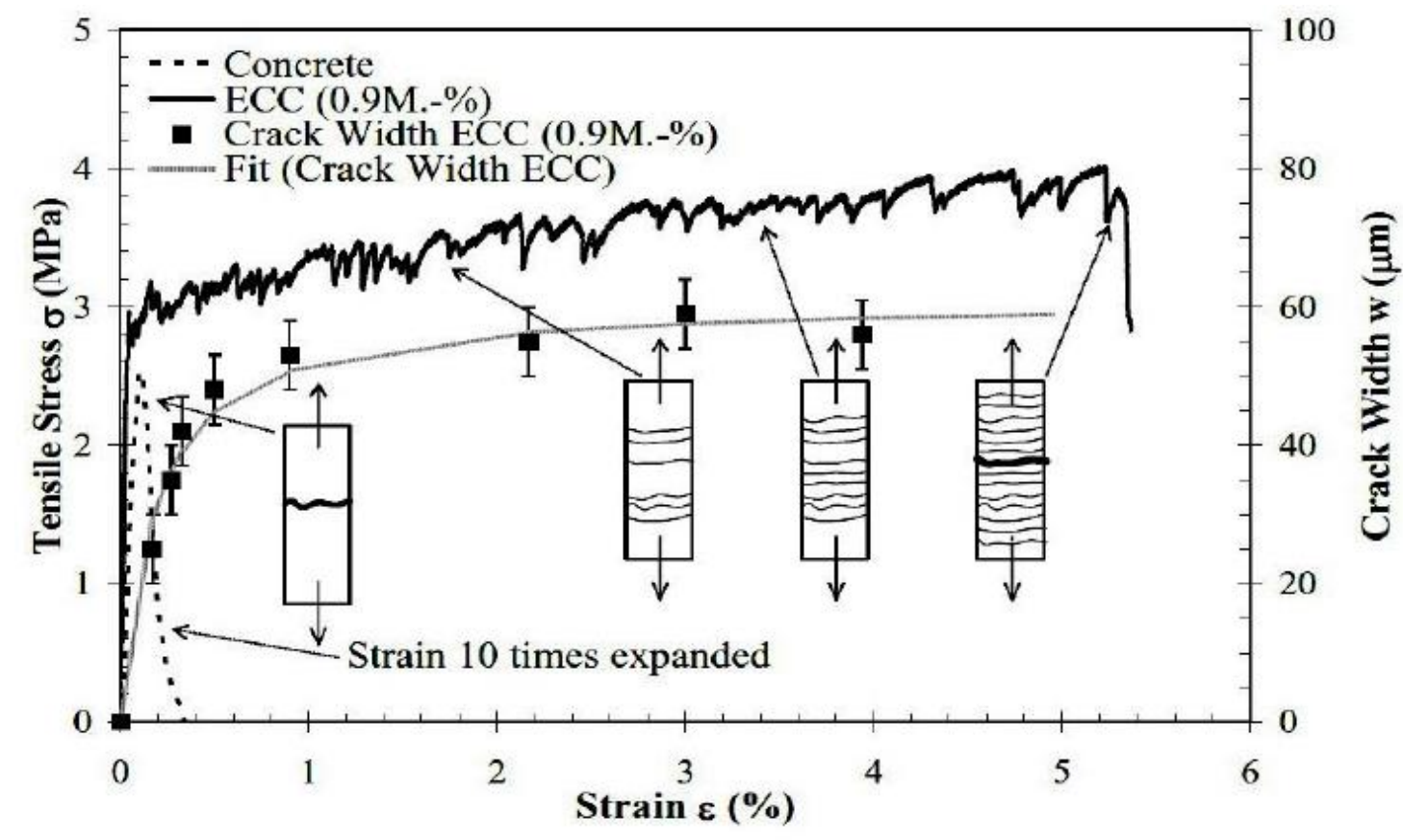

Fig. 2.1: Tensile Stress-Strain Curve and Crack Width Development (Weimann \& Li. 2003)

After first crack formation, ECC's tensile stress is increased further due to its unique strain hardening characteristic. The crack widths at ultimate loading are remained below $80 \mu \mathrm{m}$. The steady-state cracking behaviour is independent to the type of the loading and amount of fiber reinforcement (Özbay et al. 2013; Ranade et al. 2014). The strain hardening characteristic and micro-cracking behaviour are attained by the strength and fracture energy criteria proposed by Kanda and $\mathrm{Li}$ (1998). The satisfaction of the criterion will ensure the initiation of micro-cracking from initial flaw sites in the composites before the tensile loading reach the fiber bridging capacity (Kanda \& Li 1998, Yang \& Li 2006). The use of these micromechanical models for tailoring ECC material ensures the strain hardening characteristic and large bending capacity (Figure 2.2) similar to a ductile metal plate at its plastic deformation phase (Li 2011; Nawy 2008). 
Using the same strength and fracture energy criteria, greener ECC mixes were developed by incorporating locally available crushed sand/mortar sand aggregates and fly $\mathrm{ash} / \mathrm{slag} / \mathrm{metakaolin} / \mathrm{volcanic}$ ash as a replacement of cement (Sahmaran et al. 2009, Ozbay et al. 2012, Sherir 2015, Hossain et al. 2015; Hossain and Anwar 2014; Sherir et al. 2014) further developed. Although each material influenced the mechanical and durability properties of the hardened ECC, but similar responses were attained as observed in experimental results.

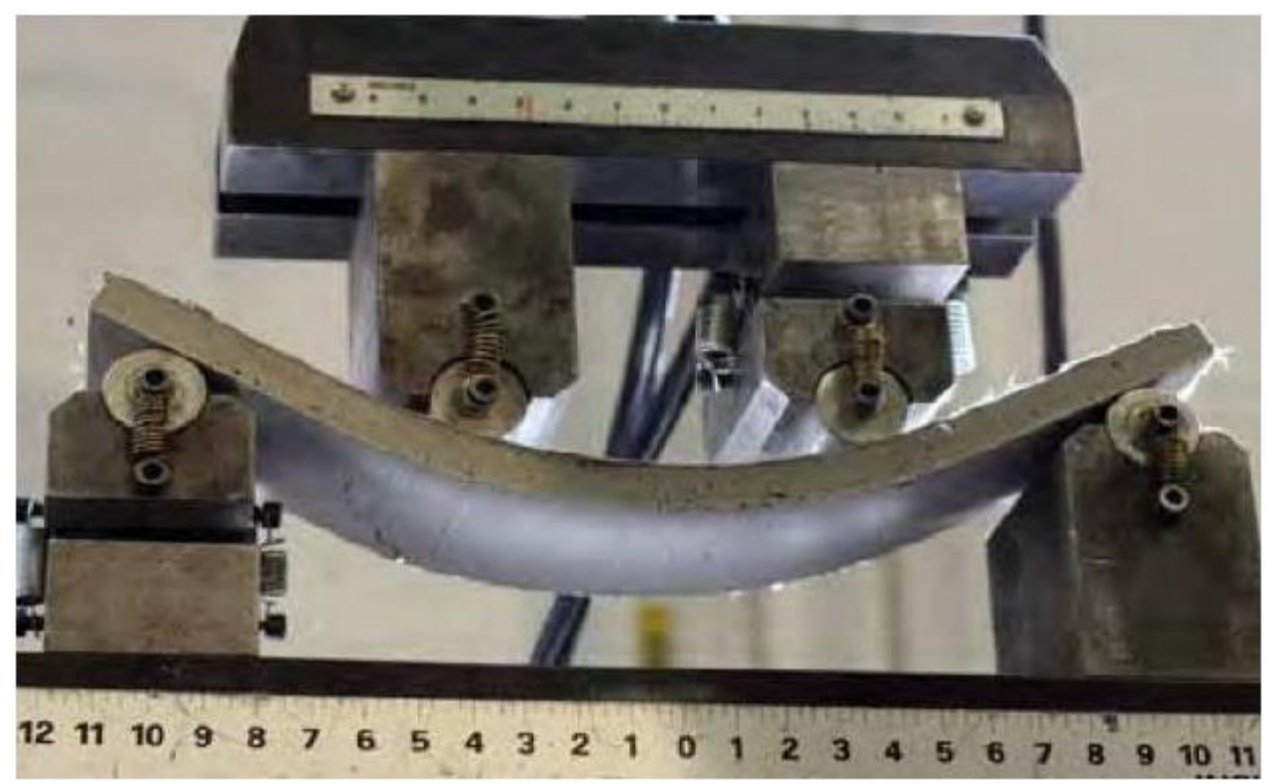

Fig. 2.2: Ductile response of ECC under flexural loading (Li 2011)

\subsection{Ultra-high performance concrete (UHPC)}

UHPC is a high-strength, ductile material formulated by combining powders (Portland cement, silica fume, quartz flour and fine silica sand), high-range water reducer, water, and steel or organic fibers (Richard and Cheyrezy 1995, Dallaire et al 1998, Bonneau et al. 1997, Reda et al. 1998, Tafraoui et al. 2009). UHPC mixtures having compressive strength, flexural strength and modulus of elasticity of more than $100 \mathrm{MPa}, 10 \mathrm{MPa}$ and $60 \mathrm{GPa}$, respectively have been developed (Acker and Behloul 2004, Tafraoui et al. 2009). UHPC offers advantages such as ability to be virtually self placing, speed of construction, and improved aesthetics as well as superior durability against corrosion and superior abrasion/ impact resistance - which translates to reduced maintenance and a longer life span for the structure (Bonneau et al. 1997, Reda et al. 1998). UHPC has the capacity to deform and support flexural and tensile loads, even after initial cracking. Better durability characteristics of UHPCs are the result of improved micro-structural properties of the matrix 
(maximum compactness and small disconnected pore structure due to combination of fine powders and their chemical reactivity) and bond between matrix and fiber.

Since its invention, UHPC technology has been evolved. Many patents have been developed and commercialized by companies such as Ductal ${ }^{\circledR}$ of Lafarge (Acker and Behloul, 2004). UHPC has been successfully used in various types of construction including bridges, seismic-resistant and explosion-resistant structures (Blais and Couture 1999, Hartmann and Graybeal 2001, Fortner 2001, Hajar et al. 2004, Bierwagen and Abu-Hawash 2005). The first bridge project using UHPC was a precast pedestrian bridge in Sherbrooke, Quebec, Canada, constructed in 1997 (Blais and Couture 1999). Since then UHPC has bee used in many bridge projects in North America, Europe, Australia, and Asia. The Footbridge of peace in South Korea is also another example of large scale use of UHPC (Brouwer 2001). A growing number of bridges are being designed and built using UHPC in Europe and United States and opened to traffic in recent years (Hajar et al. 2004, Bierwagen and Abu-Hawash 2005). Such a success is essentially due to UHPCs improved durability and mechanical properties, notably flexural strength, toughness, impact strength, resistance to fatigue and low vulnerability to cracking/spalling. The superior mechanical properties of UHPC make it ideal for prestressed bridge application. Researches have been conducted to study the bond performance of steel and prestressing strands with UHPC where UHPC showed superior bond performance compared to conventional concrete (Logan 1997, Rose and Russel 1997, Mitchel et al. 1993).

While UHPC materials clearly outperform conventional concrete in mechanical and durability performance, their production is proprietary and development of economically competitive alternatives is warranted.

Comprehensive research has been conducted to develop ultra-high performance concrete (UHPC) having a compressive strength of over $140 \mathrm{MPa}$. Fresh, mechanical and durability properties including bond strength of developed UHPC have been investigated (Ametrano 2010, Mak 2011). For the last three years, extensive research has been conducted at Ryerson University in collaboration Ministry of Transportation Ontario (MTO), to develop competitive UHPC materials (Hossain et al. 2010, 2012). The developed UHPC materials have been used to study the bond strength of glass fiber reinforced polymer (GFRP) bars using by pullout/beam specimens, the 
splice length of GFRP bars embedded in UHPC simulating bridge deck construction joints subjected to monotonic/cyclic loading. Recommendations for the bond strength and splice length of GFRP bars embedded in UHPC were made. GFRP bars offer a superior alternative to ordinary steel bars because of their high tensile strength, high elastic modulus and better corrosion resistance (Hossain et al. 2010). In recent times, fiber reinforced polymer (FRP) bar reinforced UHPC is used in accelerated bridge deck construction (Zhu and Ma 2010, Park 2011).

Comprehensive documents on accelerated bridge construction describing design, fabrication and erection of prefabricated bridge elements/systems are available (Culmo 2011). Many systems or connection details are researched between pre-fabricated components (Brackus et al. 2013, Zhu et al. 2012, Li et al. 2010). In terms of connecting deck-type elements, most common technique is to extend reinforcing steel from both prefabricated deck elements forming non-contact lap splice connection, thereafter filling the connection (closure strip) with concrete/grout. However, spliced connection is wide for mild steel bar and requires a large volume of fill material. Other commonly used method is to use bolted, welded, or post-tensioned discrete connecting element within the connection. Such joint detailing proved expensive and difficult to handle at the construction site (Brackus et al. 2013, Zhu et al. 2012, Li et al. 2010).

The use of UHPC in closure strips of prefabricated bridge systems is continually increasing in USA and Canada (Zhu and Ma 2010). UHPC with its ultra-high strength, enhanced ductility and superior durability is accepted as an ideal closure strip material for prefabricated bridge construction. The UHPC closure strips can provide superior deck-level connections between prefabricated components in terms of high shear/flexure strength, better load distribution between adjacent components, reduced splice length, better ductility and superior durability.

In order to have high strength, UHPC usually has low water-to-cementitious material ratio, which is accompanied with higher cement content compared with conventional concrete (Behnood and Ziari 2008). In order to have adequate workability, while maintaining a water-to-cementitious material ratio of around 0.25 to 0.35 , a high range water reducer or superplastizer must be employed, usually in large dosages. This is done to achieve deflocculation of cement particles to allow the mix to be sufficiently flowable and for the solids to be dispersed in a way that dense packing of the solids can occur (Behnood and Ziari 2008; Neville, 2010). This high cement content 
is used to promote better fiber dispersion and workability, and most importantly to promote strain hardening behavior. In order to decrease pores, aggregates used in UHPC can be very fine, such as silica sand (average size 100 to 200 micrometers), crushed sand, or gravel sand of nominal sizes of around one or two millimeters. In order to reduce the amount of cement in UHPC, supplementary cementing materials such as silica fume is incorporated into the mix design.

Silica fume is produced as a by-product from electric arc furnaces from the manufacturing of ferrosilicon alloys and silicon metal. It is used today to improve the mechanical properties and durability of HPC/HSC (Behnood and Ziari 2008). It serves as excellent filler between cement and the aggregates and improves the cement paste-aggregate interface in concrete, which is the weakest zone in a concrete matrix (Koksal et al. 2008). Silica fume increases the water demand of concrete because it acts as an addition to concrete mix and not just as a supplementary cementing material. Silica fume is generally used in tandem with superplasticizer to control the workability. It is used to produce high strength concrete, but as a side effect it causes the ductility of the concrete to decrease and become more brittle (Koksal et al. 2008). The pozzolanic reactions found in silica fume form very dense microstructures in concretes. The high pozzolanic activity found in silica fume is a result of the very high content of amorphous silicon dioxide and very fine spherical particles (Behnood and Ziari 2008).

Tests conducted by Poon et al. (2004a), Behnood and Ziari (2008), and Koksal et al. (2008) have shown that the addition of silica fume as a replacement for a certain portion of cement in concretes such as UHPC has increased the initial compressive strength in comparison to concretes using only cement. Analysis of stress-strain curves from previous tests have shown that the addition of silica fume resulted in higher strains at the peak stresses, with steeper descending branch in stress-strain curves.

Fibers are used in concrete to increase energy absorption capacity of concrete and increase ductility of the concrete. Steel fibers limit crack propagation and delay crack formation by behaving as crack arresters or bridging mechanism in the concrete. This is best observed after the cracking begins in the concrete (Koksal et al. 2008). Analysis of stress-strain curves from previous tests conducted by Poon et al. (2004a) has shown that the addition of steel fibres significantly changed the stress-strain curves by flattening the descending paths. The steel fibres also increased the strain 
at the peak stresses in concretes with normal cement, but did not do so in concretes containing silica fume.

\subsection{ECC/UHPC structural applications and Research on structural performance}

\subsubsection{Structural applications}

Members made of ECC in combination with steel plates provide higher flexural resistance with a thinner cross section than normal steel-concrete members. Figure 2.3 shows the Mihara Bridge in Hokkaido, Japan with a bridge length of $972 \mathrm{~m}$ and central span of $340 \mathrm{~m}$ (Mitamura et al., 2005). In 2004, half the depth of the asphalt overlay on the steel deck of this bridge was replaced with 40 $\mathrm{mm}$ thick ECC to increase the load bearing capacity and stiffness of the decks while reducing the stress generated, thereby improving the fatigue resistance of the stiffener for the steel deck. This became necessary because the requirements for fatigue resistance in the standard specifications were revised while the bridge was under construction. The bridge was opened to traffic in 2005. The steel-reinforced road bed contains nearly $800 \mathrm{~m}^{3}$ of ECC material. The tensile ductility and tight crack control behavior of ECC led to a $40 \%$ reduction in material used during construction.

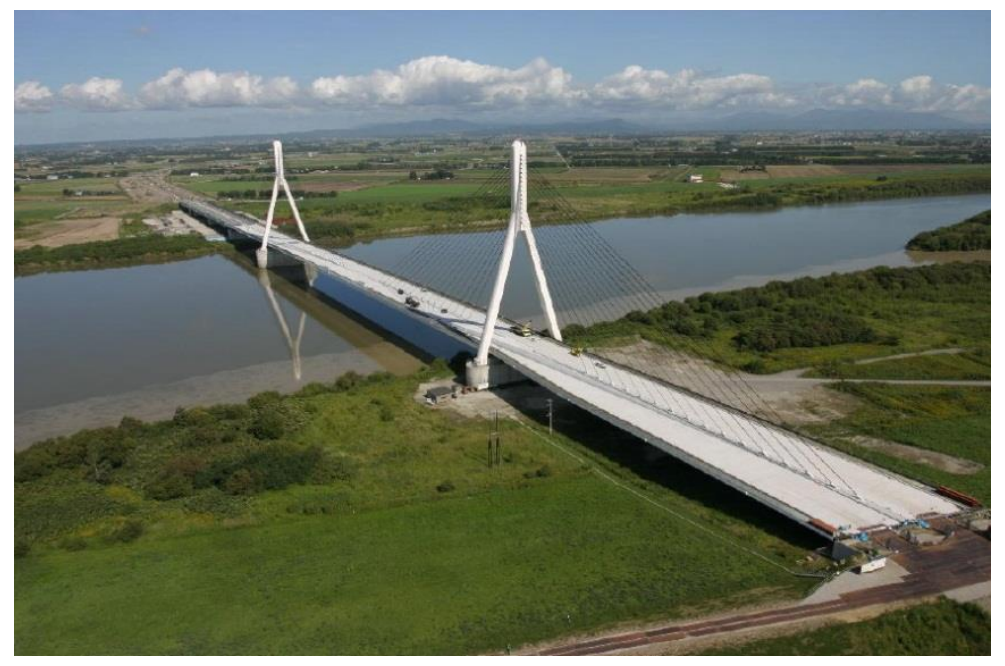

Figure 2.3 Overview of Mihara Bridge (Mitamura et al., 2005)

Figure 2.4 shows the repair of the Mitaka Dam in Hiroshima-Prefecture, Japan in 2003 (Kojima et al., 2004). This dam is over 60 years old, with a severely damaged concrete surface. Cracks, spalling, and water leakage were concerns that prompted the use of ECC as a water-tight cover layer. This $20 \mathrm{~mm}$ layer was applied by spraying the ECC material directly onto approximately $600 \mathrm{~m}^{2}$ of the upstream dam surface. 


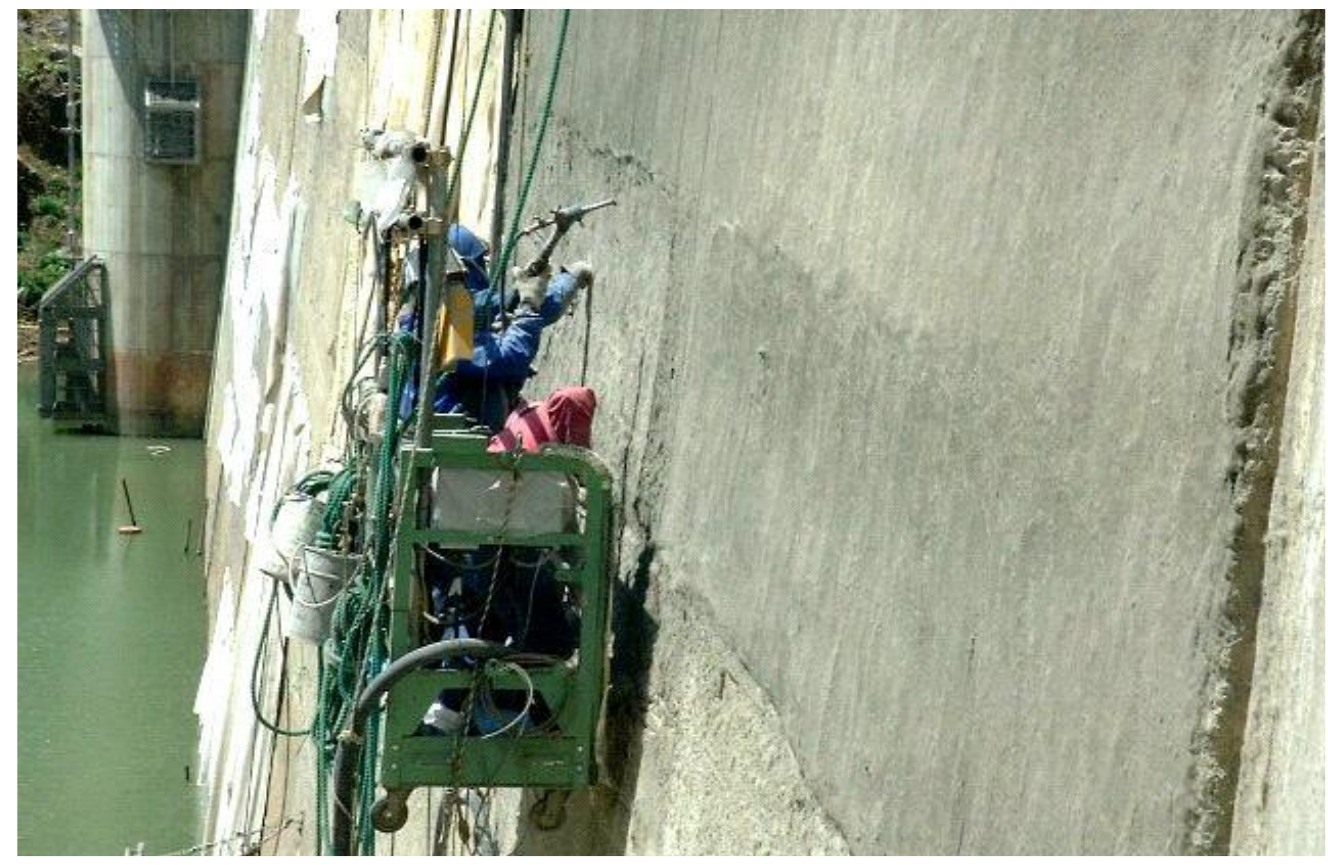

Figure 2.4 Spray repair of the Mitaka Dam with ECC for water-proofing (Kojima et al., 2004)

A gravity concrete retaining wall in Gifu, Japan measuring approximately $18 \mathrm{~m}$ in width and $5 \mathrm{~m}$ in height was constructed in the 1970s. It was repaired using ECC in 2003 (Rokugo et al., 2005) as shown in Figure 2.5. Ordinary Portland cement could not be used due to the severity of the cracking in the original structure, which would have caused reflective cracking. ECC was intended to minimize this danger; after one year only micro cracks of tolerable width were observed. Cracking was harder to observe 24 months after repair compared to 12 months after, being hidden by dirt accumulated on the surface.
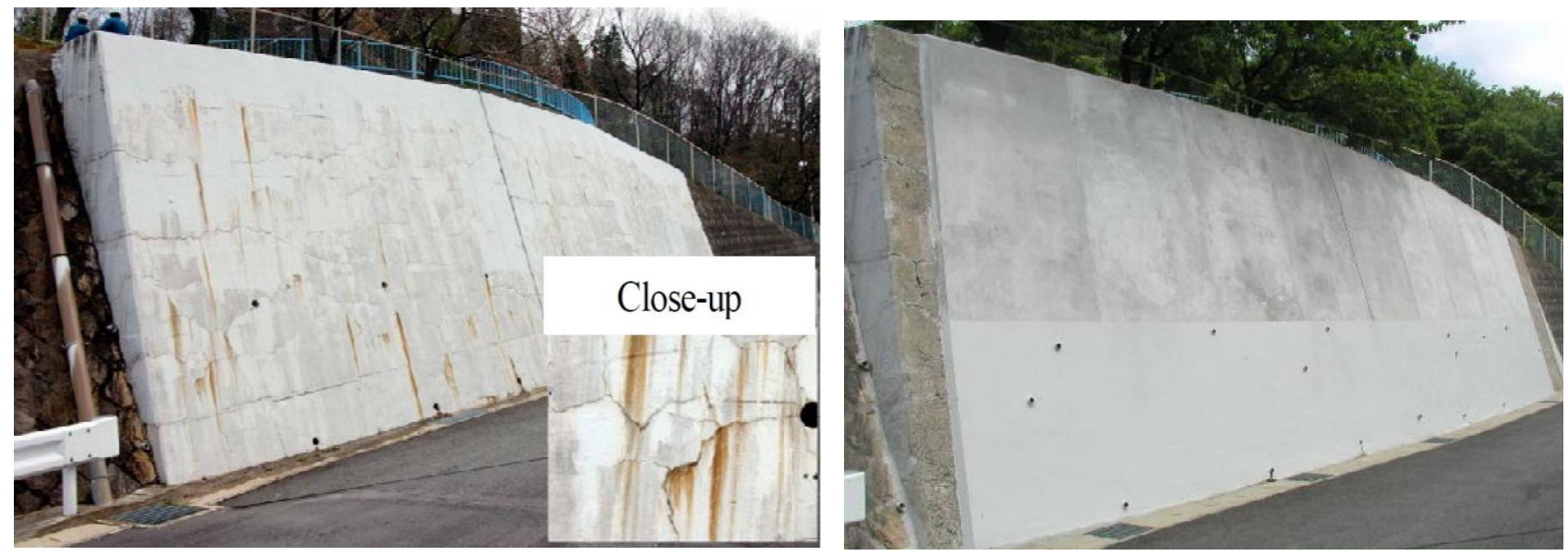

Figure 2.5: Surface repair of concrete retaining wall (Rokugo et al., 2005)
(a) Before repair
(b) After repair 
As one of the first field applications of ECC in the USA, an ECC patch repair Figure 2.6(a) placed on the deck of the Curtis Road Bridge in Michigan, US in 2002. A complete summary of this work has been outlined by Li and Lepech (2004). During this work, one small section of a deteriorated bridge deck was repaired with ECC while the remaining portion was repaired with a commercial concrete patching material commonly used by the Michigan Department of Transportation (MDOT). This repair scenario allowed for a unique ECC/concrete comparison subjected to identical environmental and traffic loads. As of the time of this writing, ECC patch and surrounding concrete have experienced almost three full winter freeze-thaw cycles. This bridge is traveled by heavily loaded 11-axle trucks. Figure 2.6 (b) shows the monitored maximum crack width as a function of age. It reveals that the crack width in the ECC patch remains almost at a constantly low level, around $50 \mu \mathrm{m}$, while the maximum crack width in the surrounding concrete is significantly higher at the same age. The last data point at 780 days after repair indicates a maximum crack width of $3.8 \mathrm{~mm}$ in the concrete.

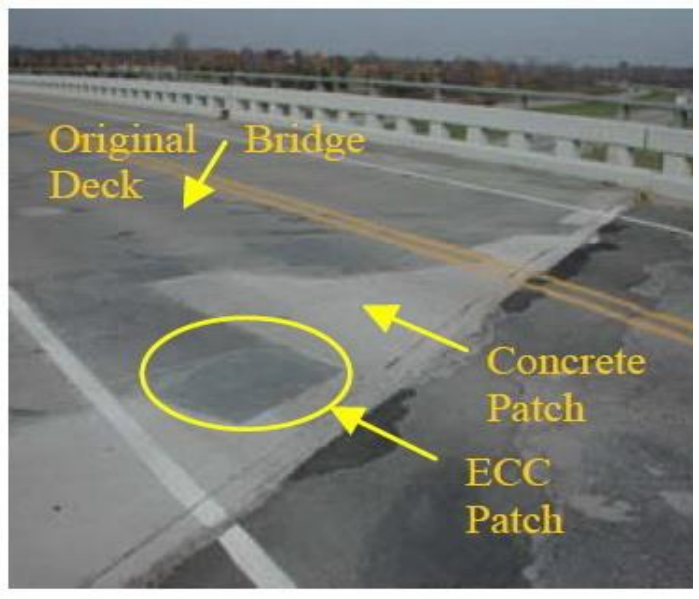

(a)

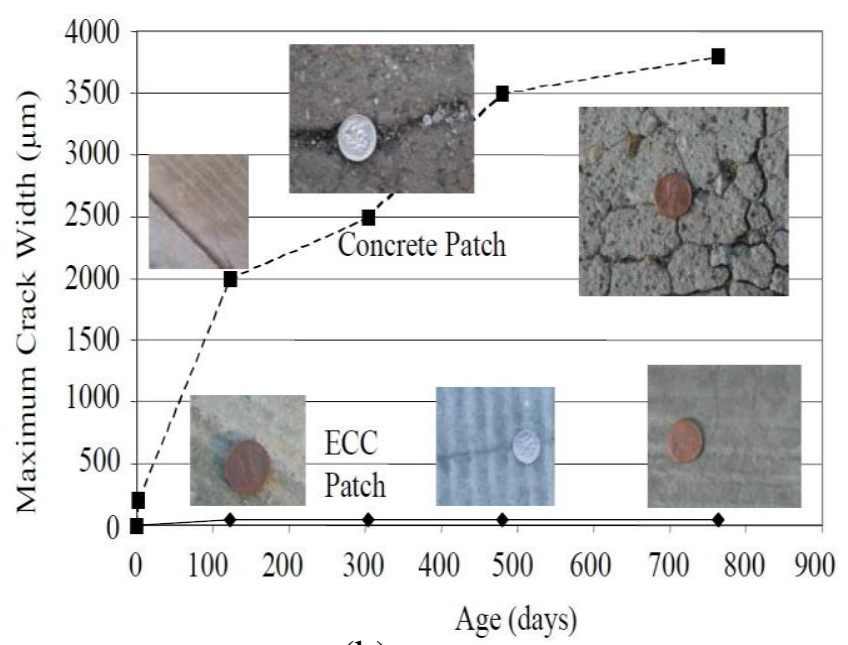

(b)

Figure 2.6 (a) Patch repair on a bridge deck (b) Crack width development in concrete patch and ECC patch over time (Li and Lepech, 2004)

In addition to bridge deck patching repairs, the most recent field application of ECC in the US is with a bridge "link slab" completed in cooperation with MDOT on Grove Street Bridge in Southeast Michigan in 2005 as shown in Figure 2.7 (Lepech and Li, 2007). The objective was to eliminate the maintenance requirements associated with typical bridge deck expansion joints. In this project, about $32 \mathrm{~m}^{3}$ of ECC were cast in place using standard ready-mix concrete trucks to 
build the first ECC link slab in US. With a strain capacity exceeding $2 \%$, these composites can be used to replace traditional steel expansion devices and can fully accommodate the thermal deformations of adjacent bridge spans. This ECC link slab design was adopted in 2006 in the highway segment that extends from Bolzano to the Austrian border bridge in north Italy.

Also in Japan ECC has been used in structural applications as coupling beams (Maruta et al., 2005) within high rise concrete construction. Due to the high energy absorption capacity of steel reinforced ECC material, the application of this material in coupling beams which connect adjacent core walls is very advantageous for high rise buildings in seismic regions. The recent development of precast ECC coupling beam elements by Kajima Corporation in Japan can be easily integrated into current seismic construction practices. Currently two high-rise buildings in Tokyo, Japan have been built integrating ECC coupling beams, Figure 2.8.

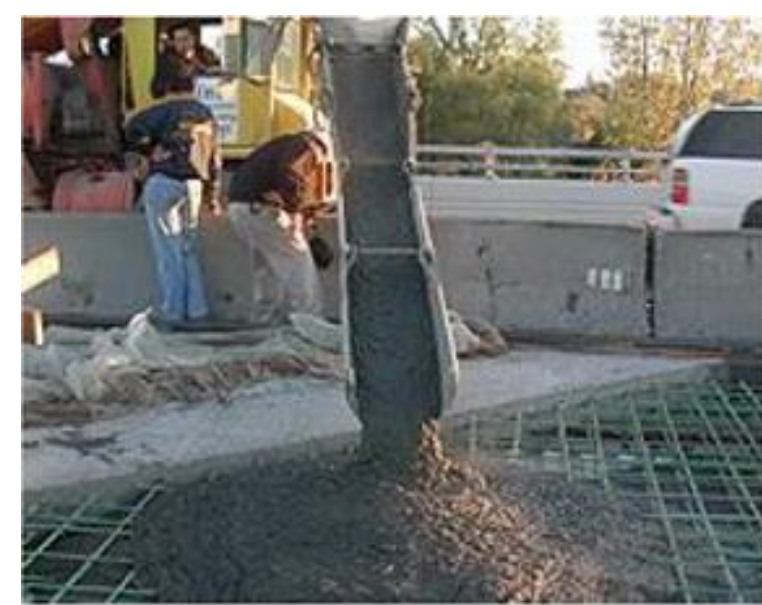

(a) During construction

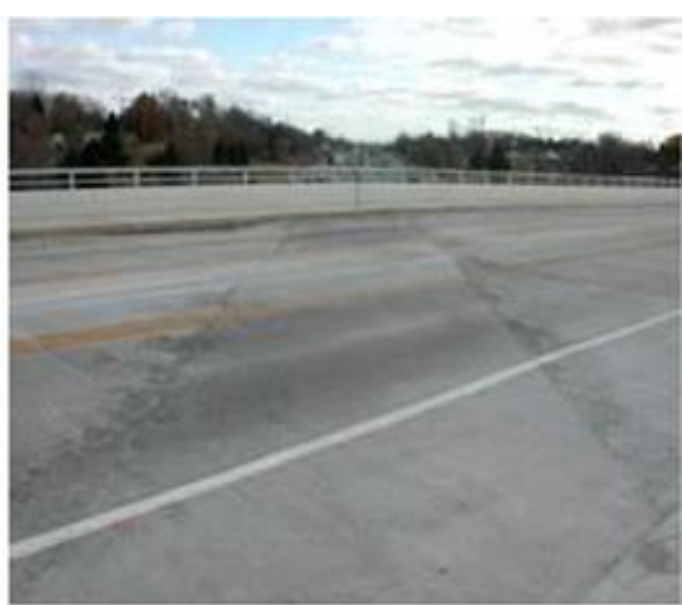

(b) After construction

Figure 2.7 ECC link slab on Grove Street Bridge, Michigan, USA (Lepech and Li, 2007) 


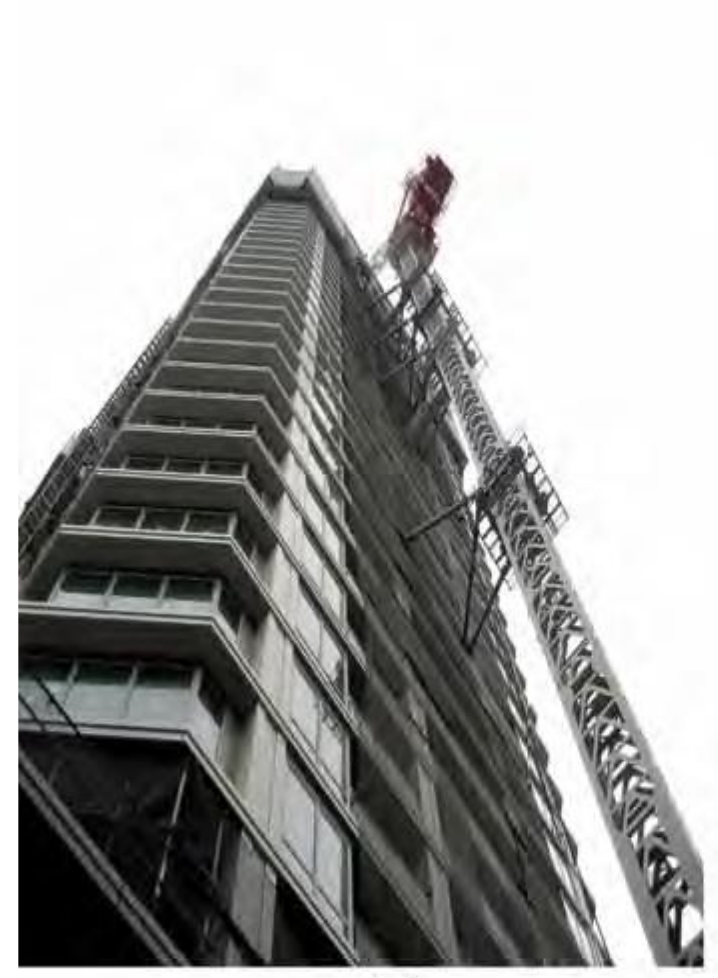

(a)

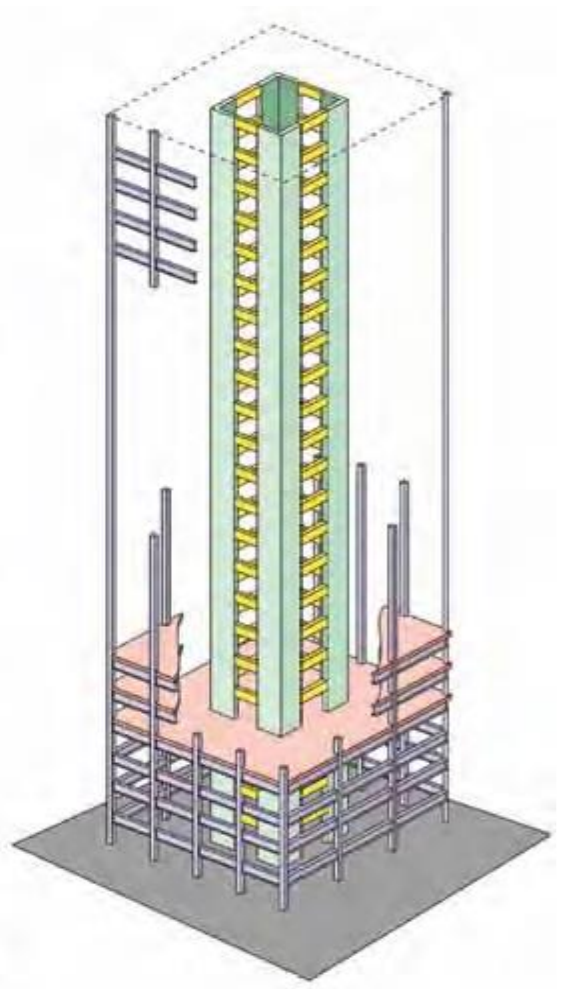

(b)

Figure 2.8 (a) The Nabeaure Tower in Yokohoma, Japan under construction, it uses precast ECC coupling beams in building core for seismic resistance and (b) Schematics showing coupling beams (in yellow) on each floor (Maruta et al., 2005).

\subsubsection{Research on structural performance research}

Taormina (2012) and Taormina and Hossain (2013) conducted research on the structural performance of double skin composite walls (DSCWs) consisting of profiled steel sheeting and concrete-infill subjected to elevated temperatures of up to $800^{\circ} \mathrm{C}$ incorporating emerging high performance concrete (HPC) of different types namely Self-Consolidating Concrete (SCC), Engineered Cementitious Composites (ECC), and Ultra High Performance Concrete (UHPC). Performance of DSCWs subjected to elevated temperatures was judged compared to unheated walls based on physical changes, residual axial load capacity, load-deformation response, stiffness/ductility, load-strain characteristics, steel-concrete interaction, concrete cracking, steel sheet buckling and overall failure modes. The use of HPCs improved both structural (strength and ductility) and fire durability characteristics of the proposed DSCWs. Analytical models for determining the residual axial strength of DSCWs were developed and their performance 
validated. The research provided useful information for the development of design guidelines for DSCWs exposed to elevated temperatures.

Sherir et al. $(2012,2013)$ investigated the influence of microsilica sand and local crushed sand, and different supplementary cementing materials on the mechanical properties of engineered cementitious composites (ECCs). The use of local aggregates in ECC production can lower its cost to mitigate the obstacles of wider commercial use. The experimental results showed that multiplecracking behavior was developed under fatigue loading for fly ash ECC (FA-ECC) mixtures, and the number of cracks was lower at both lower fatigue stress level and higher fatigue number of cycles. FA-ECC mixtures with silica sand exhibited higher deflection evolution under fatigue loading than FA-ECC mixtures with crushed sand. Based on the experimental results on link slab specimens, both FA-ECC mixtures with silica and crushed sands exhibited almost the same creep behavior.

Shirin (2015) and Hossain and Samani (2015) conducted experimental investigation on $1 / 4^{\text {th }}$ scale link slabs for joint-free bridge deck construction subjected to monotonic and fatigue loading incorporating different ECC mixtures and self-consolidating concrete (SCC). The structural performance for the link slabs were evaluated based on the load-deformation/moment-rotation responses, strain developments, cracking patterns, ductility index and energy absorption capacity. Test results of a $1 / 6^{\text {th }}$ scale full scale joint free bridge with ECC link slab tested under monotonic loading up to service stage was also described. The experimental link slab moment resistance and its length were compared with those obtained from theoretical and design specifications. The ECC link slabs demonstrated superior performance exhibiting high residual strength and energy absorbing capacity and prolonged life (associated with enduring large number of fatigue cycles) compared to their SCC even though subjected to higher fatigue stress levels. Research confirmed the viability of ECC link slab to construct joint-free bridges satisfying serviceability and design specifications.

Chu (2014), Chu and Hossain $(2014,2015)$ conducted research on the axial load behaviour of circular, square and rectangular concrete filled steel tube (CFST) columns incorporating highperformance self-consolidating concretes such as ultra-high strength concrete (UHSC), engineered cementitious composite (ECC), lightweight concrete (LWC), and crumb rubber concrete (CRC). 
Seventy-four CFST specimens with varying slenderness, shape, concrete type and presence of internal bar reinforcements are tested experimentally under axial compression loading. The effect of these variables on axial load-deformation response, strain characteristics, failure modes, concrete confinement and axial strength are evaluated through experimental results. Performance of existing analytical/code based models for axial strength and concrete confined strength is evaluated. Concretes without coarse aggregates including UHSC proved less effective at enhancing axial strength of filled tube columns through confinement.

Rafiei (2011) and Rafiei et al. (2013, 2015) investigated the behaviour of a new form of composite shear wall system consisting of two skins of profiled steel sheeting and an infill of concrete under in-plane monotonic, cyclic and impact loading. The extensive experimental, analytical and numerical investigations of composite shear walls provided information on strength, stiffness, load-deformation response, steel sheet-concrete interaction, stress-strain characteristics and failure modes. Eight composite wall specimens with overall dimensions of $1626 \mathrm{~mm}$ (height) x $720 \mathrm{~mm}$ (width) were tested under monotonic, cyclic and impact loading. Steel sheet-concrete connections were provided by intermediate fasteners to generate composite action. Two types of steel sheets classified based on strength as mild and high strength and also, two types of concrete-infill namely Self-Consolidating Concrete (SCC) and Engineered Cementitious Composites (ECC) were used to construct the walls. An analytical model for shear resistance of the composite wall was developed based on existing models taking into account the shear capacity of the steel sheets, concrete core and steel sheet-concrete interaction. Moreover, two non-linear finite element models for the composite wall under monotonic/cyclic and impact loading were developed using proprietary ABAQUS/CAE software. The performance of developed numerical models was validated against experimental results and then the models were utilized to carry out an extensive parametric study to understand the influence of material and steel-concrete interaction on the structural behavior of the walls.

Issani (2012) and Issani and Hossain (2013) investigated flexural stiffness or effective width of floor slab acting as coupling beam in Coupled Shear Wall (CSW) building. New generation of high performance concretes provide an alternative to conventional concrete to enhance the performance of coupling slabs. Research investigated the flexural behaviour of coupling slabs incorporating Engineered Cementitious Composite (ECC) compared to conventional Self- 
Consolidating Concrete (SCC). The high strain capacity and low crack width makes ECC an ideal material for coupling slab. Non-linear coupling action of ECC slabs is investigated experimentally with small-scale models having variable geometric parameters under monotonic loading. The performance is judged based on moment-rotation response, flexural stiffness/effective width, deflection, cracking, strain development and failure modes. Design charts for flexural stiffness/effective width of coupling slabs are presented in pre-cracking/cracking/post-yielding stages. CSW systems with ECC are found stronger and ductile than their SCC counterparts confirming the viability of constructing such structures.

Orton et al. (2013) tested a series of three one-quarter scale, two-bay by two-story frames under static and dynamic loads. The research considered the ability of frames with different reinforcement designs to develop resistance mechanisms, and evaluated the effective dynamic increase in response when a frame was loaded dynamically. The static tests were slowly loaded through a hydraulic actuator at the location of the removed column. The dynamic test was loaded with additional dead weight and the center supporting column suddenly removed to simulate a collapse scenario. The dynamic loads and strains in the horizontal direction were 1.3 to 3.4 times greater than the corresponding static loads. Subsequent analysis of the test data and results from static simplified analyses and dynamic single degree of freedom (SDOF) models showed that there is a very fine tipping point at which the structure is pushed past the compressive arch or flexural range of response into the catenary action range of response. At this point the dynamic effects increase significantly due to a snap through type of effect.

Steel bar fracture of reinforced concrete (RC) column under strong cyclic load has been tested by Saisho (2009). On the basis of the test results, the steel bar fracture of specimen is considered as the very low cycle fatigue behavior and the calculation method of steel bar fracture is derived by the use of Coffin-Manson equation and the Palmgren-Miner rule. The obtained damage ratio equation of steel bar fracture can be easily applied to the seismic response damage analysis of multi-story RC frame under extremely strong ground motion. By the use of the derived damage analysis method, the effects of design conditions on the seismic response damage of $\mathrm{RC}$ frame are investigated. 
Tateishi et al. (2009) developed new infill units made of the Carbon Fiber Reinforced Polymer (CFRP) for one of the seismic retrofit technologies. The CFRP shear wall consisted of the CFRP units by epoxy resin bonding. The thickness and the weight of the wall are about $100 \mathrm{~mm}$ and 41 $\mathrm{kg} / \mathrm{m}^{2}$. As for the connections between CFRP shear wall and existing concrete, boundary steel plates are installed with epoxy resin. Three types of reinforced concrete frames with CFRP shear walls were tested under axial and cyclic lateral loads. The parameters of the specimens were anchorage bond strengths and with/without splice plates on unit joints. From the test results, the average shear strength of CFRP shear wall was over $3.5 \mathrm{~N} / \mathrm{mm}^{2}$ without splice plates and over 6.4 $\mathrm{N} / \mathrm{mm}^{2}$ with splice plates. These values can be enough for the strength of seismic rehabilitation. As for the ductility, the story drift of the wall without splice plates was $0.26 \%$ that with splice plates $0.74 \%$. In the additional case of slipping along the anchorage connection, the story drift of the specimen with splice plates was about $2.0 \%$. From the viewpoints of strength and ductility, the CFRP shear walls with splice plates are better suited for the strength resistant type of seismic rehabilitation.

Gencturk (2012) carried out Life-cycle cost assessment of RC and ECC frames using structural optimization. Two different materials, reinforced concrete (RC) and reinforced engineered cementitious composites (ECC), with different response characteristics are used to model the frames. ECC is characterized by high tensile ductility and energy absorption and reduced crack widths when compared to conventional concrete. However, the material is more expensive than conventional concrete; therefore, in order to quantify the potential benefits that could be obtained by replacing concrete with ECC, the life-cycle performance is evaluated in an optimization framework. Three different structural frames are considered: an RC only frame, an ECC only frame and a multi-material (MX) frame in which ECC is selectively applied at the potential plastic hinge locations while the remainder of the frame is made of RC. The structural capacity and earthquake demand are evaluated using rigorous analysis methods to capitalize on different characteristics of concrete and ECC, and both aleatory and epistemic uncertainties are incorporated into the LCC formulation. It is found that both the initial and LCC of frames that use ECC are lower due to savings in material and labor cost of transverse reinforcement for the former and due to increased capacity and reduced demand for the latter. 
Tawfik et al. (2014) carried out an experimental study on behavior and ductility of HSRC frames under cyclic loading. This experimental program was conducted on five frames with different beam/column cross section. In addition, the aspect ratio $h / L$ of frames and beam and column connection details was different. In this research they observed that, as the inertia of the beam for HSRC frames increased the ultimate lateral load, energy dissipation and stiffness are increased by small value while the ductility factor $(R)$ is decreases significantly. On the other hand, they revealed that by increasing the inertia of columns in HSRC frames the ultimate lateral load, energy dissipation and stiffness of the frame are increased significantly. They also reported a significant increase of ultimate lateral load and displacement by increasing the stirrups connections.

Several equations were proposed by Slater et al. (2014) for evaluation of shear strength of steel fiber reinforced concrete (SFRC) beams. To obtain this, they used a large data base containing 222 shear test strength tests of SFRC beams without stirrups. The SFRC beams were divided in different group's base on their compressive strength, span-depth ratio and steel fiber shapes. Both linear and non-linear regression analysis were performed for each data base for the proposed equations. Their study revealed that the equation for each beam type using linear regression predicted the shear strength of SFRC beams more accurately.

The behavior of Ultra-High Performance Fiber Reinforced Concrete (UHPFRC) columns under axial loading were studied by Hosinieh et al. (2015). The research conducted with an experimental program which contained six large-scale columns. They tested the columns under pure axial loading to examine the effect of UHPFRC and transverse reinforcement detailing on column performance. This researched revealed that, using closely-spaced and well detailed transverse reinforcement allows for the development of excellent ductility in UHPFRC columns. They also indicated that, spacing and configuration of transverse reinforcement are playing an important role in affecting the axial strength and toughness of UHPFRC columns. 


\subsection{Design aspects of high performance concrete members}

Design procedures for calculating flexural and shear strength of UHPC, ECC and SCC beams are described based on Codes and other existing procedures.

\subsubsection{Flexural Strength of UHPC beam}

The general stress-strain and force distribution for reinforced UHPC beam for flexural resistance is shown in shown in Figure 2.9 (Hossain 2014). In linear strain distribution, $\varepsilon_{m c}, \varepsilon_{p s}$ and $\varepsilon_{m t}$ represent concrete compressive strain at the top fiber, strain in reinforcement, and concrete tensile strain at the bottom fiber. Typically it assumes a triangular concrete stress distribution and nonuniform tensile stress distribution $\left(\mathrm{f}_{\mathrm{t}}\right)$ below the neutral axis $(\mathrm{NA})$ due to fiber contribution.

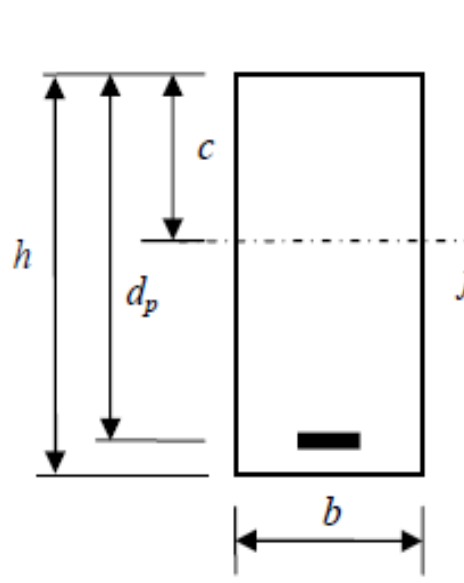

(a)

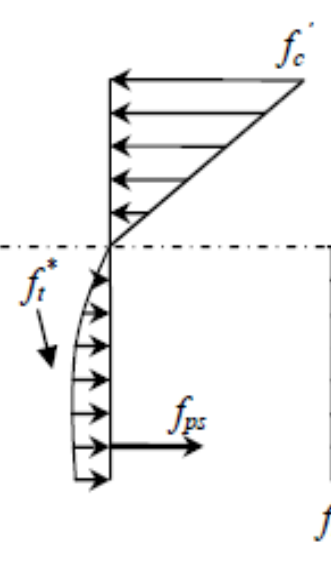

(b)

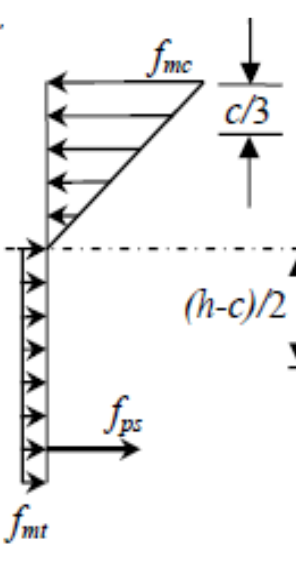

(c)

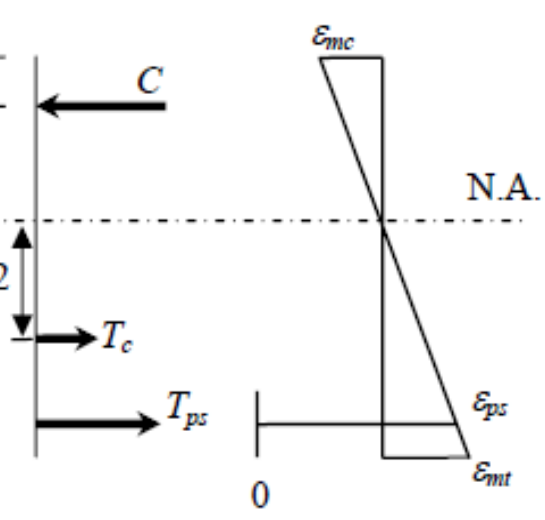

(d) (e)

Fig. 2.9 Stress-force-strain distribution of reinforced UHPC beam

The limiting compressive strength $\left(\mathrm{f}_{\mathrm{mc}}\right)$ for UHPC beam can be calculated as a function of compressive strength $\left(\mathrm{f}^{\prime} \mathrm{c}\right)$ based on Equation 2.1:

$f m c=0.85 f_{c}^{\prime}$.

A uniform tensile stress distribution of $f_{m t}$ acting from the neutral axis to the extreme tension fiber can be used to approximate the UHPC tensile force based on fiber contribution $\left(\mathrm{T}_{\mathrm{c}}\right)$ as shown in Equation 2.2, where $h$ is the overall height of the beam and $\mathrm{c}$ is the distance of NA from the top fiber.

$T_{c}=f_{m t}(h-c) b$ 
Compressive concrete force (C) can be calculated from Equation 2.3:

$C=\frac{1}{2} f_{m c} c b$

Where

Force in the steel reinforcement $\left(\mathrm{T}_{\mathrm{ps}}\right)$ can be calculated based on steel stress and flexural resistance of UHPC beam can be calculated by using equilibrium of forces as used in normal RC beam.

Moment/flexural resistance of reinforced UHPC beam can be derived by using usual procedures and by assuming some modifications in the stress-strain and force distribution of reinforced UHPC beam (Henager and Doherty 1976; Khalil and Tayfur 2013; Hossain 2014) as shown in Figure 2.10 with the following assumptions:

- all fibers are aligned in the direction of the stress,

- before cracking the fibers are fully bonded to the matrix, equal strains in fiber and matrix occurs,

- The Poisson's ratio in fiber and matrix is equal to zero.

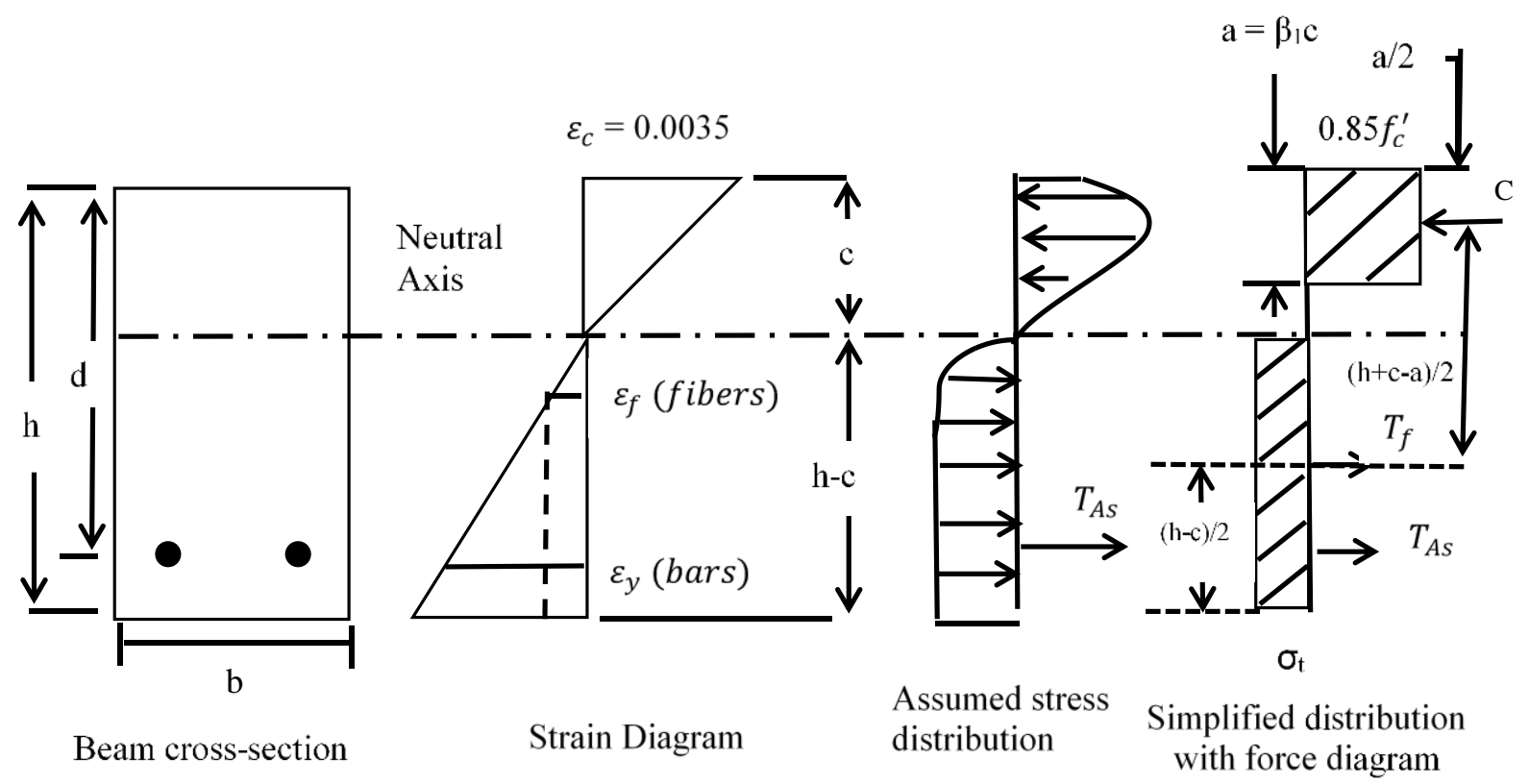

Fig. 2.10: Modified strain- stress-force distribution of reinforced UHPC beam

The ultimate tensile strength of steel fiber reinforced composite prior to cracking $\left(\sigma_{c}\right)$ in MPa can be derived from Equation 2.4: 
$\sigma_{c}=\sigma_{f} V_{f}+\sigma_{m} V_{m}$

Where $\sigma_{f}$ : ultimate pull out strength of steel fiber (MPa); $\sigma_{m}$ : ultimate tensile strength of uncracked concrete matrix $(\mathrm{MPa}) ; V_{f}$ : volume fraction of fibers and $V_{m}$ : volume fraction of the matrix.

The orientation, length and bonding characteristics of fibers will influence the strength of fiber reinforced concrete; Equation 2.5 derived from Equation 2.4 has incorporated all of these parameters:

$\sigma_{c}=\sigma_{m} V_{m}+2 \eta_{o} \eta_{b} \eta_{l} V_{f} \tau_{f}\left(l_{f} / d_{f}\right)$

Neglecting the contribution of the matrix in carrying any stress based on the law of mixture and applying the corrections of orientation, bond efficiency and length efficiency factor, the most common expression of ultimate tensile strength of fiber reinforced concrete $\left(\sigma_{t}\right.$ in $\mathrm{MPa}$ ) as shown in Figure 2.10 is given by equation 2.6 (Ahmed and Pama 1992; Hossain 2014):

$\sigma_{t}=2 \eta_{o} \eta_{b} \eta_{l} V_{f} \tau_{f}\left(l_{f} / d_{f}\right)$

where $\eta_{o}$ : orientation factor $=0.41 ; \eta_{b}$ : bond efficiency factor $=0.5$ for round fibers; $\eta_{l}:$ length efficiency factor can be calculated from Equation 2.7:

$\eta_{t}==1-\left[\left(\tanh \left(\frac{\beta l_{f}}{2}\right)\right) /\left(\beta l_{f} / 2\right)\right]$

where the value for $\beta$ coefficient can be obtained from Equation 2.8:

$\beta=\sqrt{\frac{2 \pi G_{m}}{E_{f} A_{f} L_{n}\left(\frac{S}{r_{f}}\right)}}$

The value for S, steel fiber characteristic is defined in Equation 2.9:

$S=25\left(\frac{l_{f}}{V_{f} d_{f}}\right)^{1 / 2}$

where $V_{f}$ : volume fraction of steel fiber; $\tau_{f}$ : bond strength between the fiber and matrix (MPa); $l_{f}$ : length of fibers $(\mathrm{mm}) ; d_{f}$. diameter of fibers $(\mathrm{mm}) ; G_{m}$ : shear modulus of concrete matrix (MPa); 
$E_{f}$ : modulus of elasticity of steel fibers (MPa); $A_{f}:$ cross-sectional area of steel fibers $\left(\mathrm{mm}^{2}\right)$ and $r_{f:}$ radius of steel fibers $(\mathrm{mm})$;.

Provided that the average sliding friction bond strength $\left(\tau_{f}\right)$ is known and assuming that it does not vary with the angle of the fiber to the crack and also assuming that the mean fiber pullout length is $(/ / 4)$ then the average pullout stress per fiber $(\mathrm{F})$ is given by Equation 2.10:

$F=\tau_{f}\left(\frac{l_{f}}{d_{f}}\right)$

Bond stress depends on a variety of factors: water cement ratio, curing conditions, fiber surface characteristics, fiber geometry, and age. According to Hannat (1978) and Hossain (2014), the measured value for $\tau_{\mathrm{f}}$ varies between 3 and $8.3 \mathrm{~N} / \mathrm{mm}^{2}$. According to Chan et al. (2004), bond characteristics of straight steel fiber in silica fume based ultra-high strength concrete (UHSC) matrix vary between 4.8 and $5.5 \mathrm{MPa}$ with $0 \%$ to $40 \%$ of silica fume, respectively. The frictional bond strength of fiber matrix $\left(\tau_{f}\right)$ is given by Equation 2.11 as per Henager and Doherty (1976) and Hossain (2014):

$\tau_{f}=0.66 \sqrt{ } f_{c}^{\prime}$

where $\mathrm{f}_{\mathrm{c}}$ is the compressive strength of normal strength concrete (MPa)

Based on Hossain (2014), the maximum usable strain at the extreme concrete compression fiber $\left(\varepsilon_{c}\right)$ as shown in Figure 2.10 can be taken as 0.0035 . There are some data that indicate 0.003 may be conservative. Work by Williamson (1974) indicates that 0.0033 may be more realistic for steel fiber concrete. Swamy and Al-Ta'an (1981) recommend 0.0035. Based on a study of plastic hinges, Hassoun and Sahebjam (1985) recommend a failure strain of 0.0035 for concrete with 1.0 percent steel fibers as per ACI Committee 544.4 R-88 (1994). Taking into account the large ductility and compressive strength of UHPC the equivalent compressive stress block values can be specified as shown in Figure 2.10. For strengths above $30 \mathrm{MPa}, \beta_{1}$ shall be reduced continuously at a rate of 0.05 for each $7 \mathrm{MPa}$ of strength in excess of $30 \mathrm{MPa}$, but $\beta 1$ shall not be taken less than 0.65 as per ACI 318 (2011). 
With the completion of compressive and tensile strength blocks, the process of flexural analysis of the beams can be carried out using the principles of force equilibrium and strain compatibility. The nominal moment capacity $\left(\mathrm{M}_{\mathrm{n}}\right)$ for singly reinforced UHPC beams can be calculated by Equation 2.12:

$M_{n}=A_{s} f_{y}(d-a / 2)+\sigma_{t} b(h-c)(h+c-a) / 2$

The value of ' $a$ ' can be calculated from Equation 2.13:

$a=\left(A_{s} f_{y}+\sigma_{t} b h\right) /\left(\lambda f_{c f}^{\prime} b+\sigma_{t} b\right)$

where $\mathrm{f}^{\prime}{ }_{\mathrm{cf}}=$ compressive strength of fibrous concrete $(\mathrm{MPa}), \mathrm{A}_{\mathrm{s}}$ : area of tensile steel bars $\left(\mathrm{mm}^{2}\right)$, fy: yield strength of tensile reinforcement bar (MPa), c: neutral axis depth (mm), b: width of beam cross section $(\mathrm{mm}), \mathrm{h}$ : height of beam cross section $(\mathrm{mm}), \lambda$ : concrete stress block parameter, (equal to 0.86 for $f^{\prime} c \geq 55 \mathrm{MPa}$ ), f'c: compressive strength of plain concrete, (MPa), $\beta 1$ :concrete stress block parameter, (equal to 0.65 for $\mathrm{f}^{\prime} \mathrm{c} \geq 55(\mathrm{MPa})$, a: depth of the equivalent compressive block (mm).

\subsubsection{Flexural Strength of ECC beam}

Lepech and $\mathrm{Li}$ (2009) developed a design guideline for flexural strength of ECC flexural members. Figure 2.11 shows strain-stress and force distribution for the cross-section of singly reinforced ECC beam.
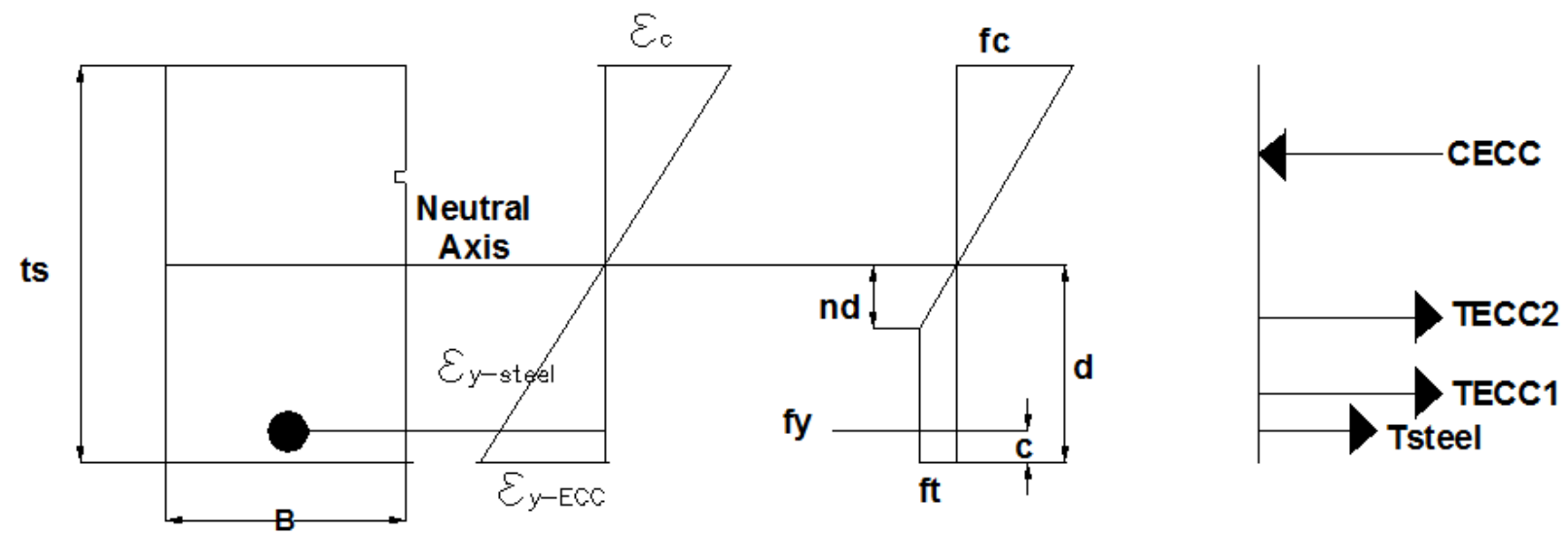

Figure 2.11 Stress-strain distribution of reinforced ECC member (Lepech \& Li 2009) 
In Figure 2.11, $\mathrm{B}$ and $\mathrm{t}_{\mathrm{s}}$ represent the width and depth of the section, respectively, $\mathrm{d}$ is the distance from neutral axis to the center of the reinforcing bars and $\mathrm{C}$ is the distance from the tension face to the center of reinforcing bars. In addition, $\varepsilon_{c}$ : compressive strain of ECC, $\varepsilon_{y-\text { steel }}$ : compressive strain of steel, $\varepsilon_{y-E C C}$ : yield strain of ECC. The $C_{E C C}, T_{E C C-1}, T_{E C C-2}, T_{S t e e l}$ respectively are representing the compressive force, tensile forces of ECC and tensile force of steel.

Caner and Zia (1998) proposed stress criterion to determine the corresponding tension kink and neutral axis for calculation the resisting moment capacity. The modular ratio is presented by Equation 2.14:

$n_{\varepsilon}=\frac{\varepsilon_{y-E C C}}{0.4 \varepsilon_{y-s t e e l}}$

The $n_{\varepsilon}$ represent the strain modular ratio, $\varepsilon_{y-s t e e l}$ and $\varepsilon_{y-E C C}$ denote the yield strain of elasticplastic behavior of steel reinforcement and ECC, respectively.

The depth of the neutral axis was determined based on the modular ratio and the equilibrium of resisting forces across the depth of ECC member. Lepech and Li (2009) proposed equations for calculating the ECC tensile forces. The resisting forces across the depth of the ECC section and their equilibrium are presented through Equations 2.15 to 2.18 and 2.19, respectively.

$T_{\text {Steel }}=0.4 f_{y} A_{s}$

$T_{E C C-1}=f_{t}\left[\left(1-n_{\varepsilon}\right) d+c\right] b$

$T_{E C C-2}=0.5 f_{t} n_{\varepsilon} d b$

$C_{E C C}=0.5 f_{t}\left(\frac{1}{n_{\varepsilon} d}\right)\left(t_{s}-d-c\right)^{2} b$

$T_{\text {steel }}+T_{E C C-1}+T_{E C C-2}=C_{E C C}$

where $f_{t}$ is the tensile stress of the ECC.

Lepech and $\mathrm{Li}$ (2009) projected the yield strain of ECC material from a pool of 40 separate tensile test results is $0.02 \%$, this value is chosen as a statistically representative value for the first cracking strain of ECC material. The yield stress of the ECC material is set at $3.45 \mathrm{MPa}$ from Lepech and 
$\mathrm{Li}$ (2009) which was again chosen as a statistically representative value from the pool of tensile test results while the actual ultimate strength is typically above this value.

The resisting moment capacity $M_{r}$ is calculated by summing the contribution of all forces about the neutral axis and is presented in Equation 2.20.

$M_{r}=\left\{T_{\text {Steel }} d+T_{E C C-1}\left(\frac{\left(1-n_{\varepsilon}\right) d+c}{2}+n_{\varepsilon} d\right)+T_{E C C-2}\left(\frac{2}{3}\right) v d+C_{E C C}\left(\frac{2}{3}\right)\left(t_{s}-d-c\right)\right\}\left(\frac{1}{1000}\right)$

\subsubsection{Shear Strength of UHPC and ECC beams without stirrups}

The equation 2.21 (in SI units) proposed by Imam et al. (1997) can be used to calculate the shear strength $\left(\mathrm{V}_{\text {shear }}\right.$ or $\left.\mathrm{Vc}\right)$ of UHPC beams consisting of steel and polypropylene fibers without web reinforcement.

$V_{\text {shear }}=0.6 \times \frac{1+\sqrt{\frac{5.08}{d_{a}}}}{\sqrt{1+\frac{d}{25 d_{a}}}} \times \sqrt[3]{\rho_{S}(1+4 F)} \times\left[\left(f_{c}^{\prime}\right)^{0.44}+275 \sqrt{\frac{\rho_{s}(1+4 F)}{\left(\frac{a_{s}}{d}\right)^{5}}}\right] b d$

In which $d_{a}$ is the maximum aggregate size $(\mathrm{mm}), \rho_{s}$ represents the longitudinal reinforcement ratio, $f_{c}^{\prime}$ is the compressive strength of the concrete (MPa), $d$ is the effective depth of the beam), $b$ is the width of the beam and $a_{s}$ is the shear span.

The value of fiber factor $(\mathrm{F})$ can be obtained from Equation (2.22):

$F=\left(\frac{L_{f}}{D_{f}}\right) V_{f} d_{f}$

where $L_{f}$ is the fiber length $(\mathrm{mm}), D_{f}$ is the fiber diameter $(\mathrm{mm}), V_{f}$ is the volume fraction of fibers, and $d_{f}$ is the bond factor (for round fibers $=0.5$, for crimped fibers $=0.75$, and for indented fibers $=1.0$ ).

In this study, Equation 2.21 is also used to calculate the shear strength ( $\left.\mathrm{V}_{\text {shear }}\right)$ of ECC beams consisting of polyvinyl alcohol fiber (PVA) without web reinforcement.

\subsubsection{Flexural strength of SCC beam}

The beam top and bottom flexural steel is designed at the location of maximum moments along the beam span. In the flexural reinforcement design, the design procedure is based on the simplified rectangular stress block shown in Figure 2.12 as per CSA Standard A23.3-04 (2010). In designing 
the beam flexural reinforcement, the limit of $f^{\prime}{ }_{c}$ is taken to be smaller than 80MPa for ordinary moment resisting frame based on clause 8.6.1.1 of CSA Standard A23.3.

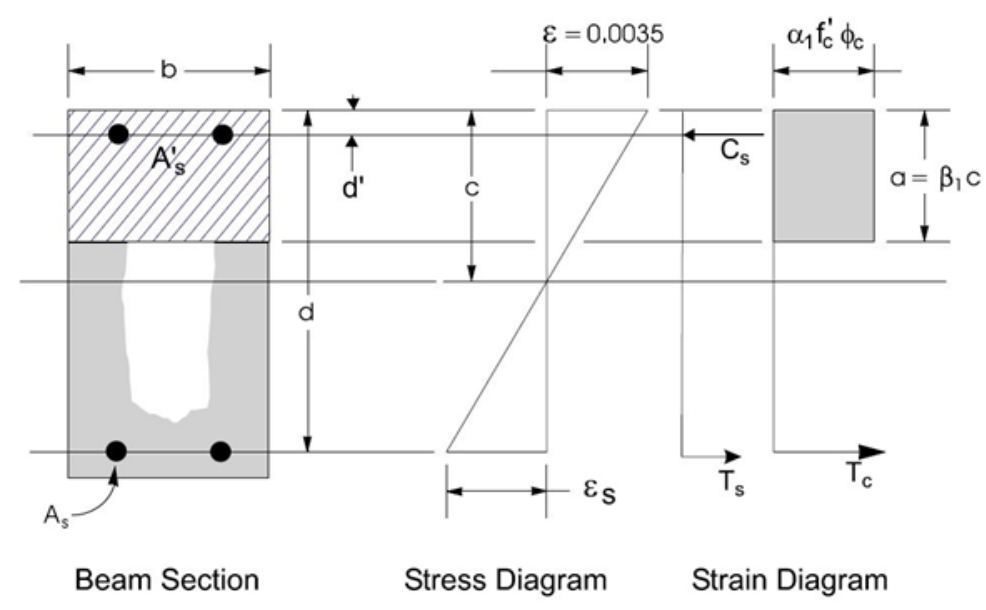

Fig. 2.12: Stress-strain and force distribution for rectangular SCC beam

The depth of the compression block 'a' can be obtained from Equation 2.23:

$a=d-\sqrt{d^{2}-\frac{2\left|M_{f}\right|}{\alpha_{1} f_{c}^{\prime} \varphi_{c} b}}$

Where the value of $\varphi_{c}$ is 0.65 as per clause 8.4.2. The values of $\alpha_{1}$ and $\beta_{1}$ and $\mathrm{C}_{\mathrm{b}}$ can be calculated based on the equations 2.24 to 2.26 using clause CSA10.1.7 and CSA 10.5.2:

$\alpha_{1}=0.85-0.0015 f_{c}^{\prime} \geq 0.67$

$\beta_{1}=0.97-0.0025 f_{c}^{\prime} \geq 0.67$

$C_{b}=\frac{700}{700+f_{y}} d$

$a_{b}$ The balance depth of the compression zone is given by equation 2.27

$a_{b}=\beta_{1} C_{b}$

Based on cause CSA 10.5.2 if the value of $a \leq a_{b}$ therefore the area of tensile reinforcement should be calculated based on the following Equation 2.28: 
$A_{s}=\frac{M_{f}}{\varphi_{s} f_{y}\left(d-\frac{a}{2}\right)}$

This steel to be placed at the bottom of the beam for negative moment and top of the beam for positive moment. For our design the amount of reinforcement located at the top of the section $A_{s}^{\prime}$ has been neglected.

The minimum amount of tensile reinforcement from clause CSA 10.5.1.2 for flexural members can be calculated from Equation 2.29:

$A_{s, \min }=\frac{0.2 \sqrt{f_{c}^{\prime}}}{f_{y}} b_{t} h$

Where, $b_{t}$ is the width of tension zone of the section.

For checking the flexural capacity of beam and column in the tested frame in this study, the value of compression block 'a' can be obtain from Equation 2.30 with related experimental values for $f_{c}^{\prime}$ and $f_{y}:$

$a=\frac{\varphi_{s} A_{s} f_{y}}{\alpha_{1} \varphi_{c} f_{c}^{\prime} b}$

Therefore the flexural or moment capacity of beam/column in the tested frame used in this study can be obtained from Equation 2.31:

$M_{f}=\varphi_{s} A_{s} f_{y}\left(d-\frac{a}{2}\right)$

\subsubsection{Shear strength of SCC members}

For ordinary moment resisting frame beam/column, the shear capacity of concrete alone (or shear capacity of beam without stirrups) can be obtained by using clause CSA 11.3.4 and from Equation 2.32 per CSA Standard A23.3-04 (2010).

$V_{c}=\varphi_{c} \lambda \beta \sqrt{f_{c}^{\prime}} b d_{v}$

Where, $\beta$ shall be taken 0.21 as described in CSA clause 11.3.6.2 as the overall thickness of the member less than $250 \mathrm{~mm} ; \sqrt{f_{c}^{\prime}}$ should be less than $8 \mathrm{MPa} ; d_{v}=\max (0.9 d$ and $0.72 h)$. 
Total shear resisting capacity of the member $\left(\mathrm{V}_{\mathrm{r}}\right)$ calculated from equations 2.33 as per CSA A 23.3:

$V_{r}=V_{c}+V_{s}+V_{p}$

Where Vc: shear resistance of concrete, Vs: shear resistance of stirrups and Vp: shear resistance capacity of pre-stress reinforcement which should be taken zero in this study.

However the value of $V_{r}$ shall not exceed as described in Equation 2.34:

$V_{r, \max }=0.25 \varphi_{c} f_{c}^{\prime} b d_{v}+V_{p}$

For the members with transverse/web/shear reinforcement perpendicular to the longitudinal axis, the value of $V_{s}$ can be obtained from equation 2.35:

$V_{s}=\varphi_{s} \frac{A_{v}}{s} f_{y} d_{v} \cot \theta$

Where $\theta$ shall be taken $42^{\circ}$ as described in clause CSA 11.3.6.2; $A_{v}$ : area of shear reinforcement; $s$ : spacing between shear reinforcement.

The value of $A_{v}$ shall be greater than minimum required shear reinforcement based on CSA 11.2.8.2 which can be obtain from Equation 2.36:

$A_{v, \min }=0.06 \sqrt{f_{c}^{\prime}} b s / f_{y}$

Where $b$ is the width of the beam.

\subsubsection{Shear strength of UHPC and ECC beams with stirrups}

The shear strength of UHPC and ECC beams with stirrup can be calculated by using Equation 2.37 derived by combining shear capacity of concrete as per Equation 2.21 and capacity of shear reinforcement as per Equation 2.35:

$V_{\text {shear }}=0.6 \times \frac{1+\sqrt{\frac{5.08}{d_{a}}}}{\sqrt{1+\frac{d}{25 d_{a}}}} \times \sqrt[3]{\rho_{s}(1+4 F)} \times\left[\left(f_{c}^{\prime}\right)^{0.44}+275 \sqrt{\frac{\rho_{s}(1+4 F)}{\left(\frac{a}{d}\right)^{5}}}\right] b d+\varphi_{s} \frac{A_{v}}{s} f_{y} d_{v} \cot \theta$ 


\subsection{Review conclusions}

Research has been conducted on the material properties of ECC, SCC and UHPC for tailoring enhanced mechanical and durability properties. SCC has been used in many structural applications over the last decades. Literature review confirmed the use of ECC and UHPC in very few structural applications and to date, very few research studies have been conducted to study their performance in building and bridge structures. This warrants investigations on the evaluation of structural performance of ECC and UHPC based structural elements and to develop design guidelines for practical construction. The proposed research on the evaluation of lateral load resistance of ECC and UHPC based reinforced frame compared to their SCC counterparts is a timely initiative. The use of ECC and UHPC frames will result in building structures with enhanced durability, ductility, energy absorbing capacity and service life. 


\section{Chapter Three: Experimental program}

\subsection{Introduction}

An experimental research had been conducted to study the behaviour of reinforced beam-column frame (flexure critical and shear critical) subjected to in-plane monotonic lateral loading. Three sets of model frame of approximately $1 / 3^{\text {rd }}$ scale were made using three different types of high performance concrete (HPC) namely ultra-high performance concrete (UHPC), engineered cementitious composite (ECC) and control self-consolidating concrete (SCC) as well as reinforcing steel. Two types of one-story frame fixed at the base were tested: flexural critical (designed with flexure and shear reinforcements to induce flexure dominated failure) and shear critical (designed with flexure reinforcements only to induce shear dominated failure). This chapter will describe the geometric dimensions of frame specimens, properties of the materials, and experimental program.

\subsection{Geometric dimensions of frame specimens and reinforcement details}

Six model frames of approximately $1 / 3^{\text {rd }}$ scale of prototype (having rectangular beam and column) were constructed and tested. Two sets of frames classified as flexural critical and shear critical were made. Each set consisted of three frames made with UHPC, ECC and SCC. Figure 3.1 shows a typical frame connected (fixed) to a strong base beam. Strong base beam footing was rigidly fixed to the strong floor of the Structural Laboratory. Figures 3.2 and 3.3 show the geometric dimensions and reinforcement details of flexural critical and shear critical frames, respectively. $120 \times 160 \mathrm{~mm}$ beams/columns were used to construct the frame. In flexural critical frames, both shear/tie and main reinforcements were used (Fig. 3.2) while no shear/tie reinforcements were used in the case of shear critical frame. Details of the experimental model frames are described in Table 3.1. The heavily reinforced strong base beam footing (Figure 3.1) made with UHPC served as a footing and acted as a means to rigidly fix the frame at the base of the column. The details of the base footing is presented in Figure 3.4. The base footing was $2210 \mathrm{~mm}$ long and ** $\mathrm{mm} \mathrm{x}$ $500 \mathrm{~mm}$ in cross-section. It had two ** $\mathrm{mm} \mathrm{x} * * \mathrm{~mm}$ rectangular vertical holes to accommodate column to be rigidly fixed to the base. It also has four $40 \mathrm{~mm}$ dia vertical holes for connecting to the strong floor of the lab through threaded rods. It also had two $40 \mathrm{~mm}$ lateral holes to connect 
frame specimens to the base footing. Overall, the base beam footing served as a rigid support to frame at the bases of the column.

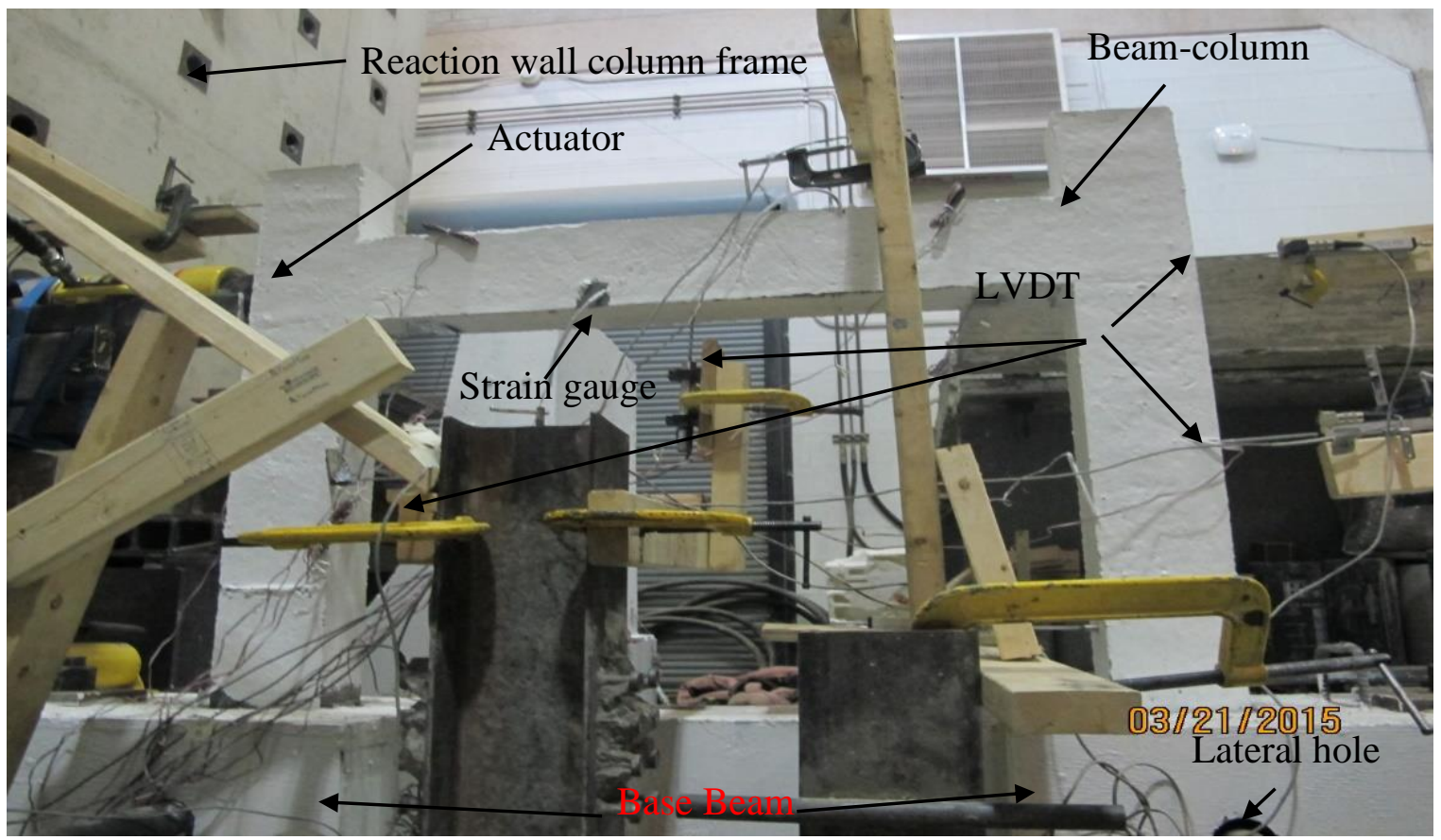

Fig. 3.1: Typical beam-column frame fixed to the based beam with instrumentation 


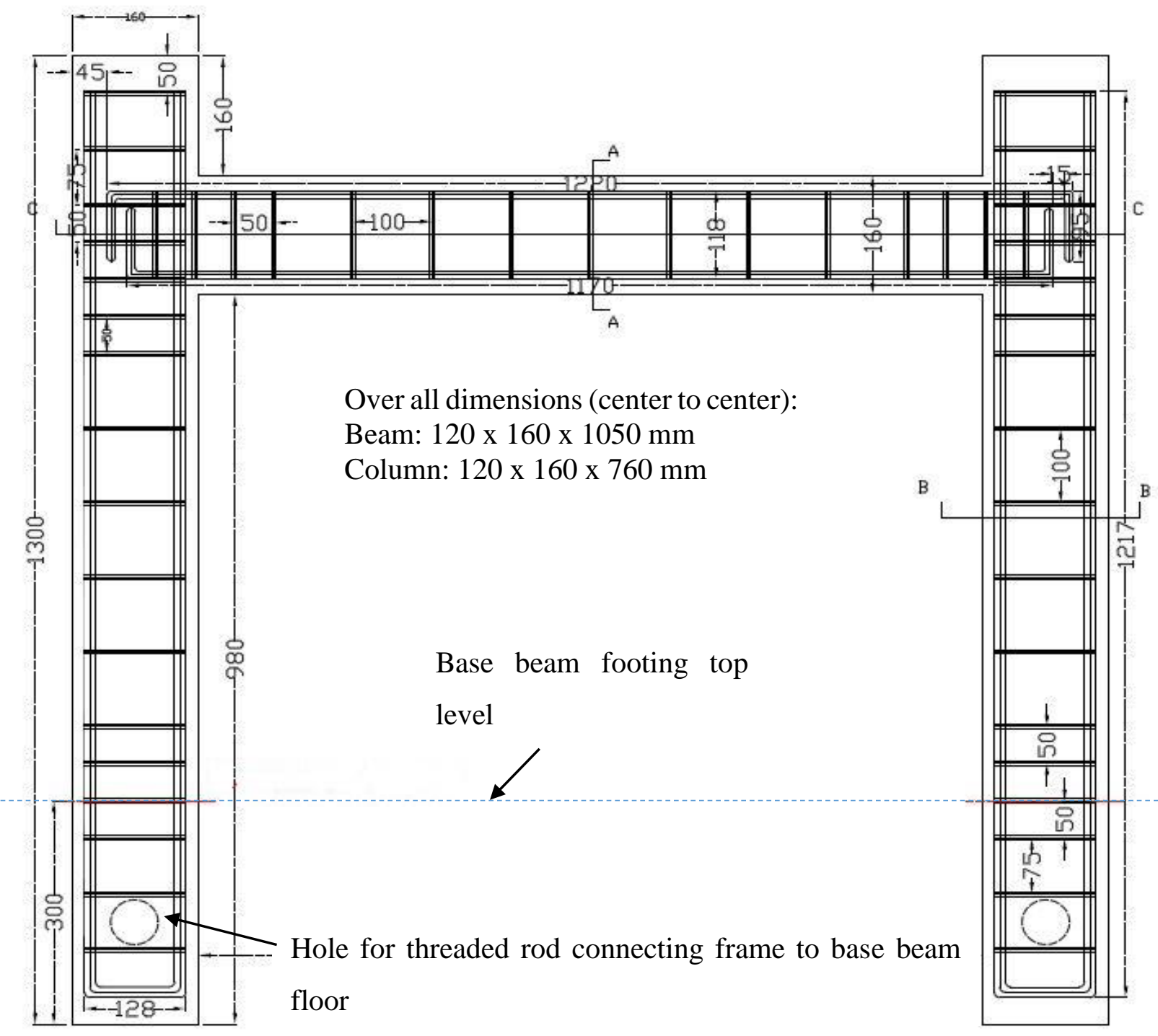

Beam cross-section

All dimensions are in $\mathrm{mm}$

\section{Column cross-section}

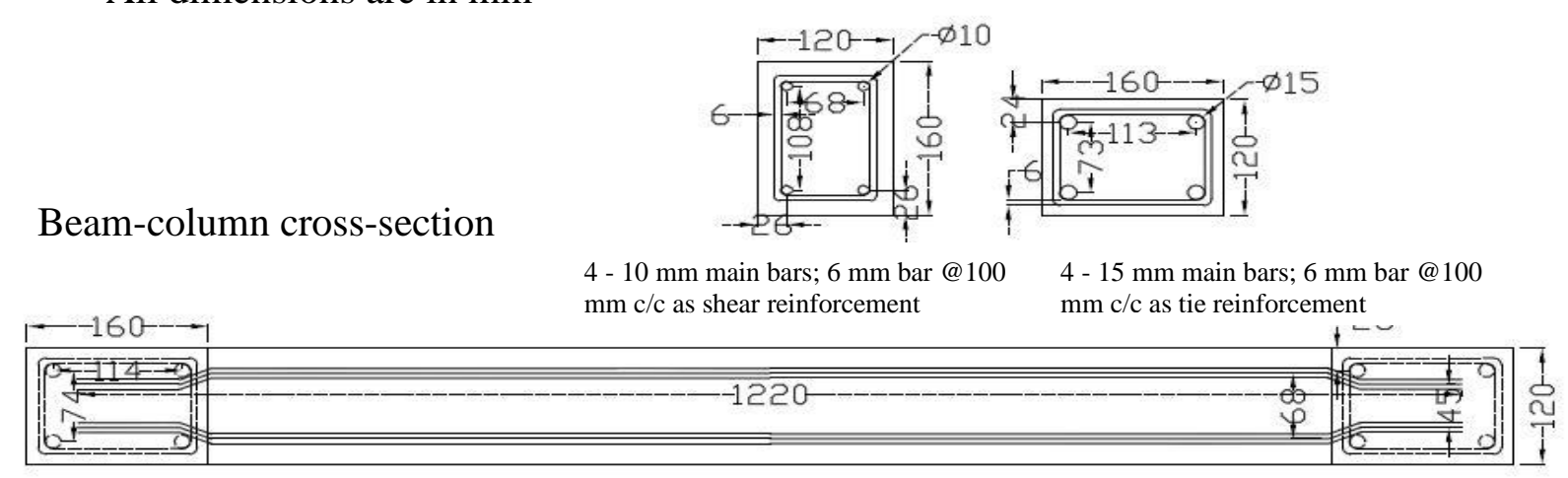

Figure 3.2: Geometric dimensions and reinforcement details for flexural critical frame 


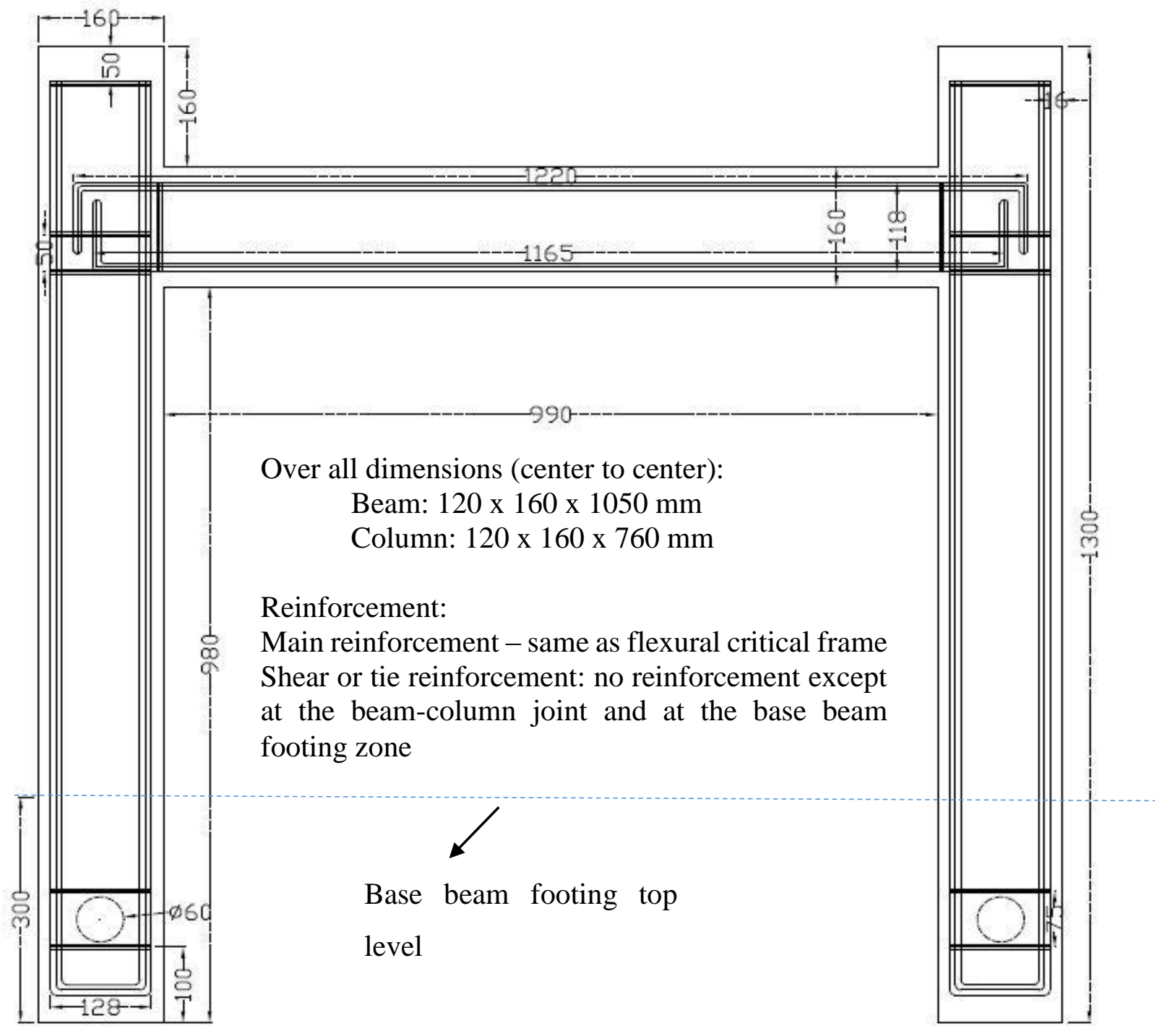

Figure 3.3: Geometric dimensions and reinforcement details for shear critical frame 
Table 3.1: Geometric dimensions and reinforcement details of frames

\begin{tabular}{|c|c|c|c|c|c|}
\hline \multirow[t]{2}{*}{ Frame } & \multirow[t]{2}{*}{ Member } & \multicolumn{2}{|c|}{ Dimensions (mm) } & \multirow[t]{2}{*}{ Main steel } & \multirow{2}{*}{$\begin{array}{c}\text { Stirrup/tie } \\
\text { reinforcement }\end{array}$} \\
\hline & & *Length & $\begin{array}{l}\text { Cross- } \\
\text { section }\end{array}$ & & \\
\hline \multicolumn{6}{|c|}{ Flexural critical (FC) frame } \\
\hline \multirow{2}{*}{$\begin{array}{l}\text { FC-SCC } \\
\text { FC-UHPC } \\
\text { FC-ECC }\end{array}$} & Beam & 1150 & $160 \times 120$ & $\begin{array}{c}4-10 \mathrm{~mm} \\
\text { bar }\end{array}$ & $6 \mathrm{~mm}$ bar $100 \mathrm{~mm} \mathrm{c/c}$ \\
\hline & Column & 760 & $160 \times 120$ & $\begin{array}{c}4-15 \mathrm{~mm} \\
\text { bar }\end{array}$ & $6 \mathrm{~mm}$ bar $100 \mathrm{~mm} \mathrm{c/c}$ \\
\hline \multicolumn{6}{|c|}{ Shear critical frame } \\
\hline \multirow{2}{*}{$\begin{array}{l}\text { SC-SCC } \\
\text { SC-UHPC } \\
\text { SC-ECC }\end{array}$} & Beam & 1150 & $160 \times 120$ & $\begin{array}{c}4-10 \mathrm{~mm} \\
\text { bar }\end{array}$ & None \\
\hline & Column & 760 & $160 \times 120$ & $\begin{array}{c}4-15 \mathrm{~mm} \\
\text { bar }\end{array}$ & None \\
\hline
\end{tabular}

*length measured from joint to joint

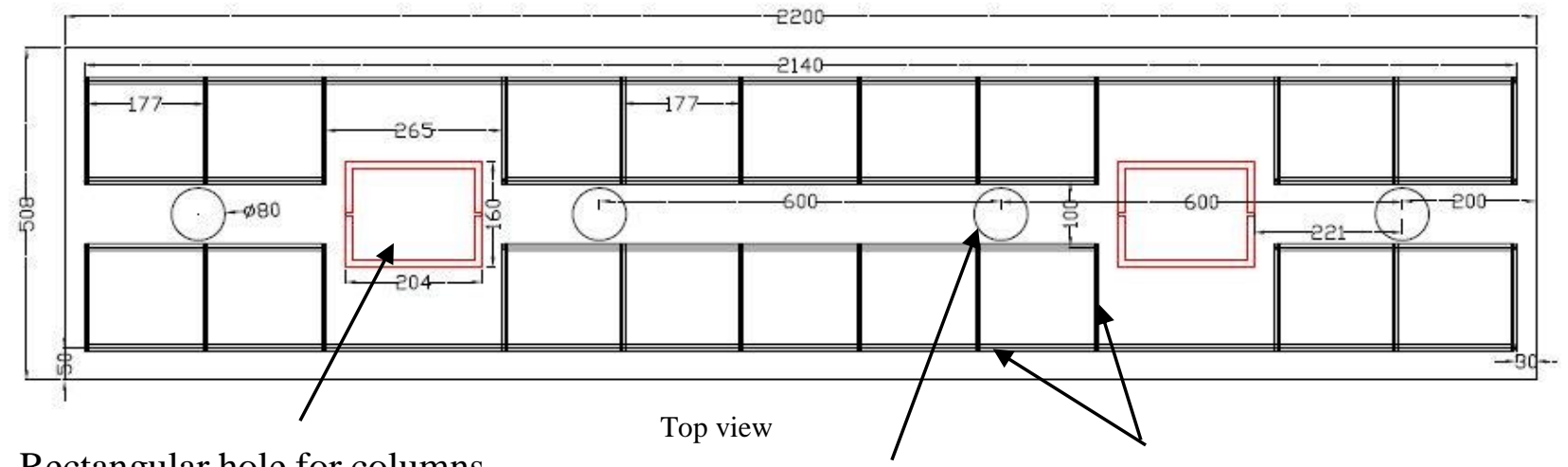

Rectangular hole for columns

Vertical hole Reinforcement

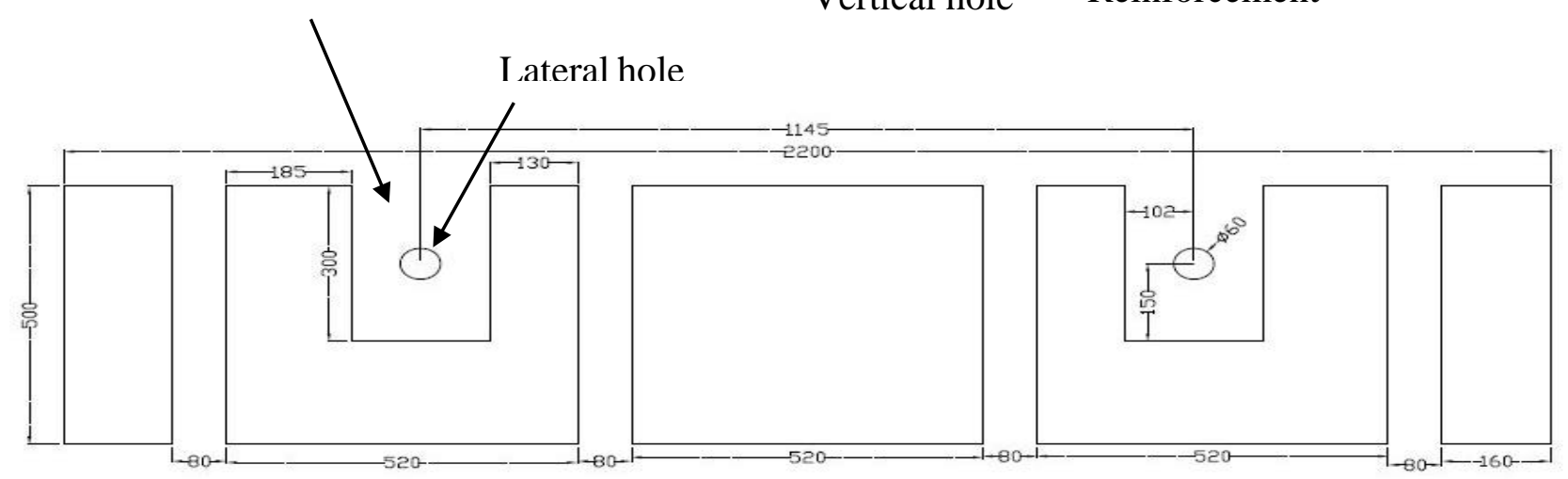

Elevation View

Figure 3.4: Details of heavily reinforced base beam footing (dimension in $\mathrm{mm}$ ) 


\subsection{Material properties and construction model frame}

This section presents the detail construction methodologies used for experimental investigation including mix design and mixing sequences for SCC/ECC/UHPC as well as casting and fabrication sequences of the specimens.

\subsubsection{Mix design and mixing sequences for SCC, ECC and UHPC}

The 120-liter shear drum mixer was used for mixing all concrete mixes. The ECC (one of the mix developed at Ryerson) has a water/cementitious material ratio of 0.30, PVA fiber content of $1 \%$ fibers $/ \mathrm{kg}$ of dry material. It consists of general purpose cement and fly ash (FA) as the cementing material, water, natural grain silica sand with 110 micrometer nominal size, Polyvinyl Alcohol (PVA) fibers and a polycarboxylate-based high range water reducer (HRWR) as shown in Table 3.2. The PVA fibers are 39 microns in diameter, $8 \mathrm{~mm}$ in length, a tensile strength of $1620 \mathrm{MPa}$, modulus of elasticity of $42.8 \mathrm{GPa}$, and has a melting point of $225^{\circ} \mathrm{C}$, as shown in Fig. 3.5. For casting ECC weighted solid contents except for the PVA fibers were introduced into the shear mixture and mixed for 1 minutes. After that $75 \%$ of the water was added to $50 \%$ HRWR and mixed together then the mix of water and HRWR was added gradually to the mixer and mixed for additional 2 to 3 minutes. Then the remaining water and HRWRA was introduced again with same procedure to the mix, and mixed for another 2 minutes for the development of a uniform and consistent mortar mixture. Lastly, the PVA fibers were added to the mortar for another 3 minutes of stirring until all fibers were dispersed with mortar mixture. The mixing sequence and the resulting flowable ECC mix is presented in Figure 3.5.

Table 3.2: Mix design of UHPC and ECC

\begin{tabular}{|l|c|c|c|c|c|c|}
\hline \multirow{2}{*}{ Mixture } & \multicolumn{2}{|l|}{ Ingredients per 1 part of Cement } & \multirow{2}{*}{ w/b } \\
\cline { 2 - 6 } & Cement & Fly Ash (FA) & $\begin{array}{l}\text { Silica } \\
\text { Sand }\end{array}$ & $\begin{array}{c}\text { PVA } \\
\mathbf{k g} / \mathbf{m}^{3}\end{array}$ & $\begin{array}{c}\text { HRWR } \\
\mathbf{k g} / \mathbf{m}^{3}\end{array}$ & \\
\hline ECC & 1 & 1.2 & 0.80 & 26 & 5.4 & 0.27 \\
\hline Mixture & Cement & Silica Fume & $\begin{array}{c}\text { Silica } \\
\text { Sand }\end{array}$ & $\begin{array}{c}\text { Steel fiber } \\
\mathbf{k g} / \mathbf{m}^{\mathbf{3}}\end{array}$ & $\begin{array}{c}\text { HRWR } \\
\mathbf{k g} / \mathbf{m}^{3}\end{array}$ & w/b \\
\hline UHPC & 1 & 0.25 & 1.10 & 164 & 26 & 0.22 \\
\hline \multicolumn{7}{|c|}{ w: water; c: cement; b: binder } \\
\hline
\end{tabular}



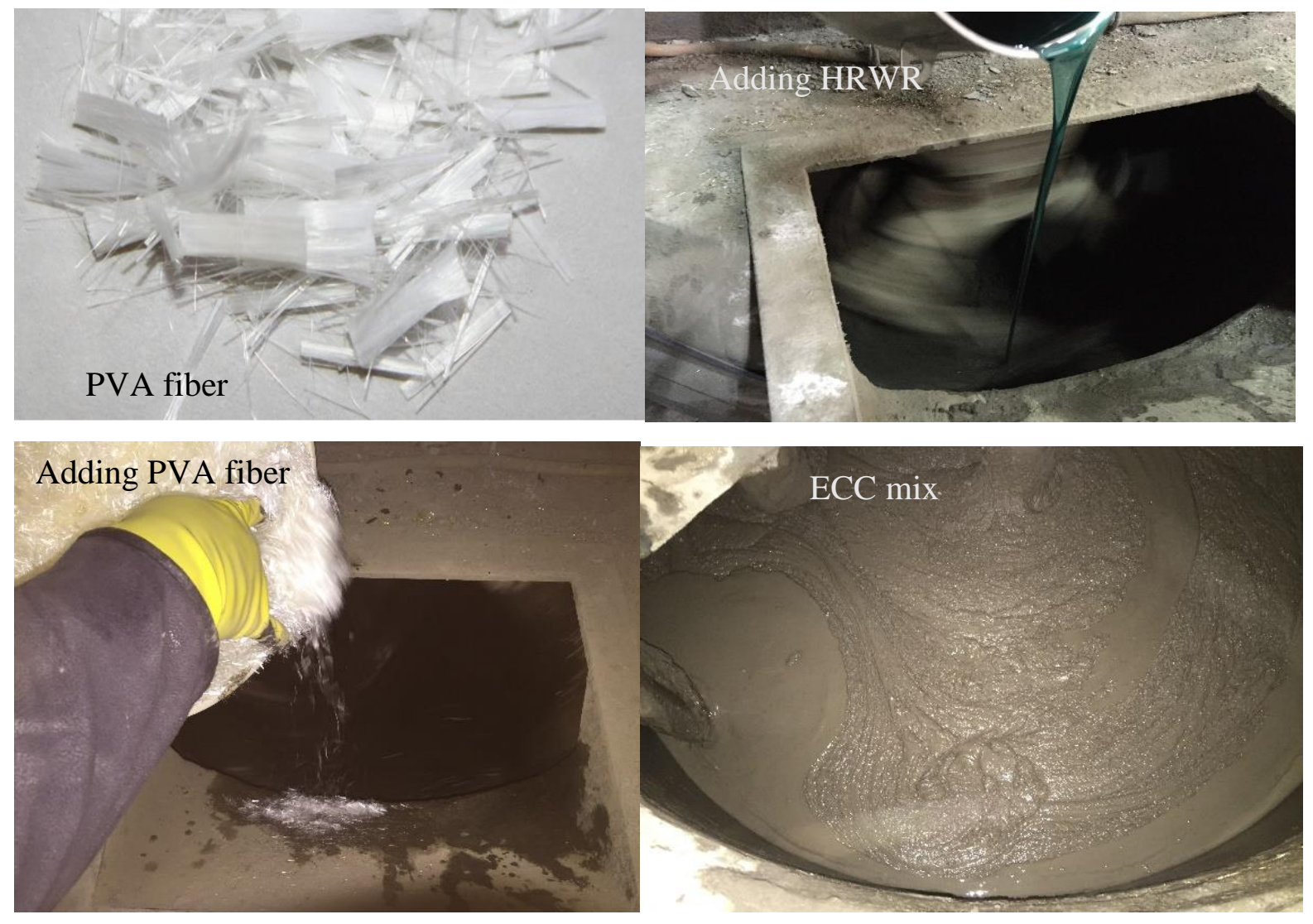

Fig. 3.5: ECC production

The UHPC developed at Ryerson has water to cementitious material ratio of 0.22 and a steel fiber content of $9 \%$ by mass of dry material. It consists of general purpose cement and silica fume as the cementing material, water, natural grain silica sand of 110 micrometer nominal size, steel fibers and a polycarboxylate-based high range water reducer (Table 3.2). The steel fibers used are 0.4 $\mathrm{mm}$ in diameter and $14 \mathrm{~mm}$ in length with a tensile strength of $2160 \mathrm{MPa}$, modulus of elasticity of $210 \mathrm{GPa}$, and melting point higher than $800^{\circ} \mathrm{C}$, as shown in Fig. 3.6. For casting UHPC, weighted dry materials except the steel fibers were introduced to shear mixer and mixed for 2 minutes. After that again $75 \%$ of the water was added to the mixer and mixed for another 2 minutes. The remaining water and the HRWR was added gradually and mixed for another 2 minutes for the development of a uniform and consistent mix. At the end the steel fibers were added to the mix until all fibers were dispersed with mortar mixture. The resulting flowable UHPC is shown in Figure 3.6 during casting. 


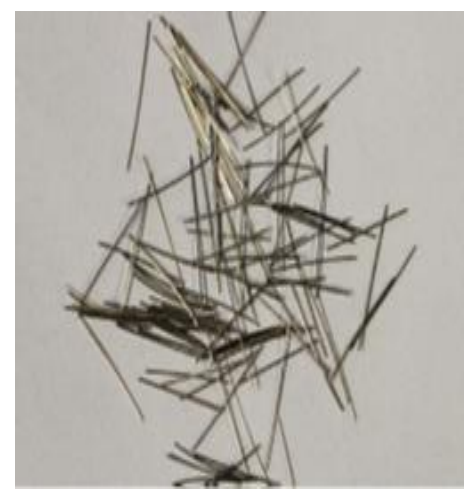

Steel fiber

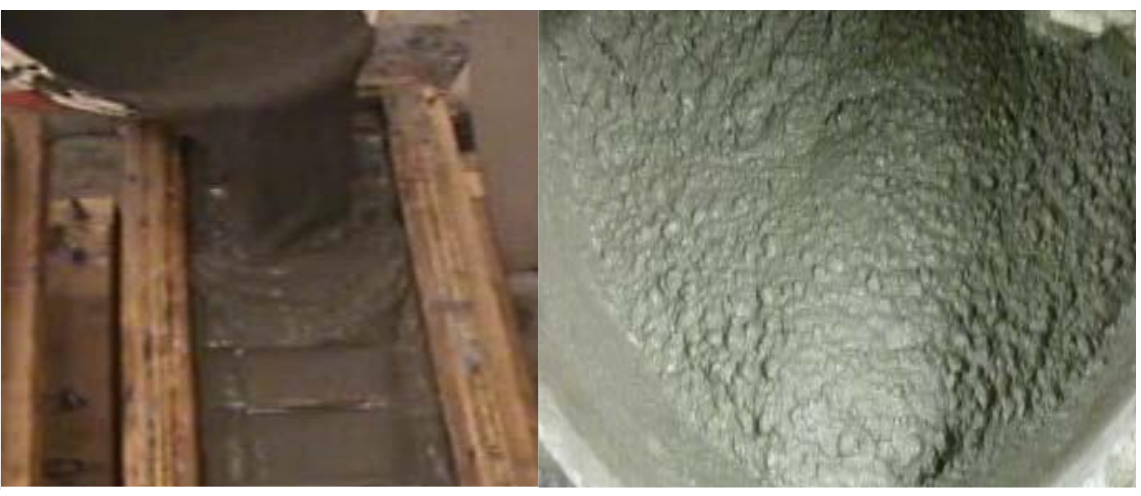

UHPC
SCC

Fig. 3.6: Steel fiber and the resulting flowable UHPC and SCC

The SCC was made with commercially available dry content $(30 \mathrm{~kg})$ pre-packaged bags. The dry content included the nominal aggregate size of $10 \mathrm{~mm}$, Portland cement, silica fume and airentraining admixtures. For each pre-package bag, a 2.4 liter of water was added for development of the SCC mixture. The dry ready mix packages were introduced into the mixer for a 30 second mixing. After that $50 \%$ of the potable water was added to the dry content in period of 2 minutes of mixing. The remaining $50 \%$ of the water was slowly added to the mix for additional 2 to 3 minutes until the required flowability and workability was achieved. The flowable SCC is shown in Figure 3.6.

\subsubsection{Fabrication and construction of model frame specimens}

Wooden formworks were prepared for casting SCC/ECC/UHPC frames. Figure 3.7 shows a typical formwork for flexural critical frame exhibiting both main and shear/tie reinforcements position for flexural frames and columns and also the position of steel strain gauges can be seen. Immediately after mixing of concrete, flowable concretes (SCC, ECC or UHPC) were poured into formwork and the frames were cast horizontally without any consolidation. Frame casting was very easy and quick especially with highly flowable ECC and UHPC mixes. Figure 3.8 shows a typical model frame and formwork after the casting. 


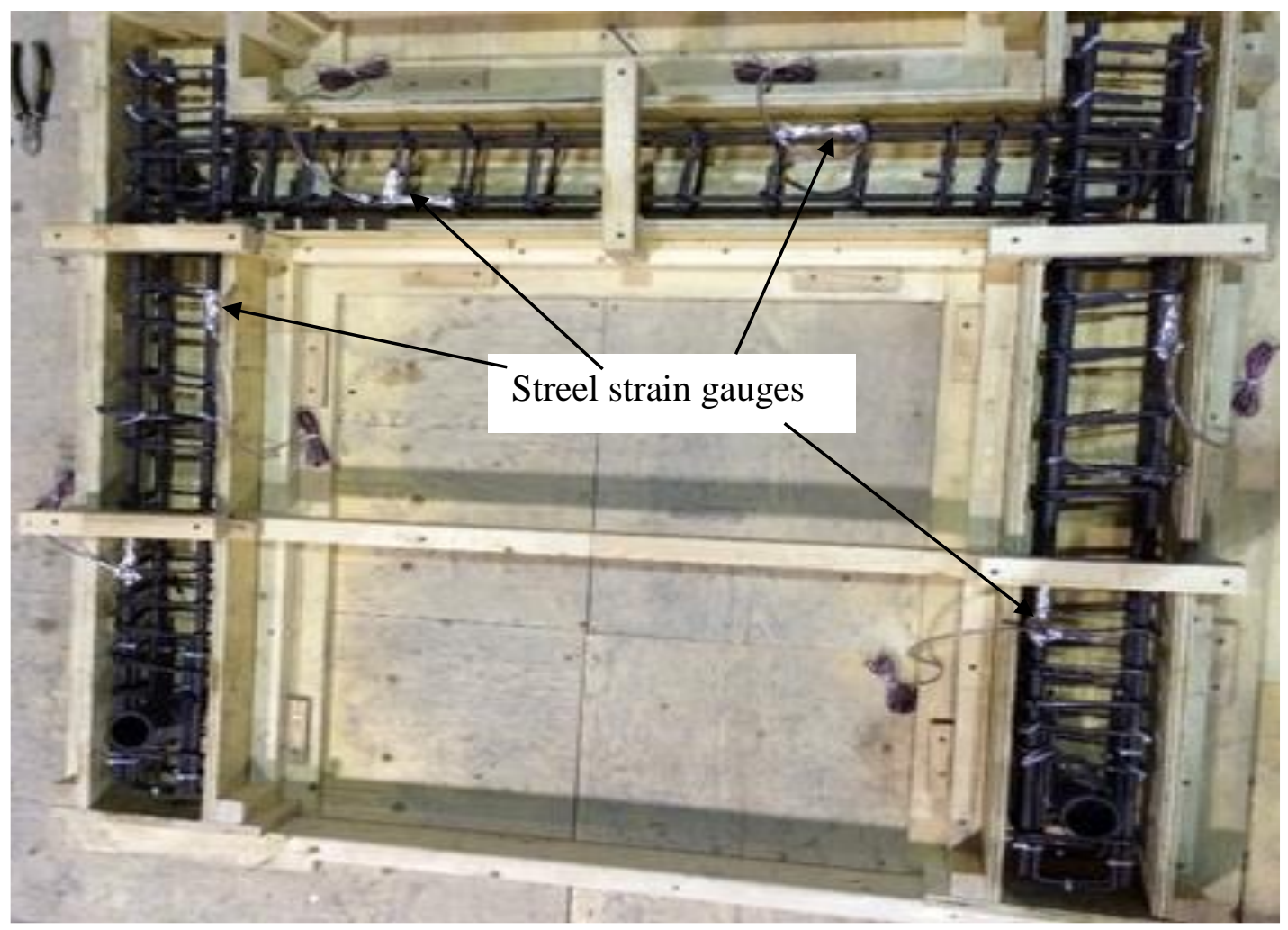

Fig. 3.7: Typical formwork showing reinforcement and strain gauges for flexural critical frame

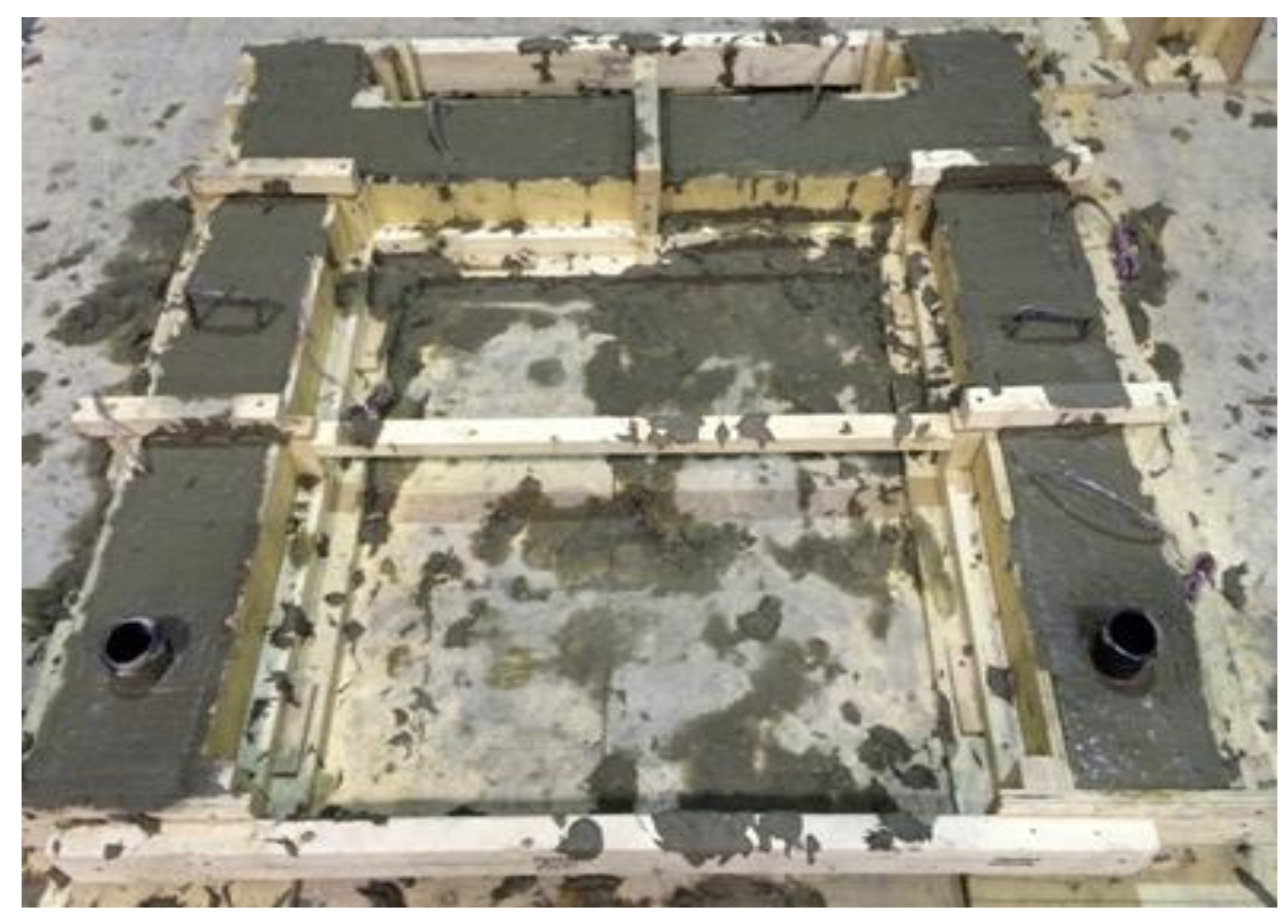

Fig. 3.8(a): Typical model frame and formwork after casting with control specimens 


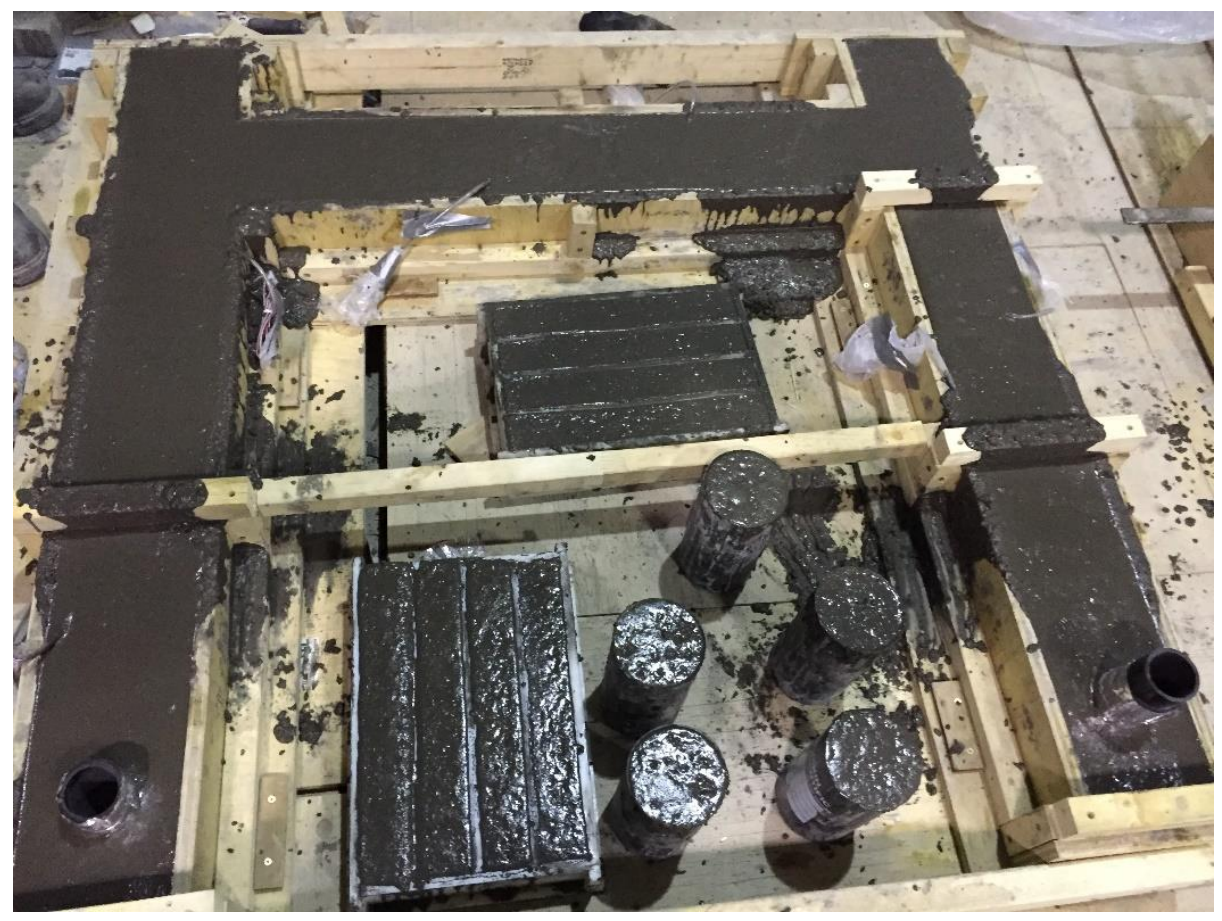

Fig. 3.8(b): Typical model frame and formwork after casting with control specimens

At least three control specimens for each types of concrete in the form of cylinders, beams and cubes were also cast at the same time (Fig. 3.8b). All the specimens with control specimens were cured until the age of testing (for 28 days) using wet burlaps in the laboratory conditions with a relative humidity and temperature of $50 \% \pm 2.5 \%$ and $24 \pm 2{ }^{\circ} \mathrm{C}$, respectively. The resulting SCC, UHPC and ECC in the hardened state as obtained from the cut cylinder specimens are shown in Figure 3.9.

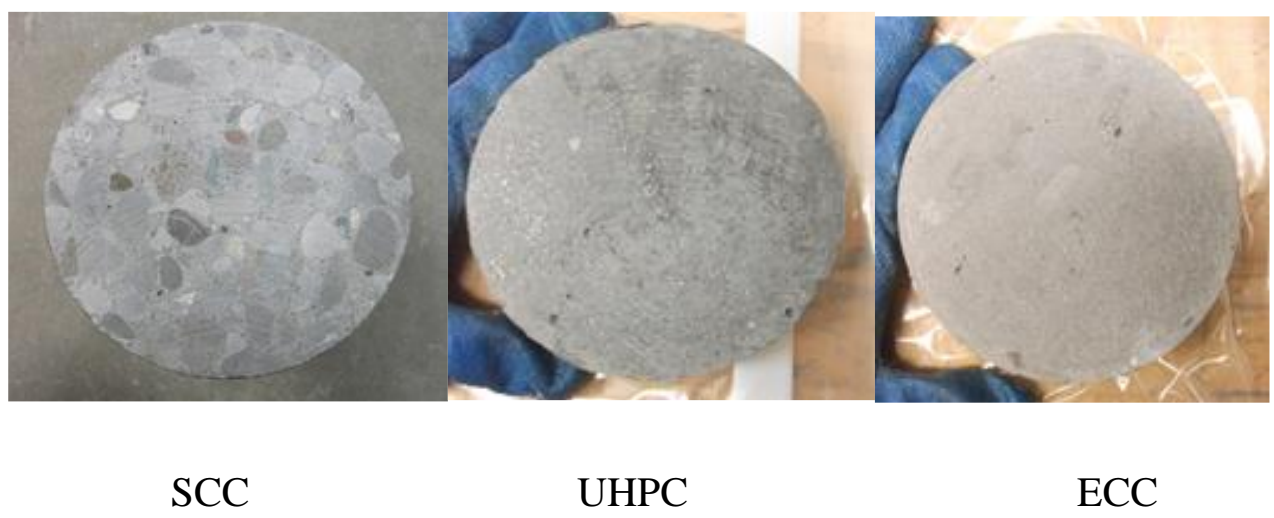

Figure 3.9: View hardened concrete specimens 
The compression test for cylindrical and cubic samples of SCC, ECC and UHPC was performed as per ASTM C39 (2003), and ASTM C109 (2011). The four-point bending test was performed on the ECC and SCC control prism specimen at 28 days in accordance to ASTM C78 (2010). The four-point bending test was performed using a closed-loop controlled servo-hydraulic system under displacement condition at a loading rate of $0.005 \mathrm{~mm} / \mathrm{s}$. The load and mid-span deflection were recorded on a computerized data acquisition system. The total span length of the flexural specimens was $304.8 \mathrm{~mm}$. Typical load/flexural stress-mid span deflection responses of $\mathrm{SCC} / \mathrm{ECC} / \mathrm{UHPC}$ are presented in Figure 3.10. ECC showed significant post-peak strain hardening (as evident from the flat post peak response) behaviour due to its micro-cracking characteristics compared to SCC and ECC (which shows softening as indicated by the post-peak descending branch). Such strain hardening behaviour will enhance ductility and energy absorbing capacity of reinforced ECC frames compared with their SCC and UHPC counterparts.
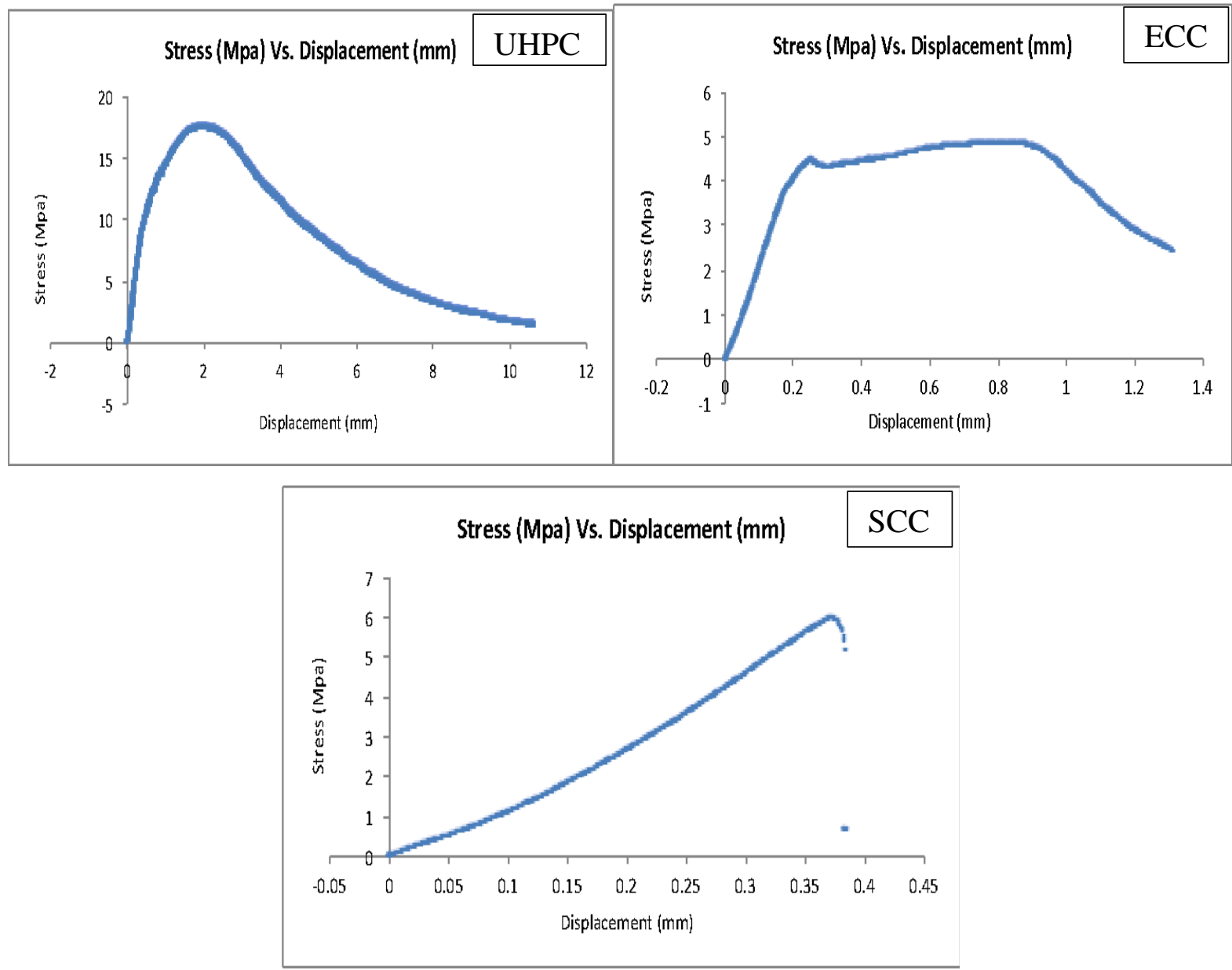

Fig. 3.10: Flexural stress-displacement responses of UHPC, ECC and SCC 
Mean compressive strength $\left(\mathrm{f}^{\prime} \mathrm{c}\right)$ and flexural/tensile strength $\left(\mathrm{f}_{\mathrm{t}}\right)$ for each concrete type (mean value of at least 8 representative samples are tabulated in Table 3.3 based on control cylinder and prism tests.

Table 3.3: Concrete compressive and flexural/tensile strength

\begin{tabular}{|c|c|c|c|}
\hline & SCC & UHPC & ECC \\
\hline $\begin{array}{c}\text { Concrete compressive } \\
\text { strength (MPa) at the age } \\
\text { of testing (28 day) }\end{array}$ & 50.6 & 136 & 63.5 \\
\hline $\begin{array}{c}\text { Flexural strength (MPa) at } \\
\text { the age of testing (28 day) }\end{array}$ & 5.9 & 15.7 & 5.1 \\
\hline
\end{tabular}

Coupon tension tests were also performed to determine yield and ultimate strength deformed reinforcing mild steel bars used to construct frame specimens. Stress-strain response of $10 \mathrm{~mm}, 15$ $\mathrm{mm}$ and $6 \mathrm{~mm}$ bars are presented in Figure 3.11. Table 3.4 lists the mean value of steel yield strength $\left(f_{y}\right)$ and yield strain for each diameter steel bar shape as derived from at least three coupon specimens.
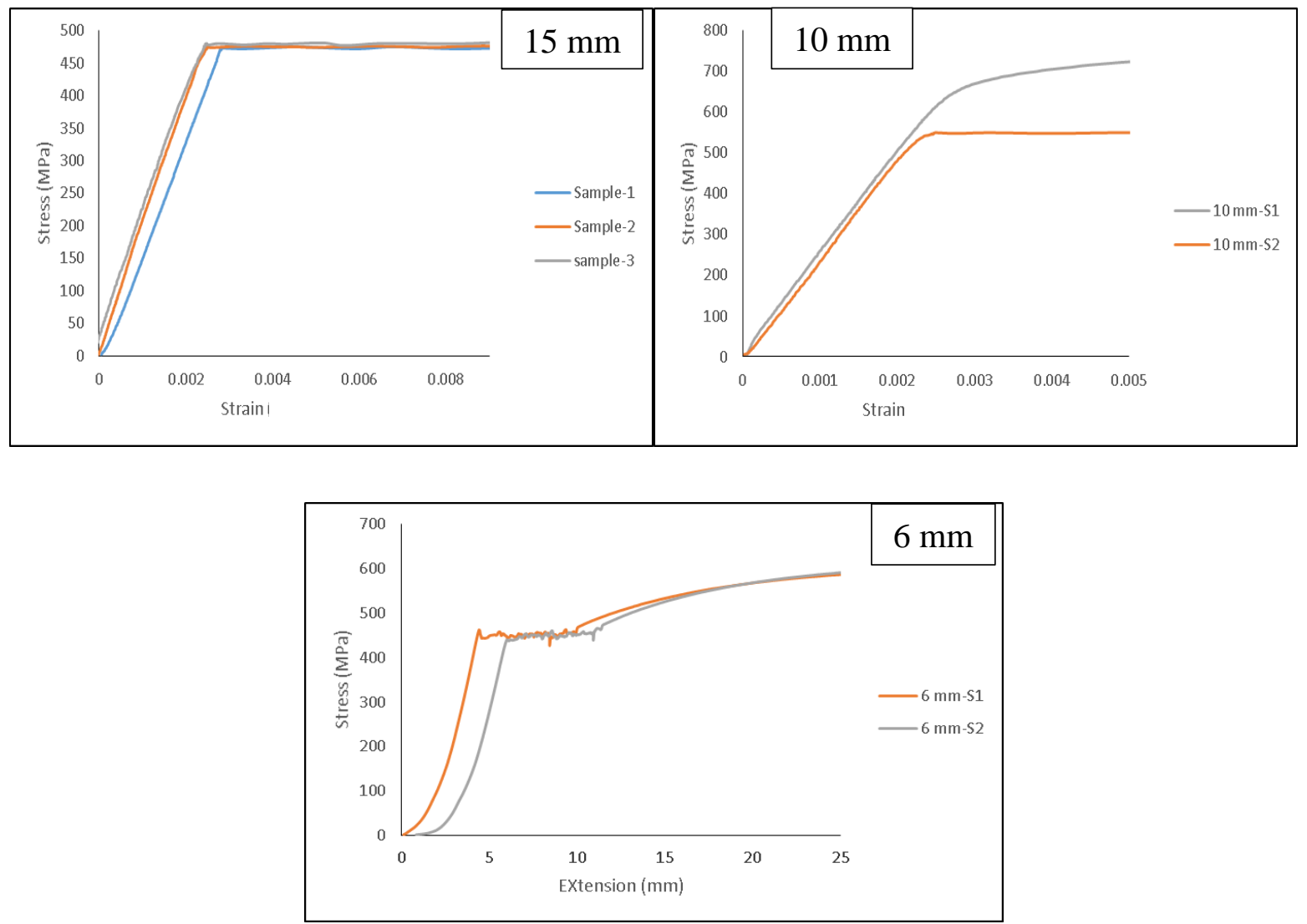

Fig. 3.12: Stress-strain/deformation responses of steel bars 
Table 3.4: Properties of steel reinforcement

\begin{tabular}{|l|c|c|}
\hline Rebar Size (mm) & Yield strain (Micro-Strain) & Yield stress (fy) MPa \\
\hline $10 \mathrm{~mm}$ & 2240 & 527 \\
\hline $15 \mathrm{~mm}$ & 2310 & 478 \\
\hline $6 \mathrm{~mm}$ & $* *$ & 429 \\
\hline
\end{tabular}

\subsection{Frame instrumentation, test set-up and testing}

Six strain gauges (S1 to S6) were installed to the longitudinal (main) reinforcements in beam and columns before casting concrete while six strain gauges ( $\mathrm{C} 1$ to $\mathrm{C} 6$ ) were installed on the concrete surface before the testing (at 28-days) at critical locations as shown in Figure 3.13. Four strain gauges were installed: two on the longitudinal (main) reinforcements (L1 and L2) and two one shear reinforcement near the joint (S1 and S2) shear critical frame as shown in Figure 3.14. Eight strain gauges ( $\mathrm{C} 1$ to $\mathrm{C} 8$ ) were installed on the concrete surface before the testing (at 28-days) at critical locations as shown in Figure 3.14. To measure the deflection (vertical and horizontal) at different points of the frames, seven linear voltage displacement transducers (LVDTs) designated as (LVDT1 to LVDT7) were connected to frames during the testing as shown in Figure 3.15. LVDT 1 and LVDT7 monitored the lateral (shear) deflection at the top of the frame and the corresponding rotation of the frame was calculated based on these readings. 


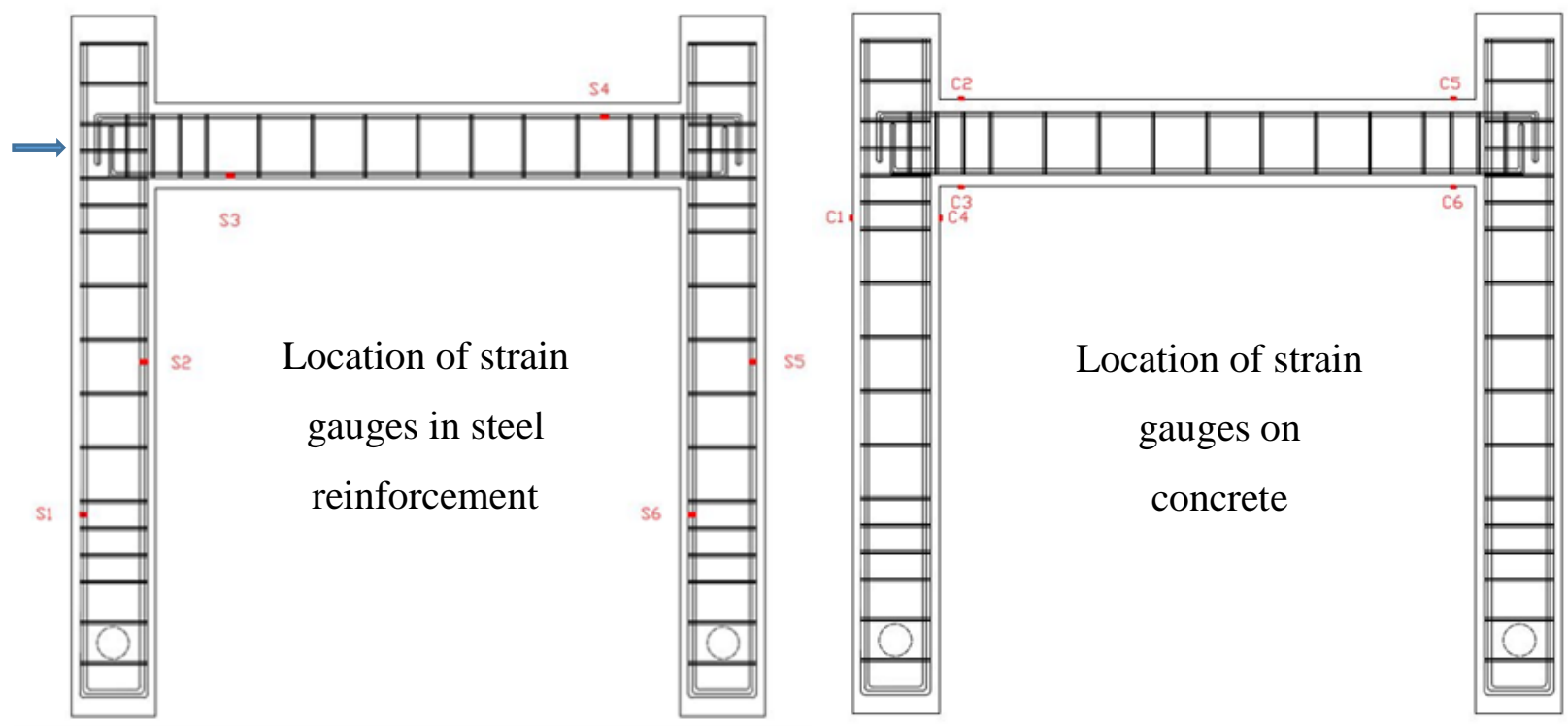

Fig. 3.13: Locations of concrete and steel strain gauges in flexural critical frames

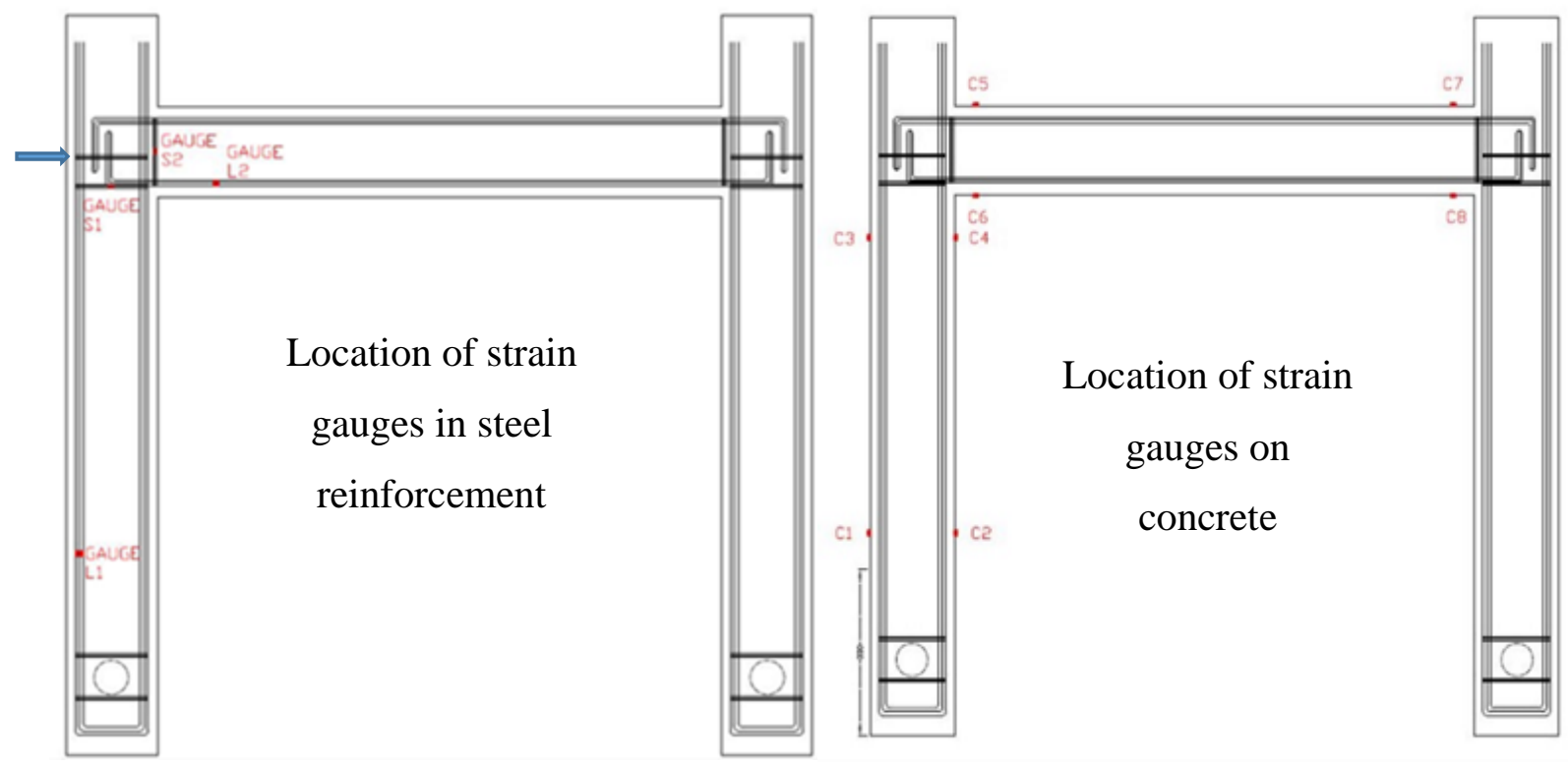

Fig. 3.14: Locations of concrete and steel strain gauges in shear critical frames 


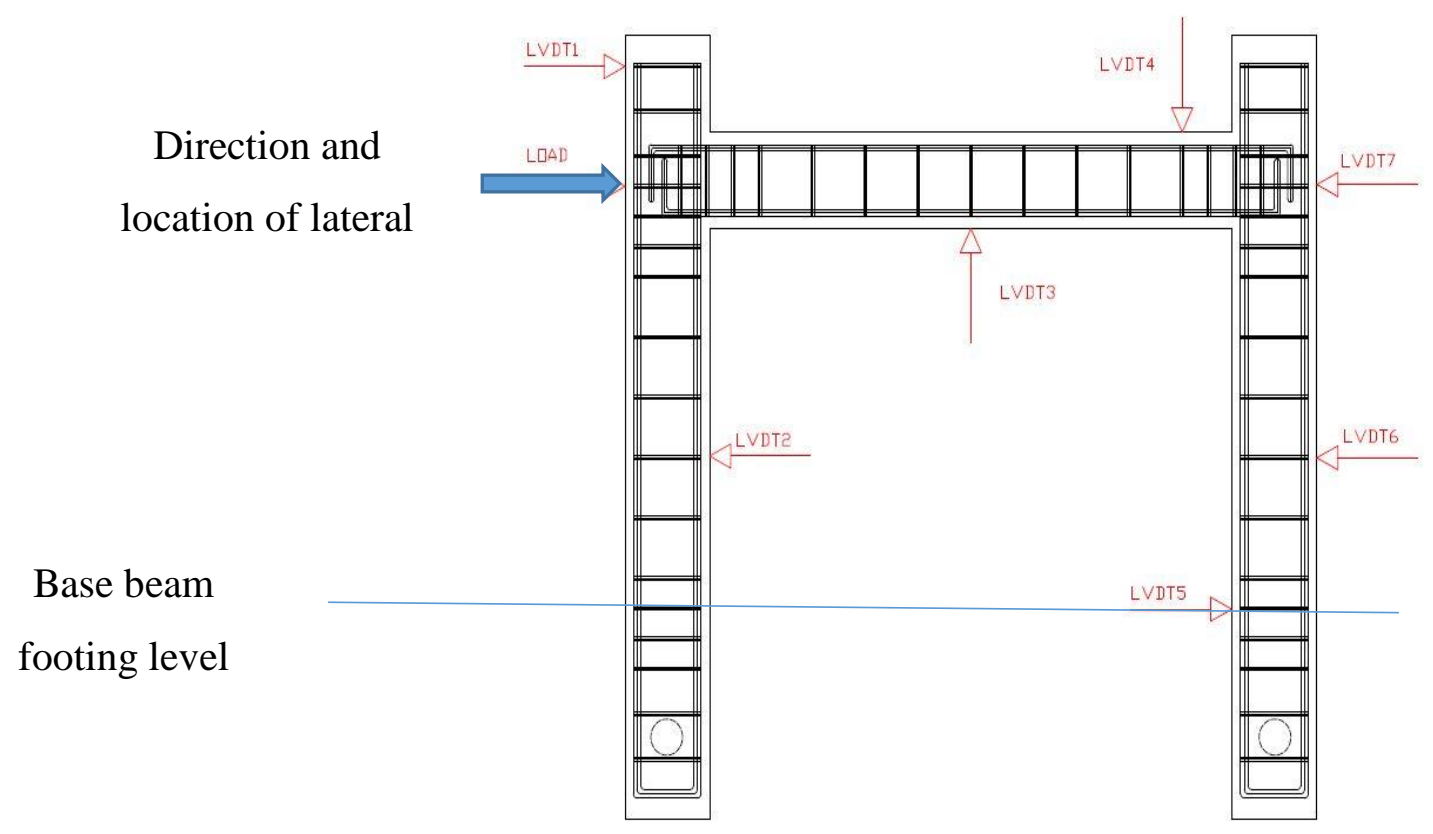

Fig. 3.15: Test set-up Locations of concrete and steel strain gauges in shear critical frames

The monotonic lateral loading was applied at the level of the beam by a hydraulic actuator at 0.2 $\mathrm{kN} / \mathrm{s}$ as shown in the test set-up shown in Figure 3.1 as well as in Figure 3.15. The loading was continued until failure of the model frame specimens. During the loading history, deflection/displacements at different points and strain developments in steel and concrete were recorded by a computer aided data acquisition system. The crack development/propagation and failure modes were visually observed and recorded during the test. The crack's width was also measured using the crack scope.

\subsection{Conclusions}

Experimental research program is described by illustrating test specimens, specimen material properties, specimen instrumentation, test set-up and testing procedure. A total six steel reinforced one story frames (made of SCC, ECC and UHPC) consisting three flexural critical and three shear critical were tested to failure by applying monotonic lateral loading at the beam level. The detailed test results is presented in discussed in Chapter Four. 


\section{Chapter Four: Structural performance of reinforced ECC/UHPC frames - Results and Discussion}

\subsection{Introduction}

The results of the experimental tests on the structural performance of flexural and shear-critical frames subjected to monotonic lateral loading are presented here. Six tests were conducted on one story frames by applying in plane lateral loading at the top beam column joint. The variable parameters in these tests were the type of concrete material (SCC, ECC and UHPC) and type of frame - flexural critical and shear critical frame (identified by the presence or absence of shear/tie reinforcement, respectively). The result of the tests presented and discussed by illustrating load versus deflection (displacement) response, moment-rotation responses, load or moment resistance, strain development in steel and concrete, crack development, crack pattern characterization, energy absorption capacity, ductility factor and failure modes. The experimental load/shear and moment resisting capacity of the frames are also compared with those obtained from Codes and other existing equations.

\subsection{Structural performance of flexural-critical frames}

The structural performance of $1 / 3^{\text {rd }}$ flexural-critical frames made with SCC, ECC and UHPC mixtures subjected to monotonic lateral loading is described and compared.

\subsubsection{Experimental load-deflection/moment-rotation responses and strength/stiffness}

Lateral load-top deflection (LVDT 7) and corresponding moment-rotation curves (moment calculated at the base of each column and column rotation) for SCC/ECC/UHPC frames are presented in Figs. 4.1(a-c). In general, load/moment increased with the increase of displacement/rotation. The slope change in the response indicated crack formation/initiation or yielding of reinforcing bars. From the load-deflection responses figure 4.1(d), it is clear that UHPC frame had the highest strength followed by its ECC and SCC frame counterparts. Table 4.1 summarizes the load at first crack and correponding deflection, ultimate load/peak and ultimate deflection, ultimate frame/column rotation and ultimate moment at the end of beam/column. The ultimate load capacity of frames varied from 59.5 to $127.25 \mathrm{kN}$. The load capacity of the UHPC frame was $113 \%$ higher than its SCC counterpart while ECC frame capacity was $30 \%$ higher than its SCC counterpart. The strength/load capacity enhancement seemed to be proportional to the $\%$ 
increase in concrete strength (ECC and UHPC compressive strength were $26.7 \%$ and $171 \%$ higher than SCC while tensile strength were 166\% higher and $13.6 \%$ lower than SCC, respectively). The ultimate lateral deflection ranged between $65.19 \mathrm{~mm}$ and $82.66 \mathrm{~mm}$ and ECC frame showed $25.9 \%$ and $17.8 \%$ higher deflection compared to its SCC and UHPC counterparts, respectively. However, SCC frame showed higher deflection at first crack compared to ECC and UHPC frames. The ultimate rotation for the ECC frame was $46 \%$ and $23 \%$ higher than its SCC and UHPC counterparts, respectively. Beam and column end moments (calculated based in ultimate lateral load) are found to be highest for UHPC frame followed by ECC and SCC frames.

Table 4.1: Summary of load-deflection and moment rotation responses

\begin{tabular}{|l|c|c|c|c|c|c|c|c|}
\hline \multirow{2}{*}{$\begin{array}{l}\text { Frame } \\
\text { Designation }\end{array}$} & \multicolumn{3}{|c|}{ Experimental load (kN) and deflection (mm) } & \multicolumn{3}{c|}{$\begin{array}{c}\text { Experimental ultimate } \\
\text { moment (kNm) and rotation } \\
\text { (radian) }\end{array}$} \\
& $\begin{array}{l}\text { Ultimate/ } \\
\text { peak load }\end{array}$ & $\begin{array}{c}\text { Ultimate } \\
\text { lateral top } \\
\text { deflection }\end{array}$ & $\begin{array}{c}\text { Ultimate } \\
\text { beam end } \\
\text { deflection }\end{array}$ & $\begin{array}{c}\text { Load } \\
\left(1^{\text {st }}\right. \\
\text { crack) }\end{array}$ & $\begin{array}{c}\text { Deflection } \\
\left(1^{\text {st }} \text { Crack) }\right.\end{array}$ & $\begin{array}{c}\text { Frame } \\
\text { rotation }\end{array}$ & $\begin{array}{c}\text { Column } \\
\text { end } \\
\text { moment }\end{array}$ & $\begin{array}{c}\text { Beam } \\
\text { end } \\
\text { moment }\end{array}$ \\
\hline FC-SCC & 59.5 & 65.19 & 7.04 & 10 & 3.80 & 0.069 & 18.5 & 11.4 \\
\hline FC-ECC & 77.5 & 82.66 & 7.08 & 15 & 3.68 & 0.101 & 24.1 & 14.8 \\
\hline FC-UHPC & 127.3 & 70.18 & 5.34 & 10 & 3.07 & 0.085 & 39.6 & 24.4 \\
\hline
\end{tabular}




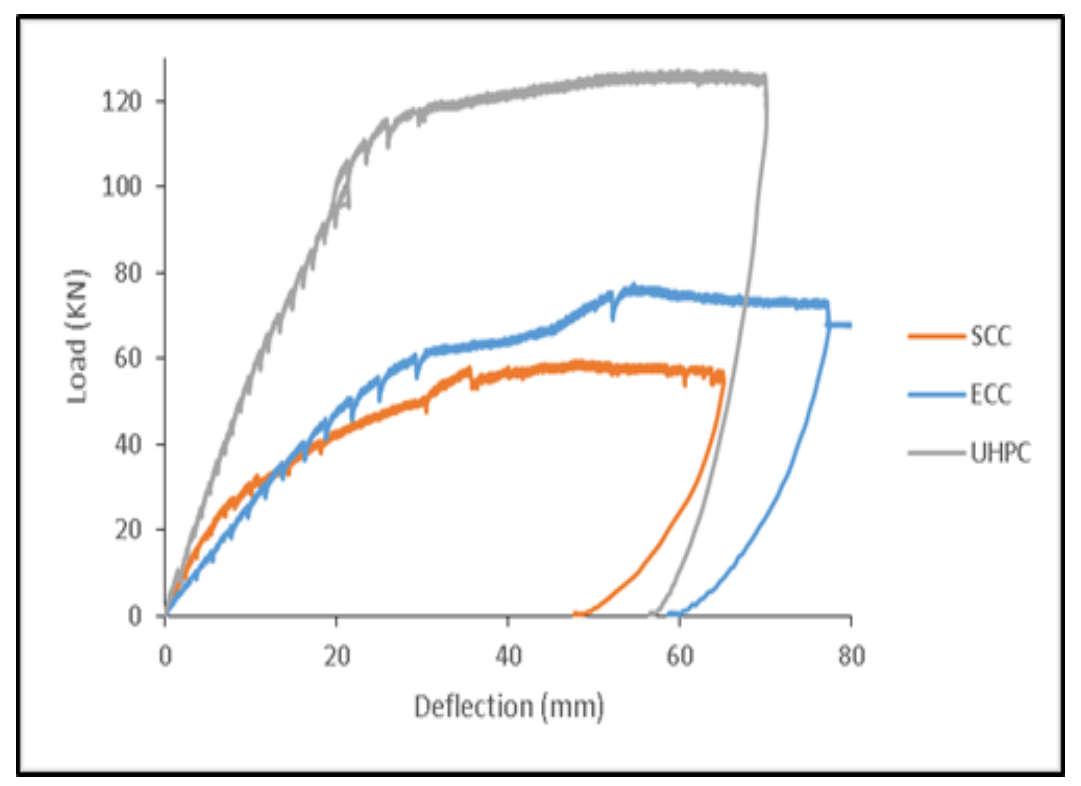

Fig. 4.1(a): Lateral load-top deflection responses of SCC/ECC/UHPC frame/column

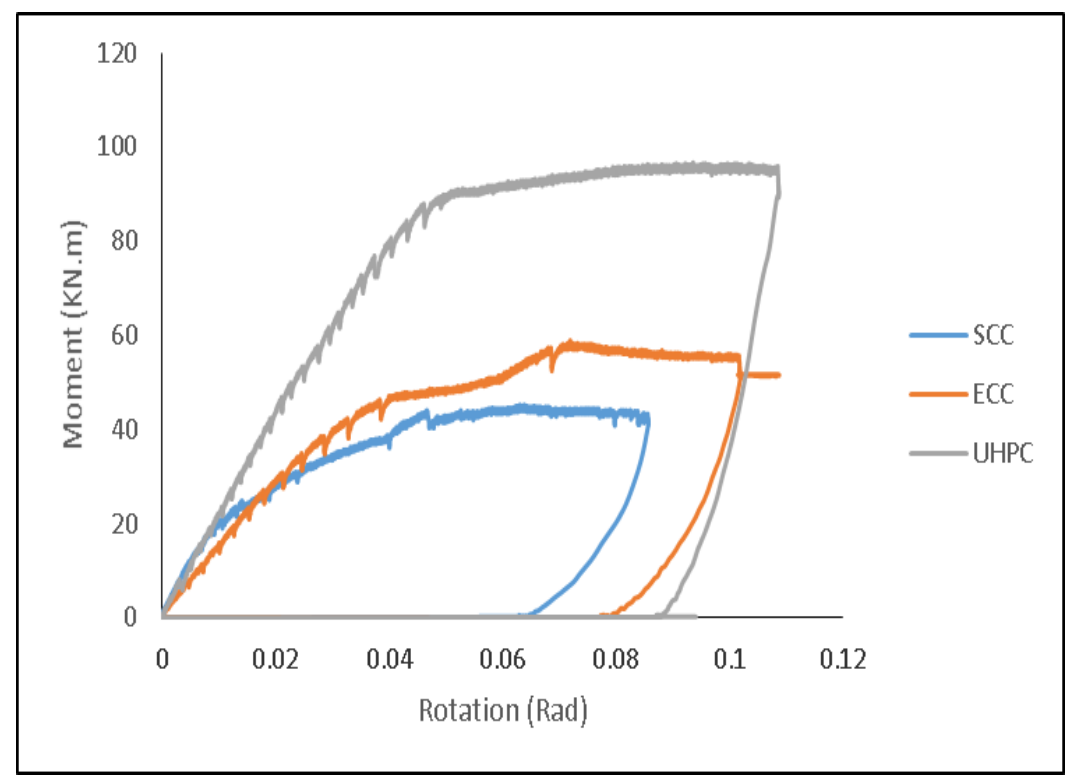

Fig. 4.1(b): Moment-rotation response of SCC/ECC/UHPC frame/column 


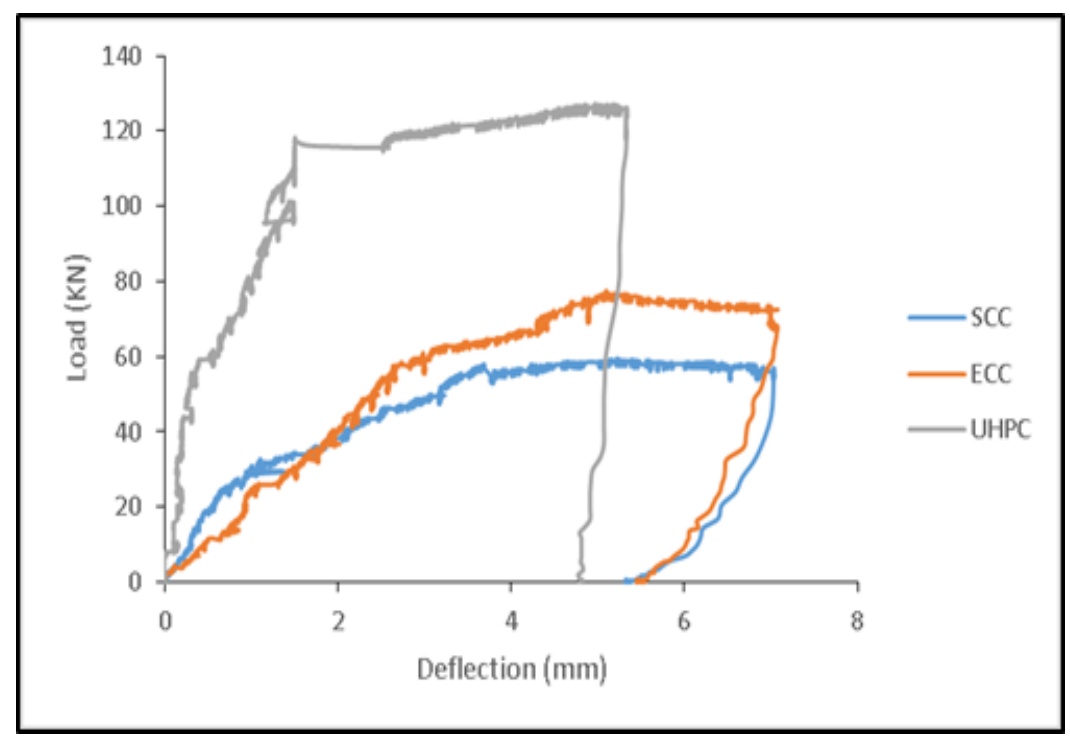

Fig. 4.1(c): Lateral load-vertical central deflection response of beam in SCC/ECC/UHPC frame
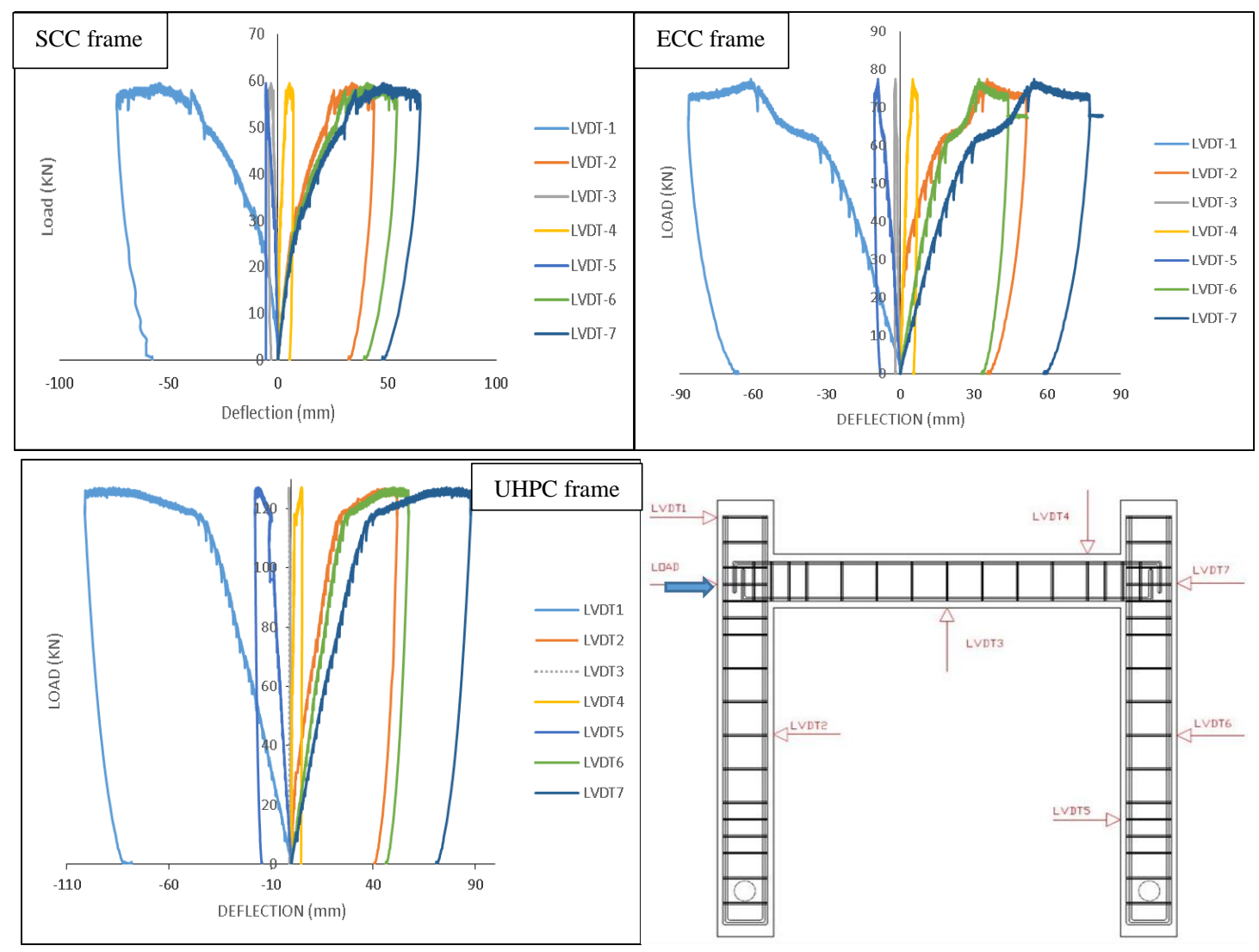

Figure 4.1(d): SCC/ECC/UHPC frame lateral load-displacement responses at LVDT locations

\subsubsection{Strain developments in steel and concrete}

Figure 4.2(a) shows the development of flexural concrete strain at various locations of beam and column in SCC/ECC/UHPC frames. As expected, gauges C1, C2 and C6 developed compressive 
strain while gauges C3, C4 and C5 developed tensile strain. Figure 4.2(b) compares the flexural strain development in SCC/ECC/UHPC frames and no definite conclusions can be drawn on the effect of concrete on strain development.
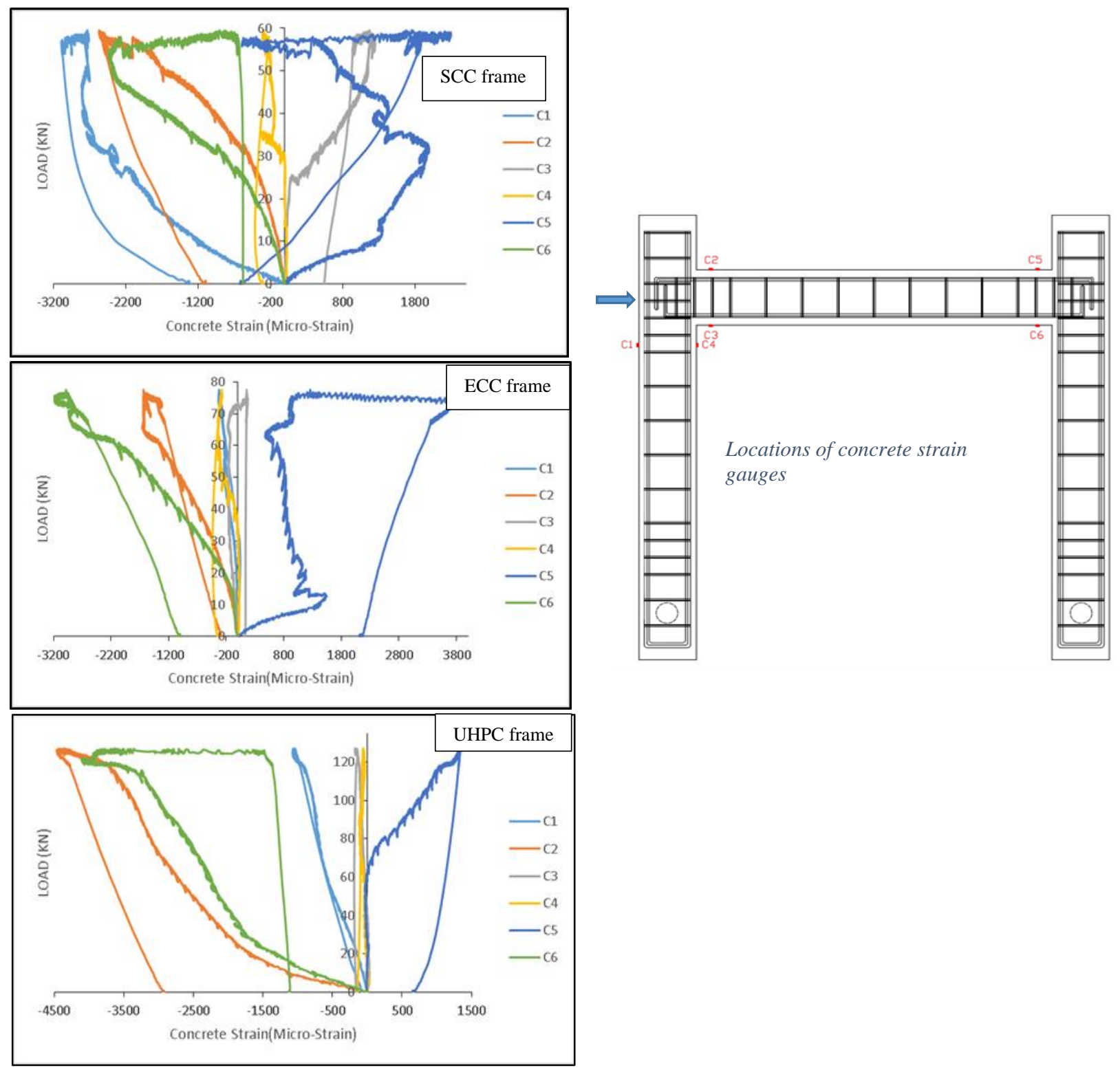

Figure 4.2(a): Concrete flexural strain development in SCC/ECC/UHPC frames 

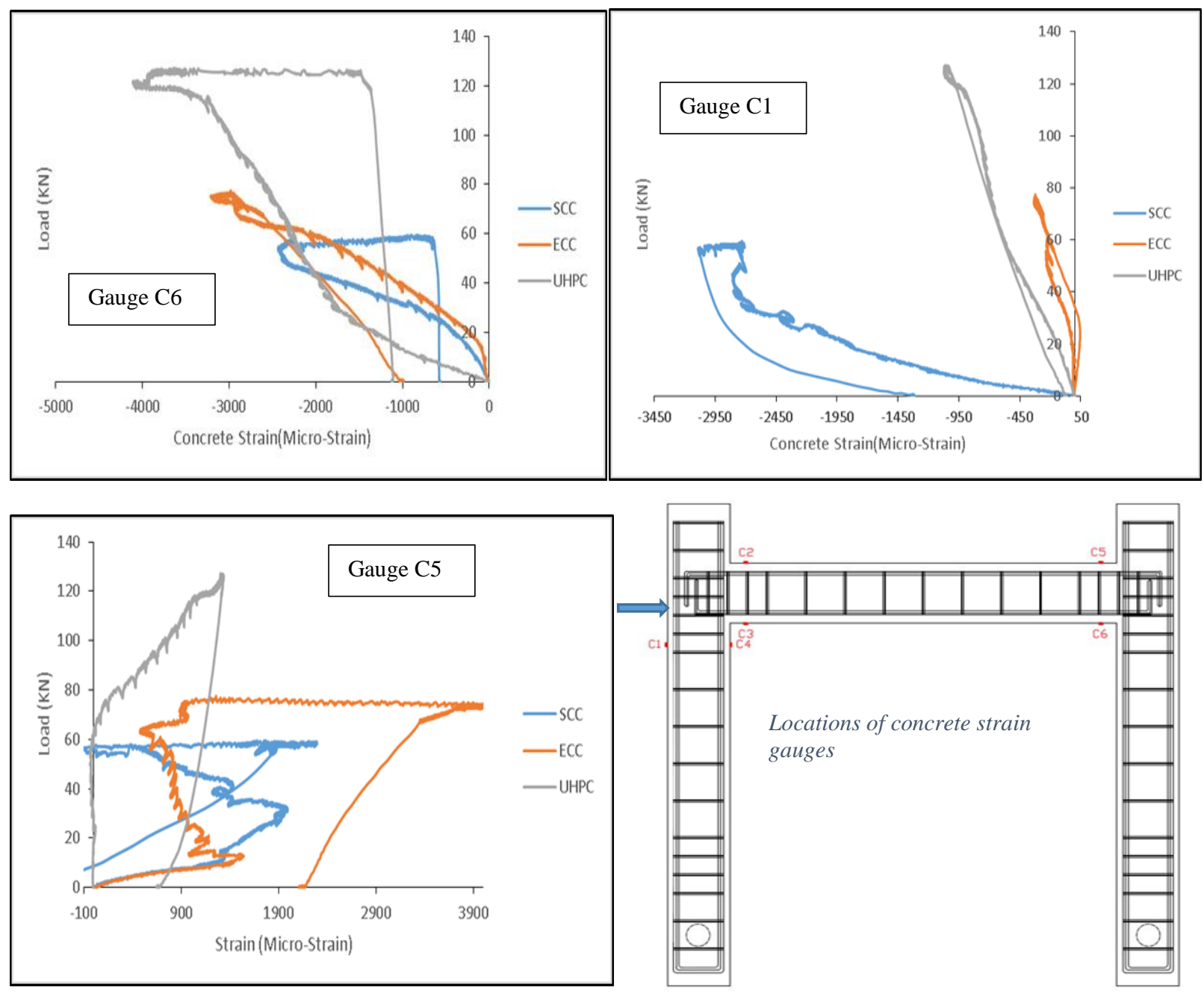

Figure 4.2(b): Comparative concrete strain development in SCC/ECC/UHPC frames

Figure 4.3(a) shows the development of flexural rebar strain at various locations of beam and column in SCC/ECC/UHPC frames. As expected, all strain gauges developed flexural tensile strain. Figure 4.3(b) compares the flexural strain development in SCC/ECC/UHPC frames. It should be noted that flexural tensile strain in rebar in UHPC frame reached the yield strain while rebar strain ECC frame reached closed to yield strain. However, rebar strain in SCC frame were not close to yield strain. 

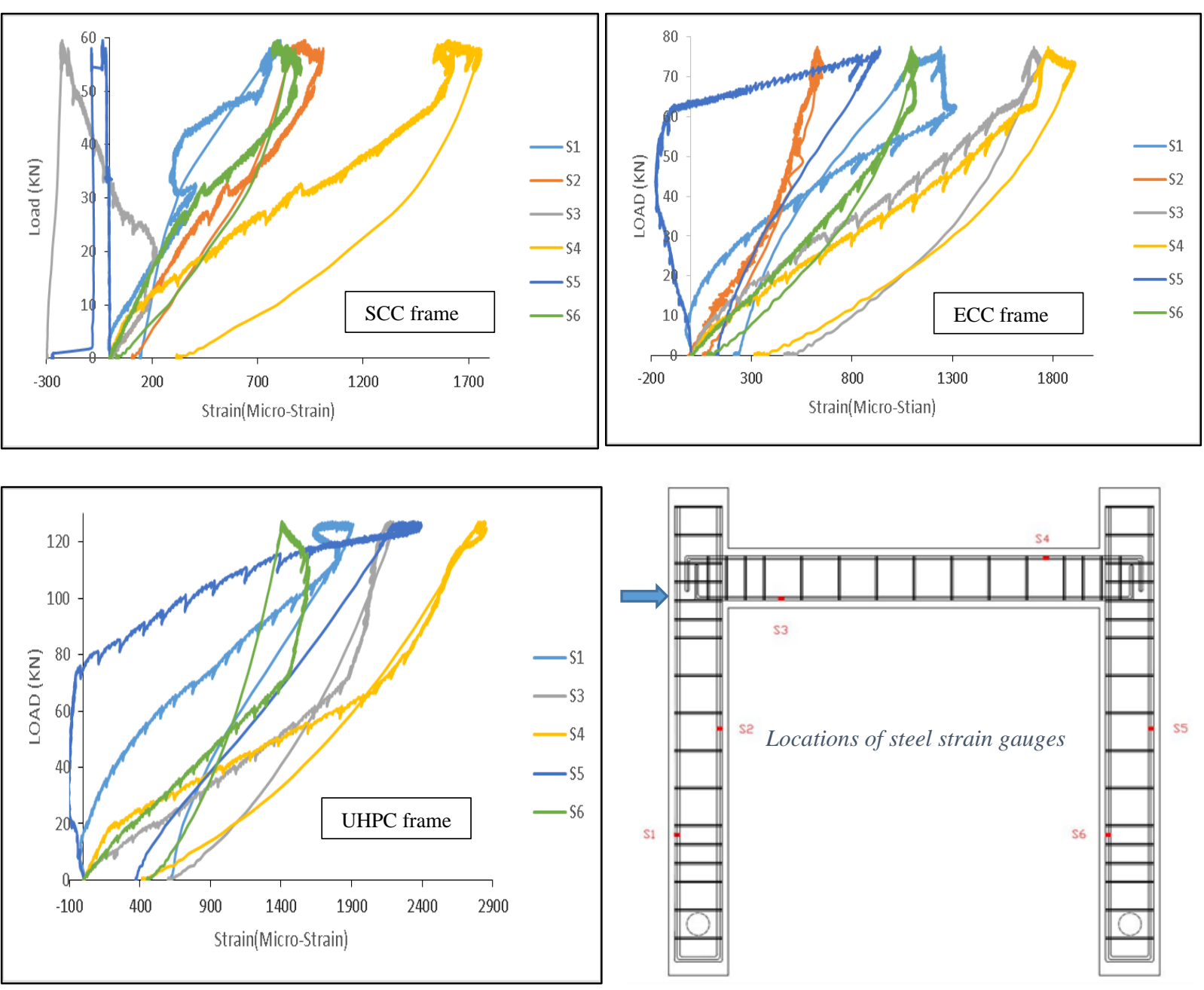

Figure 4.3(a): Rebar strain development for SCC/ECC/UHPC frame

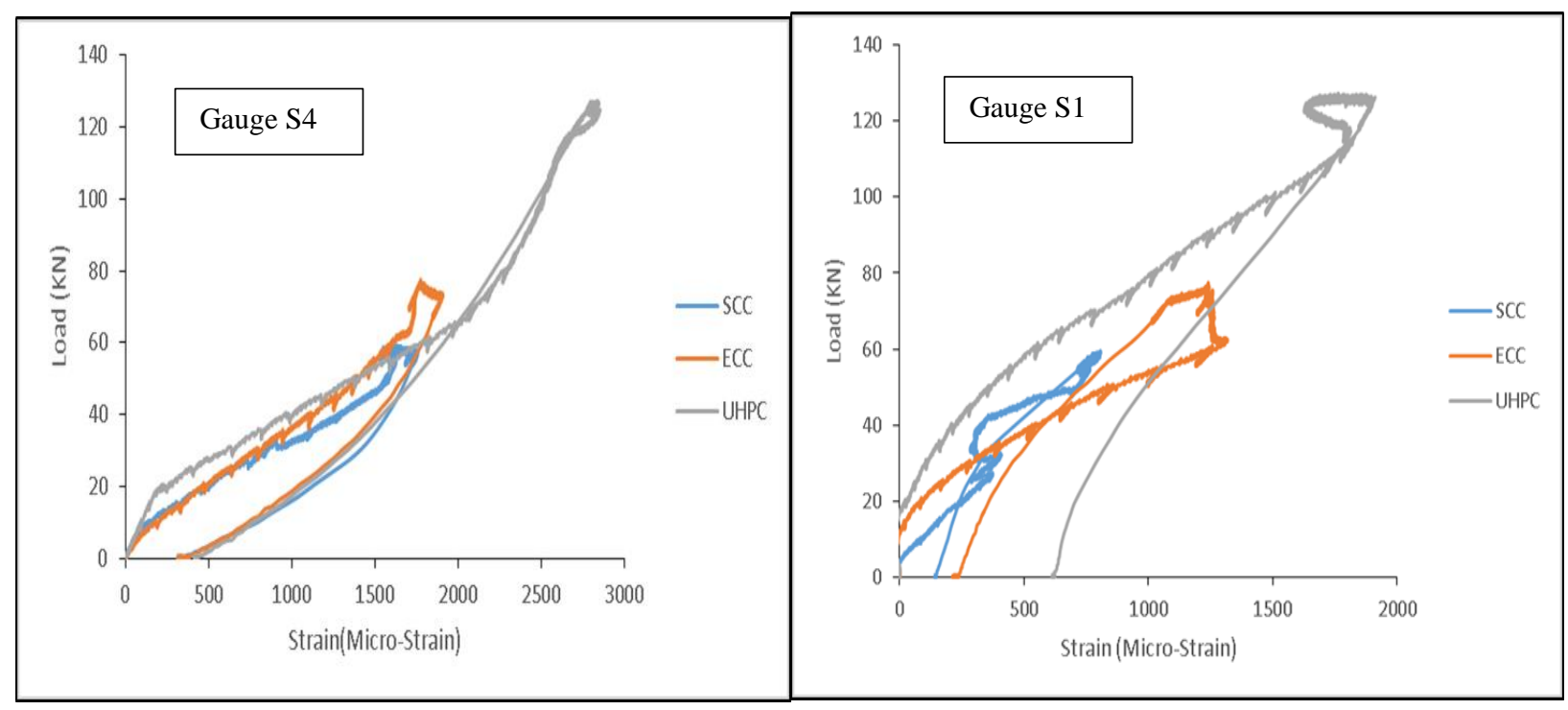

Figure 4.3(b): Comparative rebar strain development at typical strain gauge locations 
Table 4.2 summarizes maximum strain developed in concrete and rebar as well as yield load of the frames. It can be observed from Figures 4.2 and Table 4.2 that the developed concrete compressive strains for UHPC and ECC frames were much higher than those of SCC frame. While concrete tensile strain in ECC frame was higher compared to that of SCC frame, the concrete tensile strain in UHPC frame was much lower compared to those in SCC and ECC. This may have illustrated the fact that that the tensile capacity of UHPC was not fully utilized even at the yielding of tensile steel rebar. The load capacity of such UHPC frame could be further enhanced by using high strength steel or increasing tensile steel reinforcement to utilize full tensile capacity of UHPC. Table 4.2 also shows that rebar strain in both column and beam in UHPC frame reached the yield strain at ultimate load while rebars did not reach yield strain for SCC and ECC frames.

Table 4.2: Summary of strain developments and yield load

\begin{tabular}{|l|c|c|c|c|c|c|c|}
\hline \multirow{2}{*}{$\begin{array}{c}\text { Frame } \\
\text { Designation }\end{array}$} & \multirow{2}{*}{$\begin{array}{c}\text { Ultimate } \\
\text { load kN }\end{array}$} & \multicolumn{2}{|c|}{ Flexural strain at ultimate load (micro-strain) } & \multicolumn{2}{|c|}{ Load (kN) } \\
\cline { 3 - 8 } & & $\begin{array}{c}\text { Concrete } \\
\text { tensile } \\
\text { strain }\end{array}$ & $\begin{array}{c}\text { Column } \\
\text { rebar } \\
\text { strain }\end{array}$ & $\begin{array}{c}\text { Beam } \\
\text { rebar } \\
\text { strain }\end{array}$ & $\begin{array}{c}\text { Concrete } \\
\text { compressive } \\
\text { strain }\end{array}$ & $\begin{array}{c}\text { At yielding of } \\
\text { Column } \\
\text { rebar }\end{array}$ & $\begin{array}{c}\text { At yielding } \\
\text { of beam } \\
\text { rebar }\end{array}$ \\
\hline FC-SCC & 59.5 & 2295 & 926 & 1600 & 2435 & Not yielded & Not yielded \\
\hline FC-ECC & 77.5 & 4020 & 1241 & 1776 & 3212 & Not yielded & Not yielded \\
\hline FC-UHPC & 127.3 & 1339 & 2337 & 2840 & 4111 & 123.75 & 77.75 \\
\hline
\end{tabular}

\subsubsection{Crack development and characterizations}

Figure 4.4 (a) and (b) shows the crack development and propagation in SCC/ECC/UHPC frames at failure. Table 4.3 summarizes the cracking, cracking zone (as per Figure 4.5), maximum crack width and failure modes of the frames. In general, cracking predominantly concentered near the beam-column joint. Initiation of cracks started from the tension face of the beam near the joints (at around $10 \mathrm{kN}-15 \mathrm{kN}$ load) and propagated towards the compression zone as load increased. 
Cracks (diagonal) were also extended to column in the joint regions. SCC frame also developed few cracks in the beam moment regions near the joints.

ECC frame also developed similar pattern of cracks as SCC frame but it exhibited multiple microcracking behavior. Extensive hairline cracks were developed in the beam moment regions near the joint. Such cracks were also formed the column at joint regions as well as along the height of the columns. UHPC frame developed similar cracks extended from the beam tension face near the joint. Cracking predominantly concentrated near the joint with crack extended to the column and beam near the joint. SCC/UHPC frames did not show multiple micro-cracking behavior and the zone of cracking is very limited compared to SCC and UHPC with no crack formation along the height of the column or beam length.

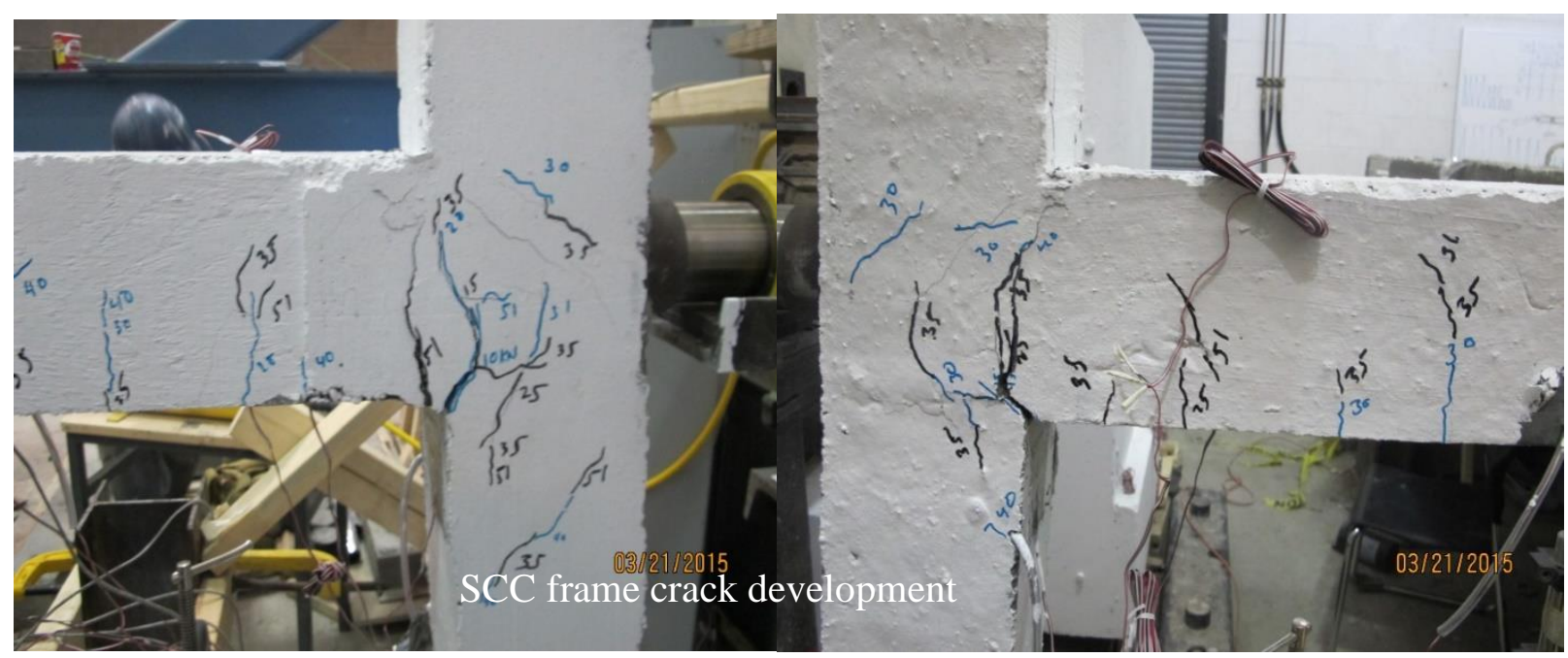

Figure 4.4(a): Crack development and failure mode of SCC frame 




Figure 4.4(b): Crack development and failure modes of ECC/UHPC frames 


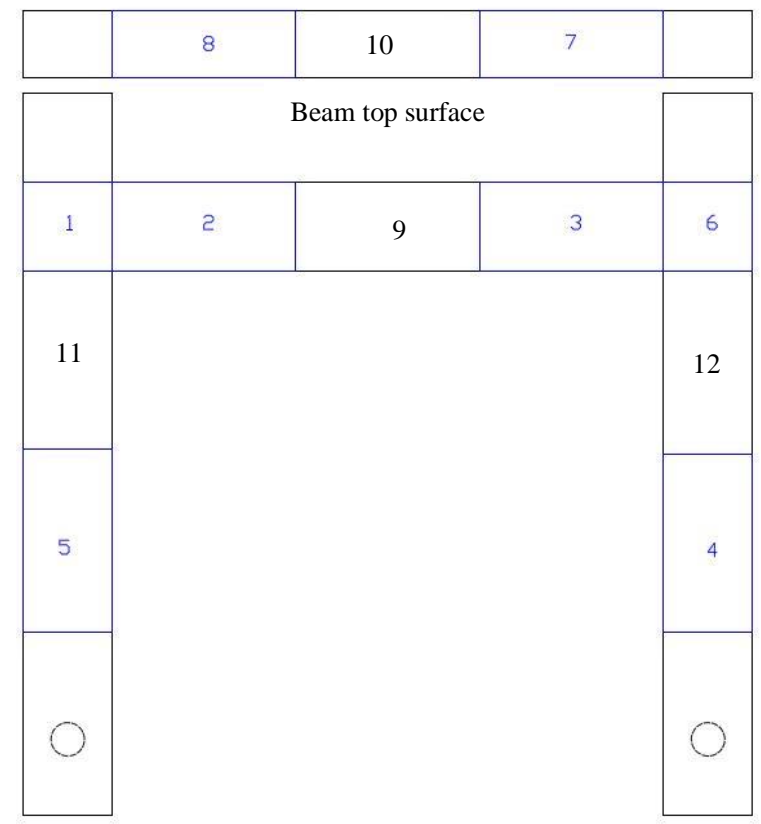

Figure 4.5: Crack zones on flexural-critical frames

SCC/ECC/UHPC frames failed due to flexure failure of beam at the joint exhibiting the formation of a major crack extended from the tension face to compression face as shown in Figure 4.4. Maximum crack widths were limited to $1.8 \mathrm{~mm}, 0.023$ and $0.22 \mathrm{~mm}$ at failure for SCC, ECC and UHPC frame, respectively (Table 4.3). For the frames major cracks were developed in beam near the beam-column joint because of higher moment of inertia in the column. As such, failure due to beam flexure was expected due to weak beam-strong column design concept used in this study which is normally adopted in practical construction.

Table 4.3: Crack width, crack zone and mode of failure

\begin{tabular}{|c|c|c|c|}
\hline Frame designation & $\begin{array}{c}\text { Average crack width } \\
(\mathbf{m m})\end{array}$ & Cracked zones & Mode of failure \\
\hline FC-SCC & 1.8 & $1,2,3,6,7$ & $\begin{array}{c}\text { Flexural failure at beam } \\
\text { end joint }\end{array}$ \\
\hline FC-ECC & 0.023 & $1,2,3,4,5,6,11,12$ & $\begin{array}{c}\text { Flexural failure at beam } \\
\text { end joint }\end{array}$ \\
\hline FC-UHPC & 0.22 & $1,6,7,8$ & $\begin{array}{c}\text { Flexural failure at beam } \\
\text { end joint }\end{array}$ \\
\hline
\end{tabular}




\subsubsection{Initial stiffness, energy absorption capacity and ductility of RC frames}

Table 4.4 summarizes the initial stiffness, energy absorbing capacity and ductility of the SCC/ECC/UHPC frames. Initial stiffness is calculated based on the initial slope of the lateral loadtop displacement responses presented in Figure 4.1(a). The energy absorbing capacity is calculated by the area under the lateral load-top displacement responses presented in Figure 4.1(a) up to 85\% of the post-peak load. The ductility of the frame is calculated based on displacement ductility index (DI) as per Tawfik et al. (2013) defined by the ratio between failure displacement to yield displacement. The yield displacement $\left(\mathrm{D}_{\mathrm{y}}\right)$ is the lateral displacement at $80 \%$ of ultimate load at the ascending part of the curve while the failure displacement $\left(D_{f}\right)$ is the lateral displacement at $80 \%$ of ultimate load at the descending part of the curve as shown in Fig. 4.1(a).The ductility index as a measure of the displacement ductility is computed using Eq. 4.1:

Ductility factor $(\mathrm{DI})=\mathrm{D}_{\mathrm{f}} / \mathrm{D}_{\mathrm{y}}$

Table 4.4: Initial stiffness, energy absorption capacity and ductility of RC frames

\begin{tabular}{|c|c|c|c|c|c|}
\hline $\begin{array}{c}\text { Frame } \\
\text { designation }\end{array}$ & $\begin{array}{c}\text { Initial } \\
\text { stiffness } \\
(\mathbf{k N} / \mathbf{m m})\end{array}$ & $\begin{array}{c}\text { Energy absorbing } \\
\text { capacity at 85\% } \\
\text { ultimate load } \\
\text { (Joules) }\end{array}$ & $\begin{array}{c}\text { Energy ratio } \\
\text { with respect to } \\
\text { SCC frame }\end{array}$ & $\begin{array}{c}\text { Ductility } \\
\text { index (DI) }\end{array}$ & $\begin{array}{c}\text { Ductility ratio } \\
\text { with respect to } \\
\text { SCC frame }\end{array}$ \\
\hline FC-SCC & 4.0 & 1006 & 1 & 2.09 & 1 \\
\hline FC-ECC & 2.5 & 3366 & 3.35 & 3.84 & 1.83 \\
\hline FC-UHPC & 5.7 & 8508 & 8.46 & 3.07 & 1.46 \\
\hline
\end{tabular}

Initial stiffness of UHPC frame $(5.7 \mathrm{kN} / \mathrm{mm})$ is the highest followed by SCC frame $(4.0 \mathrm{kN} / \mathrm{mm})$ and ECC frame $(2.5 \mathrm{kN} / \mathrm{mm})$. The energy absorbing capacity of UHPC frame is 8.46 and 2.53 times higher than its SCC and ECC counterparts, respectively. Displacement ductility of ECC frame is 1.83 and 1.25 times higher than SCC and UHPC frames, respectively. Low stiffness and high ductility coupled with good energy absorbing capacity, strain hardening and multi-cracking 
characteristics with tight crack width makes ECC frame superior compared to SCC/UHPC frames for construction applications.

\subsection{Structural performance of shear-critical frames}

The structural performance of $1 / 3^{\text {rd }}$ scale model shear-critical frames made with SCC, ECC and UHPC mixtures subjected to monotonic lateral loading is described and compared.

\subsubsection{Experimental load-deflection/moment-rotation responses and strength}

Lateral load-displacement responses at different locations of the frame (designated by LVDT1 to LVDT7) are presented in Figure 4.6. Lateral load-top deflection (LVDT 7) and corresponding moment-rotation curves (moment calculated at the base of each column and column rotation) for SCC/ECC/UHPC frames are presented in Figs. 4.7(a-c). In general, load/moment increased with the increase of displacement/rotation. The slope change in the response indicated crack formation/initiation or yielding of reinforcing bars. Load-vertical displacement response based on LVDT3 showed negligible displacement development - this indicated that the location zero moment at the center of the beam which was expected. Similar findings were also observed for flexure critical frame.

From the load-deflection responses, it is clear that UHPC frame had the highest strength followed by its ECC and SCC frame counterparts. Table 4.5 summarizes the load at first crack and correponding deflection, ultimate load/peak and ultimate deflection, ultimate frame/column rotation and ultimate moment at the end of beam/column. The ultimate load capacity of frames varied from 29.5 to $124.8 \mathrm{kN}$. The load capacity of the UHPC frame was $324 \%$ higher than its SCC counterpart while ECC frame capacity was 95\% higher than its SCC counterpart. The strength/load capacity enhancement seemed to be not proportional to the \% increase in concrete strength (UHPC and ECC compressive strength were 171\% and 26.7\% higher than SCC while tensile strength were $166 \%$ higher and $13.6 \%$ lower than SCC, respectively). The ultimate lateral deflection ranged between 29.24 and $68.56 \mathrm{~mm}$ and ECC frame showed $134.5 \%$ and $55 \%$ higher deflection compared to its SCC and UHPC counterparts, respectively. However, SCC frame showed higher deflection at first crack compared to ECC and UHPC frames. The ultimate rotation for the ECC frame was 141\% and 55\% higher than its SCC and UHPC counterparts, respectively. 
Beam and column end moments (calculated based in ultimate lateral load) are found to be highest for UHPC frame followed by ECC and SCC frames.
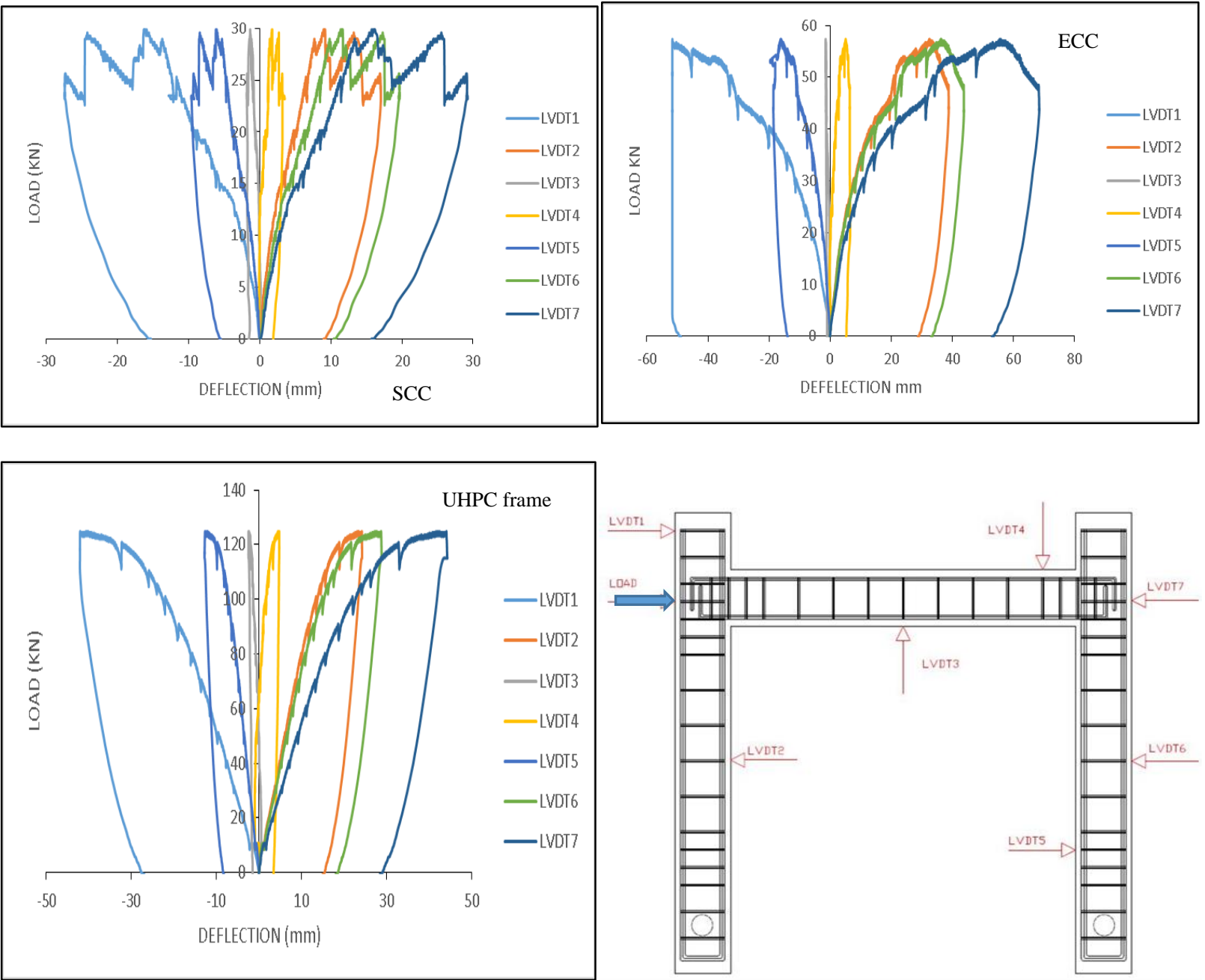

Fig. 4.6: SCC/ECC/UHPC frame lateral load-displacement responses at LVDT locations 


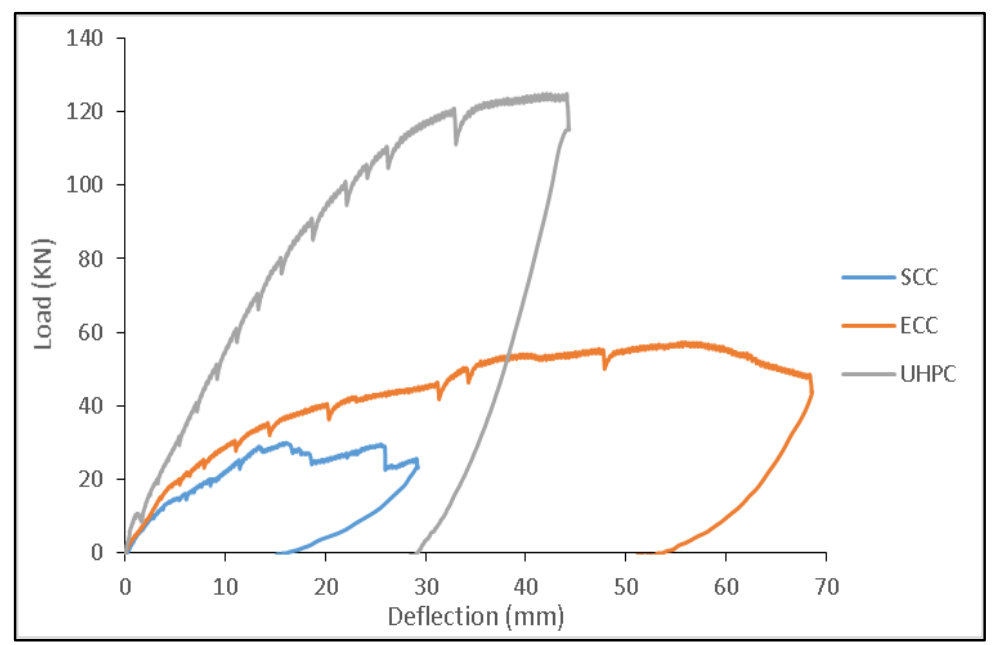

Fig. 4.7(a): Lateral load-top deflection responses of SCC/ECC/UHPC frame/column

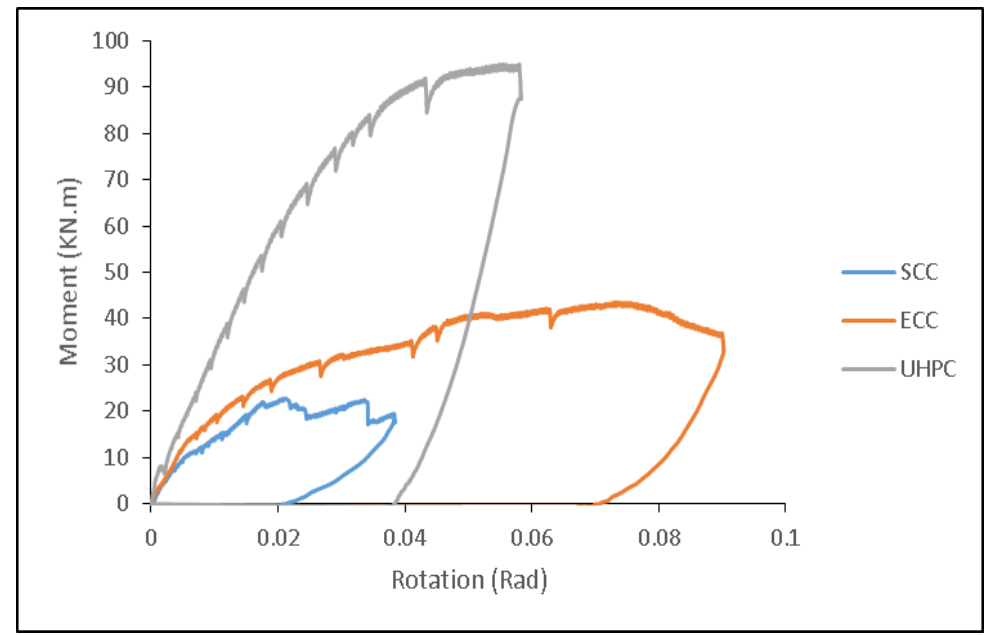

Fig. 4.7(b): Moment-rotation response of SCC/ECC/UHPC frame/column

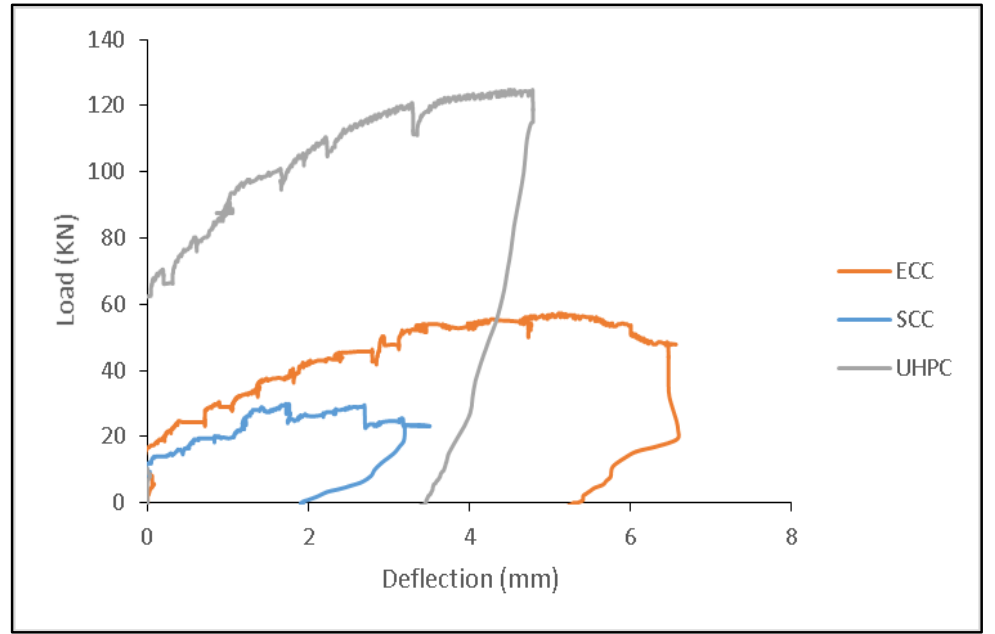

Fig. 4.7(c): Lateral load-vertical central deflection response of beam in SCC/ECC/UHPC frame 
Table 4.5: Summary of load-deflection and moment rotation responses

\begin{tabular}{|l|c|c|c|c|c|c|c|c|}
\hline Frame & \multicolumn{3}{|c|}{ Experimental load (kN) and deflection (mm) } & \multicolumn{3}{|c|}{$\begin{array}{c}\text { Experimental ultimate } \\
\text { moment (kNm) and rotation } \\
\text { (radian) }\end{array}$} \\
& $\begin{array}{l}\text { Designation } \\
\text { peak load }\end{array}$ & $\begin{array}{c}\text { Ultimate } \\
\text { lateral top } \\
\text { deflection }\end{array}$ & $\begin{array}{c}\text { Ultimate } \\
\text { beam end } \\
\text { deflection }\end{array}$ & $\begin{array}{c}\text { Load } \\
\left(1^{\text {st }}\right. \\
\text { crack) }\end{array}$ & $\begin{array}{c}\text { Deflection } \\
\left(1^{\text {st }} \text { Crack) }\right.\end{array}$ & $\begin{array}{c}\text { Frame } \\
\text { rotation }\end{array}$ & $\begin{array}{c}\text { Column } \\
\text { end } \\
\text { moment }\end{array}$ & $\begin{array}{c}\text { Beam } \\
\text { end } \\
\text { moment }\end{array}$ \\
\hline SC-SCC & 29.5 & 29.24 & 3.50 & 10 & 3.80 & 0.027 & 9.17 & 5.65 \\
\hline SC-ECC & 57.4 & 68.56 & 6.59 & 15 & 3.68 & 0.065 & 17.84 & 10.99 \\
\hline SC-UHPC & 124.8 & 44.34 & 4.79 & 10 & 3.07 & 0.042 & 38.81 & 23.9 \\
\hline
\end{tabular}

\subsubsection{Strain developments in steel and concrete}

Figure 4.8(a) shows the development of flexural concrete strain at various locations of beam and column in SCC/ECC/UHPC frames. As expected, gauges C1, C4, C6 and C7 developed tensile strain while gauges C2, C3, C5 and C8 developed compressive strain. Figure 4.8(b) compares the flexural strain development in SCC/ECC/UHPC frames (for typical gauge locations) and ECC frame showed higher strain development compared to UHPC/SCC frames. 


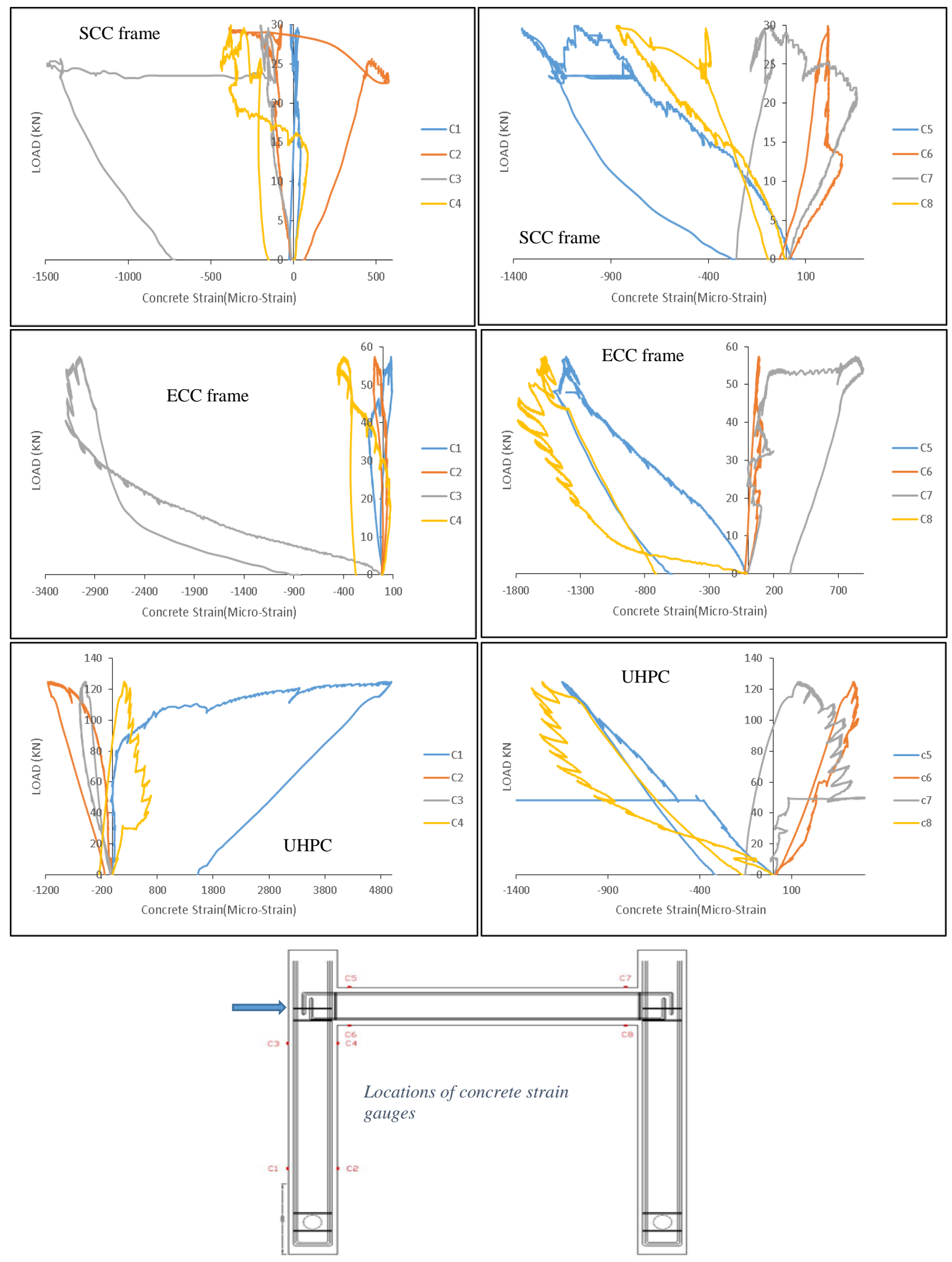

Figure 4.8(a): Concrete flexural strain development in SCC/ECC/UHPC frames 


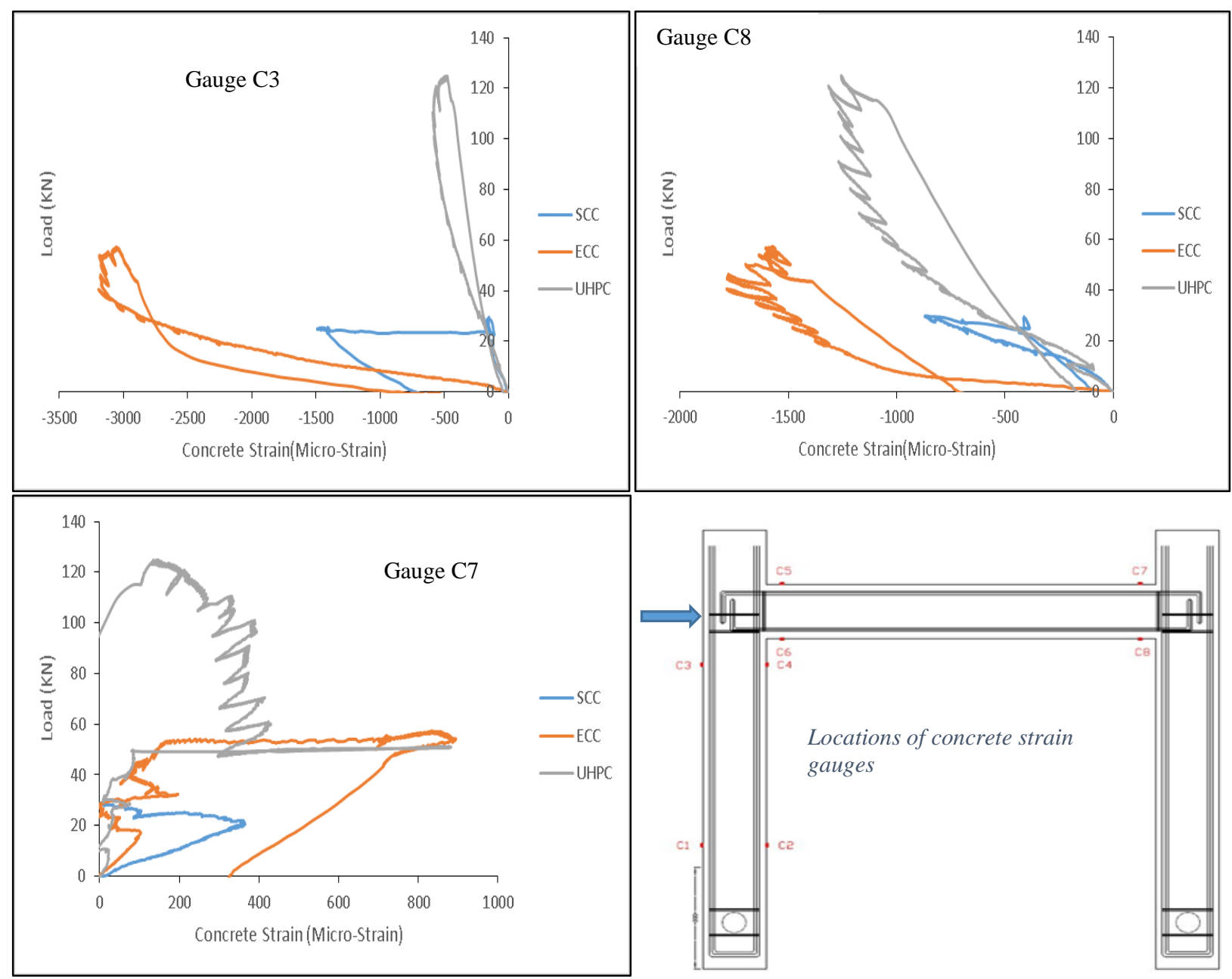

Figure 4.8(b): Comparative concrete strain development in SCC/ECC/UHPC frames

Figure 4.9(a) shows the development of strain in longitudinal (L1 and L2) and shear (S1 and S2) reinforcement at various locations of beam and column of SCC/ECC/UHPC frames. Generally, longitudinal bars developed flexural tensile strain as expected. Figure 4.9(b) compares the strain development in longitudinal and shear reinforcement in SCC/ECC/UHPC frames. It should be noted that flexural tensile strain in rebar in UHPC frame reached the yield strain. While strain in longitudinal strains in ECC/SCC were not close to yield strain with ECC frame showing the lowest strain. The shear reinforcements provided at the beam-column junction, were not yielded in all the frames. 

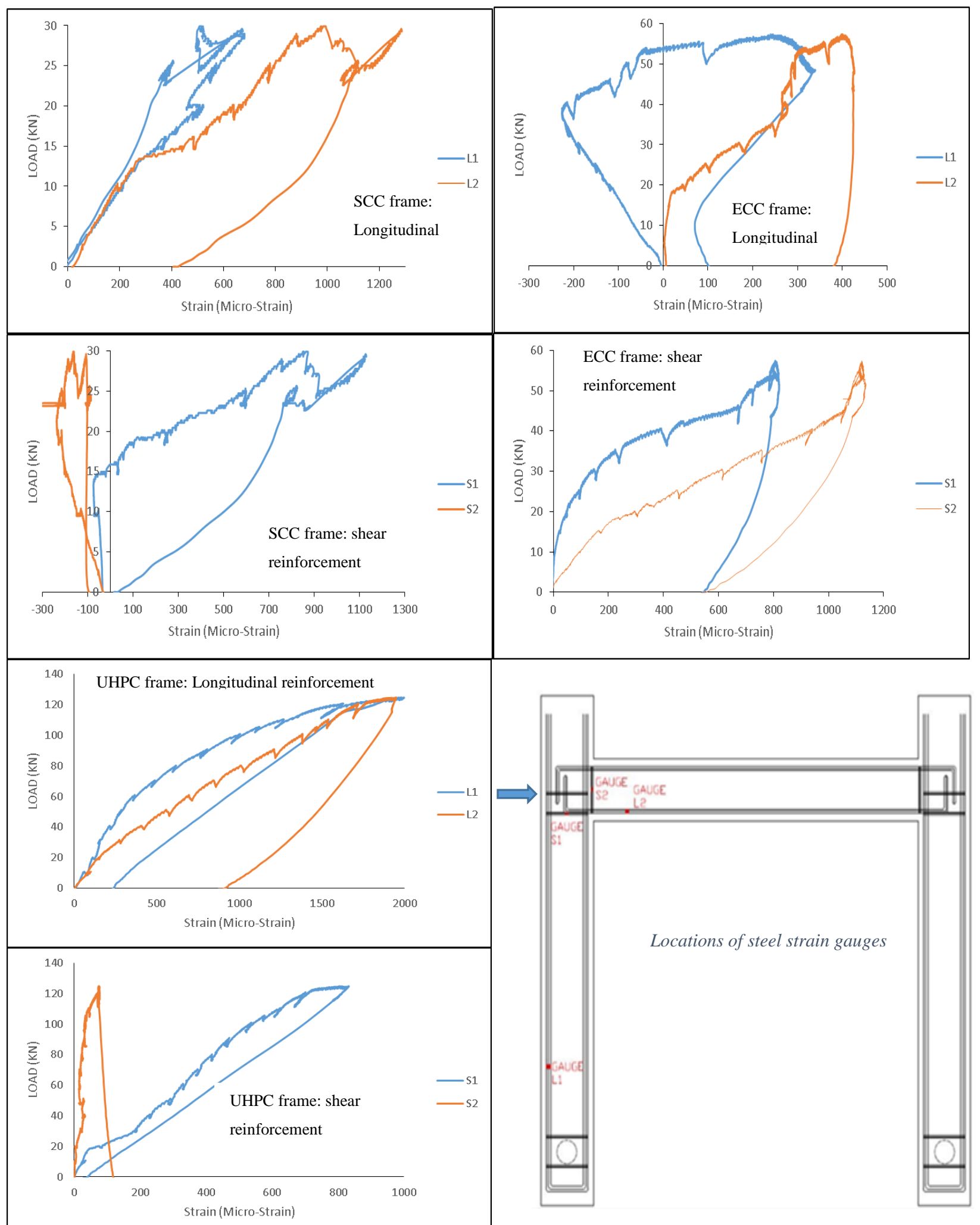

Figure 4.9(a): Strain development in longitudinal and shear reinforcement- SCC/ECC/UHPC frame 


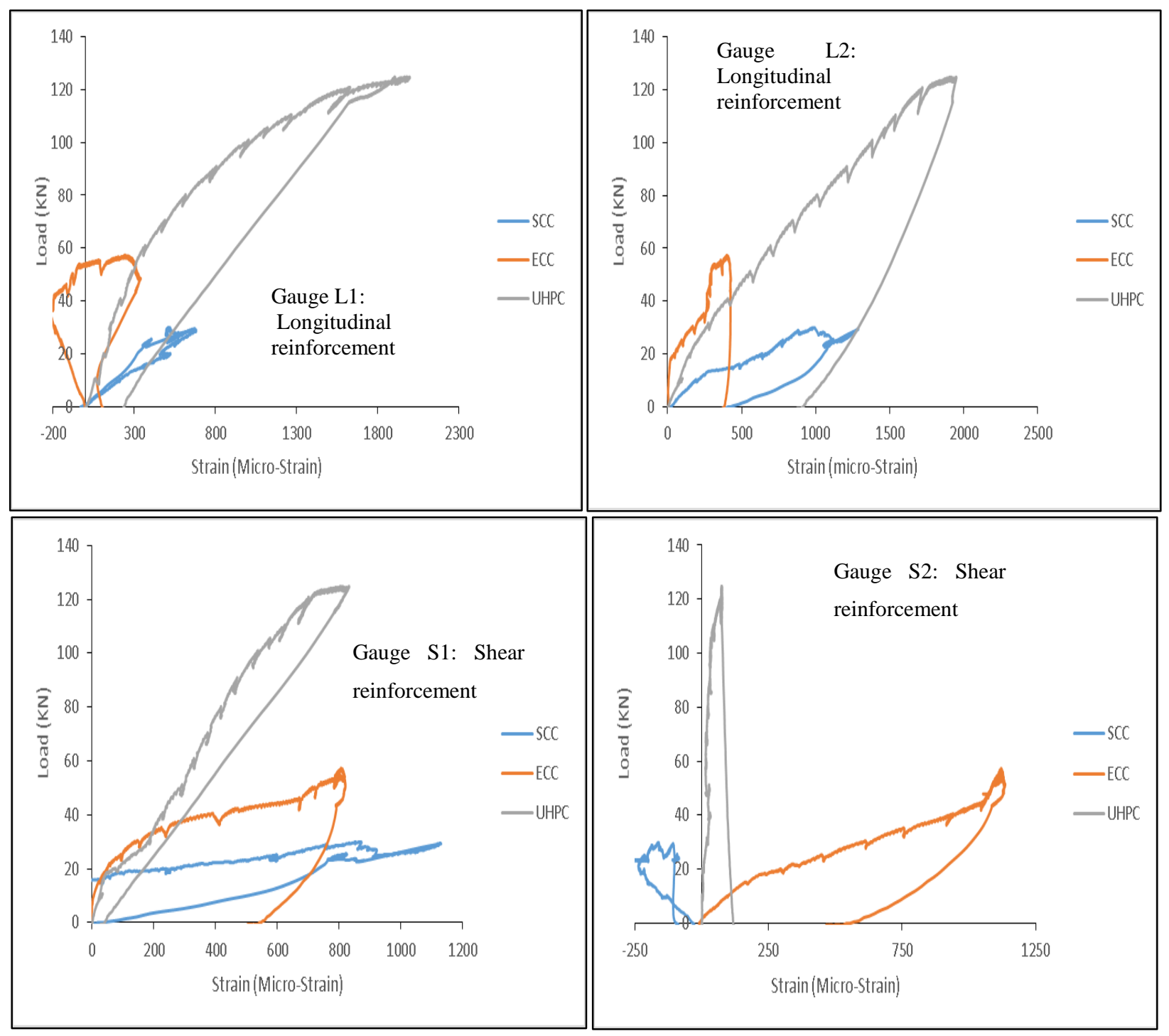

Figure 4.9(b): Comparative rebar strain development at typical strain gauge locations

Table 4.6 summarizes maximum strain developed in concrete and rebar of the frames. It can be observed from the Table that the developed concrete compressive strains for UHPC and ECC frames were much higher than those of SCC frame. While concrete tensile strain in ECC frame was higher compared to that of SCC frame, the concrete tensile strain in UHPC frame was much lower compared to those in SCC and ECC as observed in the case flexure-critical frames. Table 4.6 also shows that rebar strain in both column and beam in UHPC frame reached very close to the yield strain (considered as yielded) at ultimate load while did not reach yield strain for SCC and ECC frames. As mentioned before the shear reinforcements were not yielded. 
Table 4.6: Summary of strain developments and yield load

\begin{tabular}{|l|c|c|c|c|c|c|c|}
\hline \multirow{2}{*}{$\begin{array}{c}\text { Frame } \\
\text { Designation }\end{array}$} & $\begin{array}{c}\text { Ultimate } \\
\text { load KN }\end{array}$ & \multicolumn{2}{|c|}{ Flexural strain at ultimate load (micro-strain) } & \multicolumn{2}{c|}{ Load (kN) } \\
\cline { 3 - 8 } & $\begin{array}{c}\text { Concrete } \\
\text { tensile } \\
\text { strain }\end{array}$ & $\begin{array}{c}\text { Column } \\
\text { rebar } \\
\text { strain }\end{array}$ & $\begin{array}{c}\text { Beam } \\
\text { rebar } \\
\text { strain }\end{array}$ & $\begin{array}{c}\text { Concrete } \\
\text { compressive } \\
\text { strain }\end{array}$ & $\begin{array}{c}\text { At yielding of } \\
\text { Column } \\
\text { rebar }\end{array}$ & $\begin{array}{c}\text { At yielding } \\
\text { of beam } \\
\text { rebar }\end{array}$ \\
\hline SC-SCC & 29.9 & 573 & 680 & $\begin{array}{c}1286 \\
(1150)\end{array}$ & 1490 & Not yielded & Not yielded \\
\hline SC-ECC & 57.37 & 894 & 339 & $\begin{array}{c}426 \\
(1100)\end{array}$ & 3194 & Not yielded & Not yielded \\
\hline SC-UHPC & 124.8 & 882 & 1997 & $\begin{array}{c}1949 \\
(800)\end{array}$ & 1316 & 123.75 & 77.75 \\
\hline \multicolumn{7}{|c|}{ Maximum strain in shear reinforcement (micro-strain) } \\
\hline
\end{tabular}

\subsubsection{Crack development and characterizations}

Figure 4.10 shows the crack development and propagation in SCC/ECC/UHPC shear critical frames at failure. Table 4.7 summarizes the cracking, cracking zone (as per Figure 4.5), maximum crack width and failure modes of the frames. In general, initiation of cracks started from the tension face of the beam near the joints (at around $10 \mathrm{kN}-15 \mathrm{kN}$ load) and propagated towards the compression zone as load increased. Cracks were also extended to column in the joint regions for SCC and UHPC frame. Maximum crack widths were limited to $1.8 \mathrm{~mm}, 0.023$ and $0.22 \mathrm{~mm}$ at failure for SCC, ECC and UHPC frame, respectively (Table 4.7).

SCC shear-critical frame failed near the column base due to shear failure as can be seen from the development diagonal cracks unlike beam flexure failure at the joint observed in the case of SCC flexure -critical frame. ECC shear critical frame failed due to beam flexure near the joint similar to its flexure -critical counterpart although it developed multiple hair cracks in columns. UHPC shear critical frame failed due to beam flexure at the joint similar to its flexure-critical counterpart without developing cracking (shear or crack) in the beam or column. (Fig4.10). It is interesting to note that both ECC and UHPC shear critical frames did not fail in shear as opposed to its SCC counterpart. This can be attributed to the contribution of fibers to the shear resistance of the beamcolumn frame. 

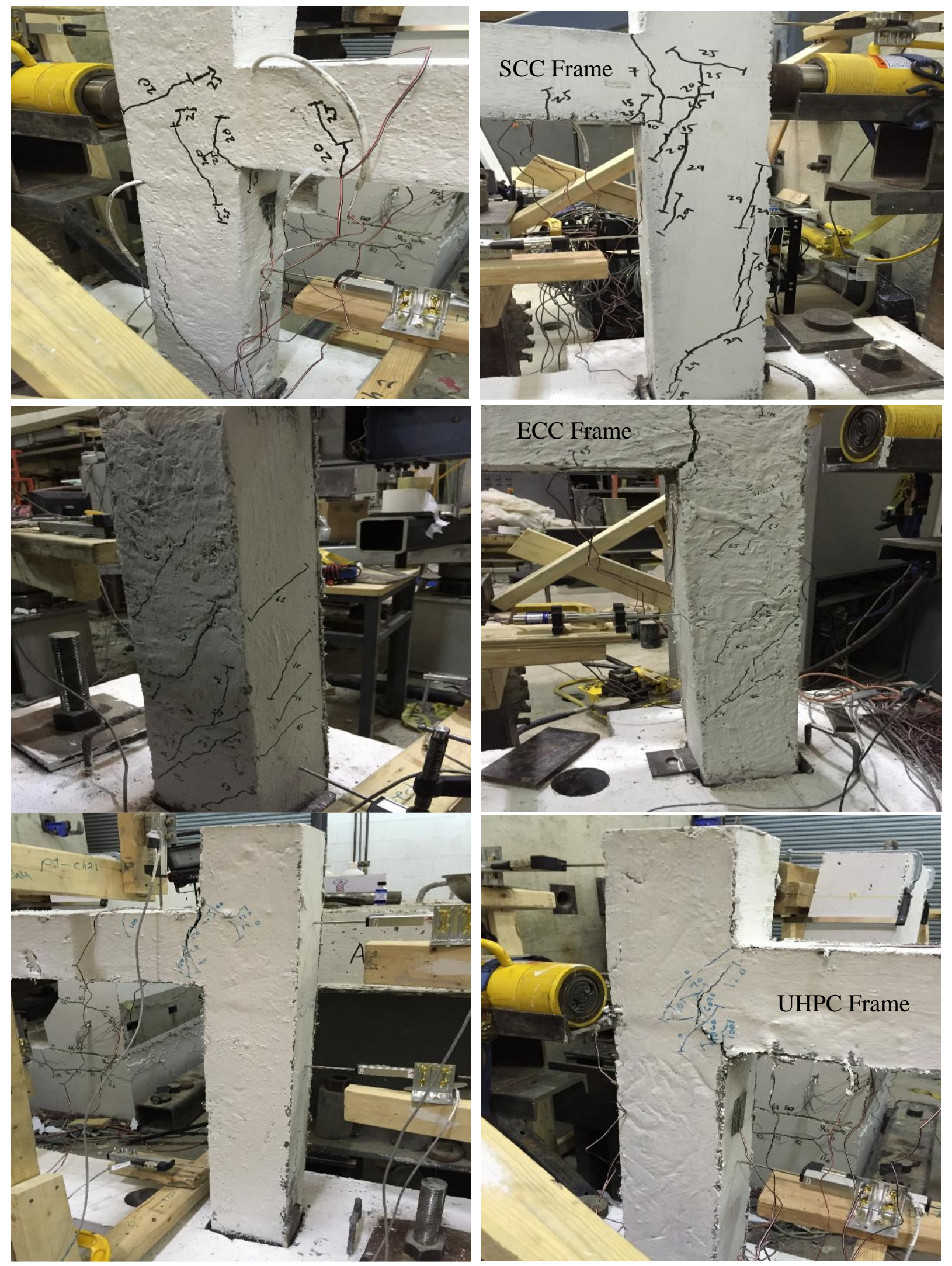

Fig. 4.10: Crack development and failure modes of shear-critical SCC/ECC/UHPC frames 
Table 4.7: Crack width, crack zone and mode of failure

\begin{tabular}{|c|c|c|c|}
\hline Frame designation & $\begin{array}{c}\text { Average crack width } \\
(\mathbf{m m})\end{array}$ & Cracked zones & Mode of failure \\
\hline SC-SCC & 2.2 & $1,2,3,4,5,6,11,12$ & $\begin{array}{c}\text { Shear failure at column } \\
\text { base }\end{array}$ \\
\hline SC-ECC & 0.019 & $1,3,11,12$ & $\begin{array}{c}\text { Flexural failure at beam } \\
\text { end joint }\end{array}$ \\
\hline SC-UHPC & 0.27 & 1,3 & $\begin{array}{c}\text { Flexural failure at beam } \\
\text { end joint }\end{array}$ \\
\hline
\end{tabular}

\subsubsection{Initial stiffness, energy absorption capacity and ductility of shear critical $\mathrm{RC}$ frames}

Table 4.8 summarizes the initial stiffness, energy absorbing capacity and ductility of the SCC/ECC/UHPC frames. Initial stiffness, energy absorbing capacity and the displacement ductility index (DI) are calculated by using lateral load-top displacement responses presented in Figure 4.7(a) as described previously.

Table 4.8: Initial stiffness, energy absorption capacity and ductility of RC frames

\begin{tabular}{|c|c|c|c|c|c|}
\hline $\begin{array}{c}\text { Frame } \\
\text { designation }\end{array}$ & $\begin{array}{c}\text { Initial } \\
\text { stiffness } \\
(\mathbf{k N} / \mathbf{m m})\end{array}$ & $\begin{array}{c}\text { Energy absorbing } \\
\text { capacity at 85\% } \\
\text { ultimate load } \\
\text { (Joules) }\end{array}$ & $\begin{array}{c}\text { Energy ratio } \\
\text { with respect to } \\
\text { SCC frame }\end{array}$ & $\begin{array}{c}\text { Ductility } \\
\text { index (DI) }\end{array}$ & $\begin{array}{c}\text { Ductility ratio } \\
\text { with respect to } \\
\text { SCC frame }\end{array}$ \\
\hline FC-SCC & 3.7 & 622 & 1 & 2.45 & 1 \\
\hline FC-ECC & 4.0 & 2841 & 4.57 & 3.67 & 1.49 \\
\hline FC-UHPC & 7.06 & 3659 & 5.98 & 1.99 & 0.82 \\
\hline
\end{tabular}

Initial stiffness of UHPC frame $(7.06 \mathrm{kN} / \mathrm{mm})$ is the highest followed by ECC frame $(4.0 \mathrm{kN} / \mathrm{mm})$ and SCC frame $(3.7 \mathrm{kN} / \mathrm{mm})$. The energy absorbing capacity of UHPC frame is 5.9 and 1.29 times higher than its SCC and ECC counterparts, respectively. Displacement ductility of ECC frame is 1.84 and 1.50 times higher than UHPC and SCC frames, respectively. 


\subsection{Comparison of performance of flexure and shear critical frames}

The performance of shear critical and flexure-critical SCC/ECC/EHPC frames are compared based on lateral load capacity, initial stiffness, energy absorbing capacity and ductility characteristics summarized in Table 4.9. Transformation of flexure critical from to shear critical frame had the flowing effects:

- For SCC frame, the load capacity, initial stiffness and energy absorbing capacity are reduced by $50 \%, 7 \%$ and $38 \%$, respectively while ductility is increased by $17 \%$ and mode of failure transformed from beam flexure $(\mathrm{BF})$ to column shear failure (SF).

- For ECC frame, the load capacity, energy absorbing capacity and ductility are reduced by $26 \%, 16 \%$ and $4 \%$, respectively while initial stiffness is increased by $60 \%$ with mode of failure remains unchanged to beam flexure $(\mathrm{BF})$.

- For UHPC frame, the load capacity, energy absorbing capacity and ductility are reduced by $2 \%, 57 \%$ and $35 \%$, respectively while initial stiffness is increased by $24 \%$ with mode of failure remains unchanged to beam flexure $(\mathrm{BF})$.

- Overall, ECC shear critical frame showed better performance in terms of retaining energy absorbing capacity and ductility compared to SCC/UHPC frames. In terms of retaining load carrying capacity, ECC/UHPC shear critical frames showed better performance compared to SCC frames. Overall, ECC and UHPC frames were able to prevent shear failure even in shear critical frame - which can be attributed to the fiberbridging and crack control characteristics in the matrix contributing to the shear resistance.

Table 4.9: Performance evaluation of shear critical and flexure critical frames

\begin{tabular}{|c|c|c|c|c|c|c|c|c|c|c|c|c|c|c|}
\hline \multirow[t]{2}{*}{$\begin{array}{c}\text { Frame } \\
\text { concrete }\end{array}$} & \multicolumn{2}{|c|}{$\begin{array}{c}\text { Ultimate } \\
\text { lateral load } \\
\text { capacity } \\
(\mathrm{kN})\end{array}$} & \multicolumn{2}{|c|}{$\begin{array}{c}\text { Initial } \\
\text { stiffness } \\
(\mathbf{K}) \\
(\mathbf{k N} / \mathbf{m m})\end{array}$} & \multicolumn{2}{|c|}{$\begin{array}{c}\text { Energy } \\
\text { absorbing } \\
\text { capacity (E) } \\
\text { (Joules) }\end{array}$} & \multicolumn{2}{|c|}{$\begin{array}{l}\text { Ductility } \\
\text { index } \\
\text { (DI) }\end{array}$} & \multicolumn{2}{|c|}{$\begin{array}{l}\text { Failure } \\
\text { modes }\end{array}$} & \multicolumn{4}{|c|}{$\begin{array}{l}\text { Ratio of shear critical } \\
\text { (SC) frame to flexure } \\
\text { critical (FC) frame }\end{array}$} \\
\hline & SC & FC & SC & FC & SC & FC & SC & FC & SC & FC & Load & $\mathbf{K}$ & $\mathbf{E}$ & DI \\
\hline SCC & 29.5 & 59.5 & 3.7 & 4.0 & 622 & 1006 & 2.45 & 2.09 & SF & $\mathrm{BF}$ & 0.50 & 0.93 & 0.62 & 1.17 \\
\hline ECC & 57.4 & 77.5 & 4.0 & 2.5 & 2841 & 3366 & 3.67 & 3.84 & $\overline{B F}$ & $\mathrm{BF}$ & 0.74 & 1.6 & 0.84 & 0.96 \\
\hline UHPC & 124.8 & 127.3 & 7.06 & 5.7 & 3659 & 8508 & 1.99 & 3.07 & $\mathrm{BF}$ & $\overline{B F}$ & 0.98 & 1.24 & 0.43 & 0.65 \\
\hline
\end{tabular}




\subsection{Comparison of experimental results with Codes/existing design equations}

The experimental lateral load capacities of the frames are used to determine the shear and moment resistances of beam and column using computer analyses. The theoretical shear and moment capacities of the frame beam and column are calculated based on Codes and design procedures presented in section 2.5 of Chapter Two. Detail calculations such as moment capacities of reinforced SCC/ECC/UHPC beam/column and shear capacities of SCC/ECC/UHPC beam/columns with or without shear reinforcements are provided in Appendix A. Table 4.6 compares the moment and shear capacities of beams/columns obtained from experiments and Codes/existing equations.

Table 4.10: Theoretical and experimental values for shear and moment capacities

\begin{tabular}{|c|c|c|c|c|c|c|c|c|c|}
\hline & & \multicolumn{4}{|c|}{ Theoretical } & \multicolumn{4}{c|}{ Experimental } \\
\cline { 2 - 10 } & Designation & $\begin{array}{c}\text { Beam } \\
\text { shear } \\
\text { capacity } \\
\text { KN }\end{array}$ & $\begin{array}{c}\text { Column } \\
\text { shear } \\
\text { capacity } \\
\text { KN }\end{array}$ & $\begin{array}{c}\text { Beam } \\
\text { moment } \\
\text { resisting } \\
\text { capacity } \\
\text { KN.m }\end{array}$ & $\begin{array}{c}\text { Column } \\
\text { moment } \\
\text { resisting } \\
\text { capacity } \\
\text { KN.m }\end{array}$ & $\begin{array}{c}\text { Beam } \\
\text { shear } \\
\text { capacity } \\
\text { KN }\end{array}$ & $\begin{array}{c}\text { Column } \\
\text { shear } \\
\text { capacity } \\
\text { KN }\end{array}$ & $\begin{array}{c}\text { Beam } \\
\text { moment } \\
\text { resisting } \\
\text { capacity } \\
\text { KN.m }\end{array}$ & $\begin{array}{c}\text { Column } \\
\text { moment } \\
\text { resisting } \\
\text { capacity } \\
\text { KN.m }\end{array}$ \\
\hline $\begin{array}{c}\text { Flexural- } \\
\text { critical } \\
\text { frames }\end{array}$ & SCC* & 43.43 & 44.09 & $8.19+$ & 13.57 & 13.35 & 30.29 & $6.99+$ & 12.76 \\
\cline { 2 - 11 } & ECC* & 53.17 & 62.77 & $8.64+$ & 11.7 & 17.39 & 39.45 & $8.63+$ & 16.62 \\
\hline \multirow{2}{*}{$\begin{array}{c}\text { Shear- } \\
\text { critical } \\
\text { frames }\end{array}$} & SCC** & 14.02 & $14.24+$ & 8.19 & 13.57 & 6.62 & $15.02+$ & 3.36 & 6.33 \\
\cline { 2 - 10 } & ECC* & 23.76 & 32.92 & $8.64+$ & 11.7 & 12.95 & 29.37 & $6.57+$ & 12.37 \\
\cline { 2 - 10 } & UHP* & 32.79 & 44.56 & $15.47+$ & 26.02 & 28.01 & 63.54 & $14.21+$ & 26.75 \\
\hline
\end{tabular}

Experimental failure mode: * beam flexure failure, $* *$ column shear failure, + values associated with failure modes

It can be noted from the table 4.10 that the column moment and shear capacities obtained from both experiment and theories are higher than those of beams indicating strong column and weak beam design concepts used in this study. For flexural critical frames, higher theoretical beam/column shear capacities compared to experimentally obtained shear loads justified failure due to beam flexure. Failure of SCC shear critical frame due to column shear failure is also justified as the experimental column shear is found to be very close to that obtained from theory and experimental beam/column moment and beam shear values are much lower than those 
predicted by theory. For theoretically predicted moment or shear capacities are found to be close to those obtained from experiments, however, theory (codes or other equations) over-predicted shear and moment capacities. This illustrates the need to modify existing equations and more research is needed on this aspect.

\subsection{Conclusions}

This chapter described the structural performance of SCC/ECC/UHPC flexure and shear critical

frames based on experimental results. Load-displacement response, load-strain responses in concrete/steel and failure modes with crack characteristics are analyzed to assess the performance in terms of lateral load capacity, initial stiffness, energy absorbing capacity and ductility characteristics. The influence of concrete types is also analyzed. The analyses revealed better performance of ECC shear critical frames in terms of retaining load carrying capacity, stiffness, ductility and energy absorbing capacity. The comparison of experimental and theoretical moment and shear capacities of frame beams and columns also suggests some modifications needed to existing standard based/other existing equations. 


\section{Chapter Five: Conclusion}

\subsection{General}

This thesis described the structural performance of reduced scale reinforced one storey beamcolumn frame incorporating high performance concrete (HPC) subjected to monotonic lateral loading based on experimental and design oriented analyses. Different types of HPC materials such as self-consolidating concrete (SCC), engineered cementations composite (ECC) and ultrahigh performance concrete (UHPC) were used to construct $1 / 3^{\text {rd }}$ scale experimental frame model specimens. The model specimens were tested to failure by applying in plane lateral loading at the beam (floor level beam column joint. The variable parameters in these tests were the type the concrete material (SCC, ECC and UHPC) and the type of the frames: the flexural-critical and the shear-critical frames designed with and without the shear reinforcement, respectively in addition flexural reinforcement. A commercial SCC mix was used as control while a green cost effective high volume fly ash ECC mix and a UHPC mix (both developed at Ryerson University) were used. The performance of SCC/ECC/UHPC based flexural-critical and the shear-critical frames are described based on load-deformation/moment-rotation responses, stiffness, strain developments, crack characterization, crack widths, failure modes, ductility and energy absorbing capacity. The experimentally obtained moment and shear capacity of flexural and shear-critical frames were compared with those obtained from Code based equations and other existing design specifications.

\subsection{Conclusion}

The following conclusions are drawn from experimental and theoretical analyses:

- UHPC and ECC flexural-critical frames had shown $113 \%$ and $30 \%$ higher ultimate load capacity, respectively compared to their SCC counterpart. UHPC and ECC flexural-critical frames had higher ultimate lateral deflection and higher ultimate frame rotation.

- Concrete compressive strains at ultimate load for ECC and UHPC frames were much higher compared to SCC frame. The concrete tensile strain in UHPC flexural-critical frame at ultimate load as much lower compared to those in SCC and ECC which illustrated the fact the tensile capacity of UHPC flexural-critical frame was not fully utilized even at the yielding of tensile steel rebar. 
- ECC flexural-critical frame showed better performance in terms of higher ductility $83 \%$ and 25\% higher than SCC and UHPC frame respectively associated with lower stiffness (compared to SCC/UHPC) frames as well as showing multiple micro-cracking characteristics with tight crack widths less than $100 \mu m$ and strain-hardening behavior due to fiber bridging characteristics in the post-cracking stage.

- The energy absorbing capacity of UHPC frame was 8.46 and 2.53 times higher than its SCC and ECC counterparts, respectively while displacement ductility of ECC frame was 1.83 and 1.25 times higher than SCC and UHPC frames, respectively.

- All the flexural-critical frames failed due to beam flexural failure near the beam-column joints which justified weak beam-strong column design principle used in this study.

- UHPC shear critical frame showed $324 \%$ higher ultimate load capacity than its SCC counterpart while ECC frame capacity was 95\% higher than its SCC counterpart. ECC shear-critical frame showed higher ultimate lateral load deflection and frame rotation compared to SCC/UHPC frames.

- Both ECC and UHPC shear-critical frame failed due to beam flexure near the beamcolumn joint similar to flexural-critical frames with ECC showing multiple cracking behavior while SCC shear-critical frame failed due to column shear. ECC and UHPC shearcritical frames were able to prevent shear failure with attribution of fiber bridging and crack control characteristics in the matrix contributing to the shear resistance.

- UHPC shear-critical frame exhibited the highest stiffness. ECC shear-critical frame had higher displacement ductility - 1.84 and 1.50 times of UHPC and SCC frames, respectively. The energy absorbing capacity of UHPC frame is 5.9 and 1.29 times higher than its SCC and ECC counterparts, respectively.

- Compared to SCC flexure critical frame, the load capacity, initial stiffness and energy absorbing capacity of shear critical frame were reduced by 50\%,7\% and 38\%, respectively while ductility was increased by $17 \%$. The energy absorbing capacity, load capacity and ductility of shear critical frame were reduced (by 26\%,16\% and 4\%, respectively for ECC and $2 \%, 57 \%$ and $35 \%$, respectively for UHPC ) compared to flexural-critical frame while initial stiffness was increased by $60 \%$ (for SCC) and 24\% (UHPC).

- For ECC and UHPC frames the shear and moment resisting capacities obtained from the theoretical analysis were less compared to those obtained from the experiments, which 
illustrated the need to modify the existing equations/procedures. The fiber contribution taken into consideration in the flexure and shear capacity prediction in existing deign procedures should be carefully reviewed.

- The study confirmed the viability of constructing building using ECC/UHPC frames with enhanced structural performance compared to traditional concrete/SCC.

\subsection{Recommendation for future works}

The following recommendations are suggested for further research studies:

- Perform investigations are to be conducted on multi-storey SCC/ECC/UHPC frames subjected to monotonic and cyclic loading. For UHPC, tests to be conducted using high strength steel to utilize full benefit of high compressive strength.

- Conduct Investigations on SCC/ECC/UHPC framed shear wall systems with in-fill panels subjected to monotonic and cyclic shear as well as combined monotonic/cyclic shear and constant axial load on columns.

- Do investigation on ECC/UHPC beam-column joints only as well as frames incorporating ECC/UHPC beam-column joints under monotonic and cyclic loading.

- Carry out extensive finite element (FE) modeling of SCC/ECC/UHPC frames, joints and framed shear wall system based on experimental investigations to develop models. After verification of the FE models with experimental results, extensive numerical modelling with varying structural parameters is to be conducted for evaluating their influence on structural performance.

- Develop design guidelines or specifications for ECC/UHPC structural elements/systems based on experimental, numerical and design oriented analyses.

- Carry out life cycle analysis of SCC/ECC/UHPC structural elements/systems. 


\section{References}

ACI 318M-11 (2011). Building Code Requirements for Structural Concrete (ACI 318M-08) and Commentary. ACI Committee 318.

ACI Committee 318. Building Code Requirements for Reinforced Concrete, ACI-2011 and Commentary ACI 318R-2011, pp. 509.

ACI Committee 318. Building Code Requirements for Structural Concrete (ACI 318-05) and Commentary (318R-05). American Concrete Institute, Farmington Hills, MI, 2005, 430 p

ACI Committee 544. (1988). Design considerations for steel fiber reinforced concrete. ACI Structural Journal, 85(5), pp. 563-580.

ACI Committee 544.4.R-88 (1994), Design Considerations for Steel Fiber Reinforced Concrete. ACI manual of concrete practice, Part 1, material and general properties of concrete. pp. 118.

Acker, P., and Behloul, M. (2004), Ductal® Technology: A Large Spectrum of Properties,-A Wide Range of Application”, Proc. of the Int. Symp. on UHPC Kassel, Germany, pp.11-23.

Ahmed, P.I., and Puma, R.P. (1992) Ultimate flexural strength of reinforced concrete beams with large volumes of short randomly oriented fibers, Proce. of the 4th international RILEM Symposium on fiber reinforced cement and concrete, July 20-23, University of Sheffield, p.467-485, E and F Spon Limited, 2-6 Boundary Road, London, England.

Ardani, A.A., Lindsey, R., and Mallela, J.(2010) "One-weekend job rapid Removal and replacement of 4500 south bridge in Salt Lake City, Utah" Transportation Research Record, No. 2200, Washington, D.C., pp. 12-16.

Behnood, A., and Ghandehari, M. (2009), "Comparison of compressive and splitting tensile strength of high-strength concrete with and without polypropylene fibers heated to high temperatures", Fire Safety Journal, 44(8) 1015-1022.

Beshara, F. B. A., Shaaban, I. G., and Mustafa, T. S. (2012). Nominal Flexural Strength of High Strength Fiber Reinforced Concrete Beams. Arabian Journal for Science and Engineering, 37(2), 291-301.

Bierwagen, D., and Abu-Hawash, A. (2005), Ultra high performance concrete highway bridge, Proc. of the 2005 Mid-Continent Transportation Research Symposium, Ames, Iowa, 1-14. 
Blais, P., and Couture, M. (1999), Precast, prestressed pedestrian bridge - World's first reactive powder concrete structures, PCI Journal, Sept-Oct., 60-71.

Bonneau, O., Lachemi, M., Dallaire, E., Dugat, J., and Aïtcin, P.C. (1997), Mechanical properties and durability of two industrial reactive powder concretes, ACI Materials J. 94(4) 286-290.

Brackus, T.R., Barr, P.J., and Cook, W. (2013), Live-load and shear connection testing of fullscale precast bridge panels, Journal of Bridge Engineering, 18 (3) 210-219.

Brouwer, G. (2001), Bridge to the future, Civil Engineering, ASCE, November.

Caner, A., and Zia, P. (1998), Behavior and Design of Link Slabs with Jointless Bridge Deck. PCI Journal. pp. 68-80.

Çavdar, A., (2012), "A study on the effects of high temperature on mechanical properties of fiber reinforced cementitious composites", Composites: Part B, 43(5) 2452-2463.

Chan, Y. W., and Chu, S. H. (2004), Effect of Silica Fume on Steel Fiber Bond Characteristics in Reactive Powder Concrete, Cement and Concrete Research. 34(7): 1167-1172.

Chu, K. (2014), Behaviour of composite columns with high performance concrete", MASc Thesis, Dept. of Civil Engineering, Ryerson University.

Chu, K., and Hossain, K.M.A. (2014), Axial load behaviour of ECC-filled steel tube columns, Katie Chu and Khandaker M.A. Hossain, CSCE 2014 4th International Structural Specialty Conference, Halifax, NS, May 28 to 31.

Chu. K., and Hossain, K.M.A. (2015), Axial load behaviour of engineered cementitious composite concrete-filled steel tube columns, J. Constructional Streel research, (in press)

CSA Standard A23.3-04. (2010). Concrete Design Handbook, 10th edition, Ontario, Canada: CSA.

Culmo, M.P. (2011), Accelerated bridge construction: Experience in design, fabrication, and erection of prefabricated bridge elements and systems, U.S. Department of Transportation, Federal Highway Administration, Washington, DC.

Dallaire, E., Aitcin, P., and Lachemi, M. (1998), High performance powder, Civil Engineering, ASCE, January, 48-51.

Fischer, G., and Li, V. C. (2003), "Deformation Behavior of Fiber-Reinforced Polymer Reinforced Engineered Cementitious Composite (ECC) Flexural Members under Reversed Cyclic Loading Conditions", ACI Structural Jounrnal, 100(1) 25-35.

Fortner, B. (2001), FHWA gives superior marks to concrete bridge girder, Civil Engineering, ASCE, October, p. 17. 
Gencturk, B. (2012), Life-cycle cost assessment of RC and ECC frames using structural optimization, Earthquake engineering \& structural dynamics published online in Wiley Online Library (wileyonlinelibrary.com). DOI: 10.1002/eqe.2193

Hajar, Z., Lecointre, D., Simon, A., and Petitjean, J. (2004), Design and construction of the world first ultra-high performance concrete road bridges, Proc. of the Int. Symp. On UHPC, Kassel, Germany, September 13-15, pp.39-48.

Hannant, D.J. (1978), Fiber Cement and Fiber Concrete, Wiley \& Sons, Chichester, 219 pp.

Hartmann, J., and Graybeal, B. (2001), Testing of ultra-high performance concrete girders, Proc. PCI annual convention, Oct. Reno. NV, USA.

Hassoun, M. N., and Sahebjam, K. (1985), Plastic Hinge in Two-Span Reinforced Concrete Beams Containing Steel Fibers, Proceedings, Canadian Society for Civil Engineering, May, Montreal, pp119-139

Hayakawa, M., Matsuoka, Y., and Shindoh, T. (1993), "Development and Application of super Workable Concrete," Proceeding of an International RILEM Workshop on special concrete: Workability and Mixing, Scotland, pp.183-190.

Henager, C. H., and Doherty, T. J. (1976), Analysis of Reinforced Fibrous Concrete Beams, ASCE J. of Structural Engineering, 102(1): 177-188.

Hossain, K.M. A., Samani, S.G., and Ehsani, Y.A. (2015), Prediction of Strength Properties of Engineered Cementitious Composites using Artificial Neural Network, CSCE conference, Building on Our Growth Opportunities, May 27 - 30, 2015, Regina, SK, Canada.

Hossain, K.M.A. (2014), Structural performance of ultra-high performance concrete beams, Research Report, Department of Civil Engineering, Ryerson University, 89p.

Hossain, K.M.A. and Anwar, M.S. (2014), Properties of Green Engineered cementitious composites incorporating volcanic materials, Structural Faults + Repair, 2014, $8^{\text {th }}-10^{\text {th }}$ July, Imperial College, London, UK.

Hossain, K.M.A., Ametrano D., Mak C., and Lachemi M. (2011). , Bond strength and development length of GFRP bars in ultra-high performance concrete, Ministry of Transport Ontario (MTO) Technical Report (HIIFP Research Project), May, 89p.

Hossain, K.M.A., Ametrano, D., and Lachemi, M. (2014), Bond strength of GFRP bars in high strength concrete, ASCE J. of Materials in Civil Engineering, 26(3) 449-456. 
Hossain, K.M.A., Ametrano, D., Mak, C., and Lachemi, M. (2011), Bond Strength and Development Length of GFRP Bars in Ultra-High Performance Concrete", Ministry of Transport Ontario (MTO) Technical Report (HIIFP Research Project), May 2011, 89p.

Hossain, K.M.A., and Anwar, M.S. (2014). Strength and Deformation Characteristic of ECC Link Slab in Joint-Free Bridge Decks, Istanbul Bridge Conference, August, Istanbul, Turkey.

Hossain, K.M.A., and Ghatrehsamani, S. Flexural Fatigue Performance of ECC Link Slabs for Bridge Deck Applications, 8th New York City Bridge Conference - August 24-25, 2015.

Hossain, K.M.A., and Lachemi, M. (2010), "Fresh, mechanical, and durability characteristics of self-consolidating concrete incorporating volcanic ash", ASCE Journal of Materials in Civil Engineering, 22(7) 651-657.

Hossain, K.M.A., and Taormina, A. (2012), Axial load behaviour of profiled composite walling system under elevated temperatures, CSCE 3rd Int. Structural Specialty Conference, June 6-9, Edmonton, Canada.

Hossain, K.M.A., Kayes, M.A., Mavani, M.B., and Lachemi M. (2013), Influence of ECC Mixture on the structural performance of link slabs in bridge decks, $3^{\text {rd }}$ CSCE Specialty Conference on Material Engineering \& Applied Mechanics, Montréal, Québec, May 29-June 1.

Hossain, K.M.A., Mak, C., and Ametrano, D. (2012), GFRP reinforced UHPC composites for sustainable bridge construction, Canadian Civil Engineer, Spring (29.1) 12-15.

Hossain, K.M.A., Mak, C., and Ametrano, D. (2012), GFRP reinforced UHPC composites for sustainable bridge construction, Canadian Civil Engineer, spring (29.1) 12-15.

Imam, M., Vandewalle, L., Mortelmans, F., and Van Gemert, D. (1997). Shear domain of fibrereinforced high-strength concrete beams. Engineering structures, 19(9), 738-747.

Imam. M., Vandewalle, L., Mortelmans, F., and Van Gemert, D. (1997), Shear domain of fiber reinforced high strength concrete beams,

Issani R., and Hossain K.M.A. (2013). High performance ECC floor slabs in coupled shear wall structures, $3^{\text {rd }}$ CSCE Int. Spec. Conf. Material Eng. \& Applied Mech, Montréal, May 29June 1.

Issani. R (2012), Flexural behavior of ECC coupling slab in coupled shear wall structures, , MASc thesis, Civil Engineering, Ryerson University.

Kanda, T., and Li, V. C. (1998). Multiple Cracking Sequence and Saturation in Fiber Reinforced Cementations Composites. Concrete Research and Technology, JCI, 9(2), pp. 19-33. 
Khalil, W.I., and Tayfur, Y.R. (2013), Flexural strength of fibrous ultra-high performance reinforced concrete beams, ARPN Journal of Engineering and Applied Sciences, 8(3), 200214

Khatib, J. M. (2008), “Performance of self-compacting concrete containing fly ash", Construction and Building Materials, 22(9) 1963-1971.

Khayat, K. H., Paultre, P., and Tremblay, S. (2001), "Structural performance and in-place properties of self-consolidating concrete used for casting highly reinforced columns", ACI Materials Journal, 98(5) 371-378.

Khayat, K.H. (1999), "Workability, Testing, and Performance of Self-Consolidating Concrete," ACI Materials Journal, 96(3) 346-35.

Kojima, S., Sakata, N., Kanda, T., and Hiraishi, T. (2004). Application of Direct Sprayed ECC for Retrofitting Dam Structure Surface -Application for Mitaka-Dam. Concrete Journal, 42(5), 135-139.

Koksal, F., Altun, F., Yigit, I., and Sahin, Y. (2008), "Combined effect of silica fume and steel fiber on the mechanical properties of high strength concretes", Construction and Building Materials, 22(8) 1874-1880.

Kunieda, M., and Rokugo, K. (2006), "Recent progress on HPFRCC in Japan: Required performance and applications", Journal of Advances in Concrete Technology, 4(1) 19-33.

Lachemi, M., Hossain, K.M.A., Lambros, V.B., and Bouzoubaâ, N. (2003), "Development of Cost-Effective Self-Consolidating Concrete Incorporating Fly Ash, Slag Cement, or Viscosity-Modifying Admixtures", ACI Materials Journal, 100(5) 419-425.

Lepech, M. D., and Li, V. C. (2009). Application of ECC for Bridge Deck Link Slabs. RILEM Journal of Materials and Structures, 42(9), pp. 1185-1195.

Lepech, M., and Li, V. C. (2007). Large Scale Processing of Engineered Cementitious Composites. Accepted for publication in American Concrete Institute Materials Journal. American Concrete Institute Materials Journal, 105(4), 358-366.

Li, L., Ma, Z.J., and Oesterle, R.G. (2010) Improved longitudinal joint details in decked bulb tees for accelerated bridge construction: fatigue evaluation. J. Bridge Engineering 15(5) 511522 .

Li, V. C. (1995), "New construction materials proliferate in Japan", Civil Engineering (N.Y.), 65(8) $38-41$. 
Li, V. C. (1998), "ECC-tailored composites through micromechanical modeling", Proceedings on the International Symposium on Fiber Reinforced Concrete: Present and the Future, CSCE, Montreal, 64-97.

Li, V. C. (2003), "On engineered cementitious composites (ECC)-A review of the material and its applications", Advances in Concrete Technology, 1(3) 215-230.

Li, V. C. (2011). High-Ductility Concrete for Resilient Infrastructures. Journal of Advanced and High-Performance Materials, pp. 16-21.

Li, V. C., Lepech, M., Wang, S., Weimann, M., and Keoleian, G. (2004). Development of Green ECC for Sustainable Infrastructure Systems. In Proceedings of the International Workshop on Sustainable Development and Concrete Technology, Beijing, China, Wang, K., Ed., 181-192.

Li, V. C., Wang, S., and Wu, C. (2001), "Tensile strain-hardening behavior of PVA-ECC", ACI Materials Journal, 98(6) 483-492.

Li, V.C. (1993), "From micromechanics to structural engineering: the design of cementitious composites for civil engineering applications", Journal of Structural Mechanics and Earthquake Engineering, 10(2) 37-48.

Logan, D. (1997), Acceptance criteria for bond quality of strand for pretensioned prestressed concrete applications, PCI Journal, March/April, 52-90.

Mak, C., Hossain, K.M.A., and Lachemi, M. (2011). Splice length of GFRP bars in UHPC, $2^{\text {nd }}$ CSCE Int. Engineering Mechanics and Materials Specialty Conf., June 14-17, Ottawa.

Mitamura, H., Sakata, N., Shakushiro, K., Suda, K., and Hiraishi, T. (2005). Application of Overlay Reinforcement Method on Steel Deck Utilizing Engineered Cementitious Composites Mihara Bridge. Bridge and Foundation Engineering, Vol. 39, No. 8, 88-91.

Mitchel, D., Cook, W., Khan, A., and Tham, T. (1993), Influence of high-strength concrete on transfer and development length of pretensioning strand, PCI Journal, 38(3) 52-56.

Nawy, E. (2008). Concrete Construction and Engineering Handbook, Second Edition, New York, CRC Press.

Neville, A.M. (2002). Properties of Concrete. Fourth and Final Edition, John Wiley \& Sons, New York, pp. 884. 
Neville, A.M. (2010), "Properties of Concrete", $4^{\text {th }}$ Edittion, Pearson- Prentice Hill, .London, p. 844

Orton, S., Stinger, S., and Kirby, J. (2013) Static and Dynamic Disproportionate Collapse Testing of a Reinforced Concrete Frame. ASCE Structures Congress 2013: pp. 67-77. Pittsburgh, Pennsylvania, United States, May 2-4, 2013, Publisher: American Society of Civil Engineers.

Ozawa, K., Maekawa, K., Kunishima, H., and Okamura, H. (1989), "Performance of concrete based on the durability design of concrete structures", Proceedings on the 2nd East-AsiaPacific Conference on Structural Engineering and Construction, Vol. 1, Chiang Mai, Thailand, 445-456.

Özbay E., Karahan O., Lachemi M., and Hossain K.M.A. and Atis C.D. (2012). Investigation of properties of ECC Incorporating high volumes of fly ash and metakaolin", ACI Materials Journal, 109 (5) 565-571.

Özbay, E. Karahan, O. Lachemi, M. Hossain, K. M. A. and Atis C. D. (2013). Dual Effectiveness of Freezing-Thawing and Sulfate Attack on High-Volume Slag-Incorporated ECC. Composites Part B: Engineering, 45(1), pp. 1384-1390.

Özbay, E. Karahan, O. Lachemi, M. Hossain, K.M.A. and Atis, C.D. (2012). Investigation of Properties of Engineered Cementitious Composites Incorporating High Volumes of Fly Ash and Metakaolin. ACI materials journal, 109(5), pp. 565-571.

Park, R. (2011), ABC in Utah, Accelerated Bridge Construction: Research, Design, and Practice Workshop, 90th Annual Meeting of the Transportation Research Board, Washington, DC.

Petersson, O. (1998), "Application of self-compacting concrete for bridge castings", Swedish Cement and Concrete Research Institute, Stockholm, Sweden.

Poon, C. S., and Ho, D. W. S. (2004b), "A feasibility study on the utilization of r-FA in SCC", Cement and Concrete Research, 34(12) 2337-2339.

Poon, C.S., Shui, Z., and Lam, L. (2004a), "Compressive behavior of fiber reinforced highperformance concrete subjected to elevated temperatures", Cement and Concrete Research , 34(12) 2215-2222.

Rafiei, S., Hossain, K.M.A. Lachemi, M., Behdinan, K., and Anwar, M. (2013), FE modeling of double skin profiled composite shear wall system under in-plane loadings, Engineering Structures, 56(Nov) 46-57. 
Rafiei, S. (2011), Behaviour of double skin composite shear wall under in-plane monotonic, cyclic and impact loading”, PhD Thesis, Dept. of Civil Engineering, Ryerson University, 315p.

Rafiei, S., Hossain, K.M.A. Lachemi, M., and Behdinan, K. (2015), Profiled sandwich composite wall with high performance concrete subjected to monotonic shear, Journal of Constructional Steel Research, Volume 107, April 2015, Pages 124-136.

Rokugo, K., Kunieda, M. and Lim, S. C. (2005). Patching repair with ECC on cracked concrete surface. Vancouver, Canada.

Şahmaran M.L., Lachemi M., Hossain K.M.A., and Li, V.C. (2009), Influence of aggregate type and size on the ductility and mechanical properties of ECC, ACI Materials Journal, 106(3) 2009, 308-316.

Şahmaran M.L., Lachemi M., Hossain K.M.A., Ranade R., and Li, V.C. (2010). Internal curing of ECCs for prevention of early age autogenous shrinkage cracking, Cement and Concrete Research, 39(10) 893-901.

Şahmaran, M.L., and Li, V. C. (2009), "Durability properties of micro-cracked ECC containing high volumes fly ash", Cement and Concrete Research, 39(11) 1033-1043.

Sahmaran, M.L., Lachemi, M. Hossain, K. M.A. and Li, V.C. (2009). Influence of Aggregate Type and Size on Ductility and Mechanical Properties of Engineered Cementitious Composites. ACI Material Journal, 106(3), pp. 308-316.

Şahmaran, M.L., Lachemi, M., and Li, V.C. (2010),“Assessing Mechanical Properties and Microstructure of Fire-Damaged Engineered Cementitious Composites", ACI Materials Journal, 107(3) 297-304.

Şahmaran, M.L., Özbay,O., Yüce, H.E., Lachemi, M., and Li, V.C. (2011), "Effect of Fly Ash and PVA Fiber on Micro-structural Damage and Residual Properties of Engineered Cementitious Composites Exposed to High Temperatures”, Journal of Materials in Civil Engineering, December 2011 1735-1745.

Saisho, M. (2009) Steel Bar Fracture of Reinforced Concrete Frame under Extremely Strong Seismic Load. ATC and SEI Conference on Improving the Seismic Performance of Existing Buildings and Other Structures: pp. 1417-1428, San Francisco, California, United States, December 9-11, 2009, American Society of Civil Engineers 
Samani, S.G. (2015), Structural Performance of Link Slabs Subjected to Monotonic and Fatigue Loading Incorporating Engineered cementitious composites, MAsc thesis, Dept, of civil engineering, Ryerson University, June. 153p,

Sherir, M.A.A. (2012), Fracture, fatigue and creep performance of ECC mixtures with reference bridge deck applications, MASc Thesis, Dept. of Civil Engineering, Ryerson University.

Sherir, M.A.A., Hossain, K.M.A., and Lachemi, M. (2013), Behaviour of Engineered Cementitious Composites Under Fatigue Loading, 3rd Specialty Conference on Material Engineering \& Applied Mechanics, Montréal, Québec, May 29 to June 1.

Sherir, M.A.A., Hossain, K.M.A., and Lachemi, M. (2014), Fracture Energy Characteristics of Engineered Cementitious Composites Incorporating Different Aggregates, CSCE 2014 4th International Structural Specialty Conference, Halifax, NS, May 28 to 31, 2014.

Sherir, M.A.A., Hossain, K.M.A., and Lachemi, M. (2015), Structural Performance of Polymer Fiber Reinforced Engineered Cementitious Composites Subjected to Static and Fatigue Flexural Loading, Polymers 2015, 7, 1299-1330.

Slater, E., Moni, M., and Alam, M.S. (2012), "Predicting the shear strength of steel fiber reinforced beams." Construction and Building Materials, (26): 423-436.

Swamy, R.N., and Al-Ta'an, A.A. (1981), Deformation and Ultimate Strength in Flexure of Reinforced Concrete Beams Made with Steel Fiber Concrete, ACI JOURNAL, 78(5) 395405.

Taormina, A. (2012), Axial Load Behaviour of Double Skin Composite Walls Subjected to Elevated Temperatures", MASc Thesis, Dept. of Civil Engineering, Ryerson University.

Taormina, A., and Hossain, K.M.A.(2013), Post-Fire Axial Load Behaviour of Double Skin Composite Walls Incorporating Ultra-High Performance Concrete, 3rd Specialty Conference on Material Engineering \& Applied Mechanics, Montréal, Québec, May 29 to June 1.

Tateishi, Y., Jinno, Y., Kimoto, Y., and Hattori, A. (2009),Seismic Behavior of Reinforced Concrete Frame with New CFRP Units Infilled Wall, _ATC and SEI Conference on Improving the Seismic Performance of Existing Buildings and Other Structures: pp. 14171428, San Francisco, California, United States, December 9-11, 2009, American Society of Civil Engineers 
Tawfik, A.S., Badr M.R., ElZanaty. (2014). Behavior and ductility of high strength reinforced frames. Housing and Building National Research Center, 10, pp. 215-221.

Wang, S., and Li, V.C. (2007), "Engineered Cementitious Composites with High-Volume Fly Ash”, ACI Materials Journal, 104(3) 233-241.

Weimann, M.B., and Li, V.C. (2003), Hygral Behavior of Engineered Cementitious Composites (ECC). International Journal for Restoration of Buildings and Monuments, 9(5), pp. 513534.

Williamson, G. R. (1974), The Effect of Steel Fibers on the Compressive Strength of Concrete, Fiber Reinforced Concrete, SP-44, American Concrete Institute, Detroit, pp. 195-207

Yahia, A., Tanimura, M., Shimabukuro, A., and Shimoyama, Y. (1999), "Effect of rheological parameters on self-compatibility of concrete containing various mineral admixtures", Proceedings of the First RILEM International Symposium on Self-Compacting Concrete, Stockholm, Sweden, September, 1999, pp. 523-535. 


\section{Appendix A}

Base on the design procedure explained on section 2.5 the shear and moment resisting capacity of different components (beam and column) for SCC, ECC and UHPC has been calculated and presented in appendix A.

\section{A.1 Moment and Shear resisting capacity for SCC beam and columns}

\section{A.1.1 Beam moment resisting capacity}

Using equations 2.30 and 2.31 the resisting moment capacity of SCC beam has been calculated based on the experimental values obtained from tested specimens.

$$
\begin{aligned}
& a=\frac{\varphi_{s} A_{s} f_{y}}{\alpha_{1} \varphi_{c} f_{c}^{\prime} b} \\
& a=\frac{0.85 \times 200 \times 527}{0.76 \times 0.65 \times 50.56 \times 120}=29.89 \mathrm{~mm} \\
& M_{r}=\varphi_{s} A_{s} f_{y}\left(d-\frac{a}{2}\right) \\
& M_{r}=0.65 \times 200 \times 527 \times\left(134.5-\frac{29.89}{2}\right)=8.19 \mathrm{kN} . \mathrm{m}
\end{aligned}
$$

The resisting moment capacity is:

$M_{r}=8.19 \mathrm{KN} \cdot \mathrm{m}$

\section{A.1.2 Column moment capacity}

$$
\begin{aligned}
& a=\frac{0.85 \times 400 \times 478}{0.76 \times 0.65 \times 50.56 \times 120}=54.54 \mathrm{~mm} \\
& M_{r}=0.65 \times 400 \times 478 \times\left(136.5-\frac{54.54}{2}\right)=13.57 \mathrm{kN} . \mathrm{m} \\
& M_{r}=13.57 \mathrm{kN} . \mathrm{m}
\end{aligned}
$$

\section{A.1.3 Beam shear resisting capacity}

The concrete shear resisting capacity and stirrups capacity for SCC beam and column calculated from equations 2.32 to 2.36 as follow: 


$$
\begin{aligned}
& V_{r}=\varphi_{c} \lambda \beta \sqrt{f_{c}^{\prime}} b d_{v}+\varphi_{s} \frac{A_{v}}{s} f_{y} d_{v} \cot \theta \leq 0.25 \varphi_{c} f_{c}^{\prime} b d_{v} \\
& V_{r}=0.65 \times 1 \times 0.21 \times \sqrt{50.6} \times 120 \times 121.05+0.85 \times \frac{2 \times 30}{100} \times 429 \times 121.05 \times \cot 42^{\circ} \\
& V_{r}=14.02+29.41=43.43 \mathrm{kN}<V_{r, \max }=0.25 \times 0.65 \times 50.6 \times 120 \times 121.05 \\
& =118.16 \mathrm{kN}
\end{aligned}
$$

Shear capacity of SCC beam:

$V_{r}=43.43 k N$

\section{A.1.4 Column shear capacity}

$$
\begin{aligned}
& d=160-10-6-\frac{15}{2}=136.5 \mathrm{~mm} \\
& d_{v}=0.9 d=0.9 \times 136.5=122.85 \mathrm{~mm}
\end{aligned}
$$$$
V_{r}=0.65 \times 1 \times 0.21 \times \sqrt{50.6} \times 120 \times 122.85+0.85 \times \frac{2 \times 30}{100} \times 429 \times 122.85 \times \cot 42^{\circ}
$$$$
V_{r}=14.24+29.85=44.09 k N<V_{r, \max }=0.25 \times 0.65 \times 50.6 \times 120 \times 121.05
$$

$$
=118.16 \mathrm{kN}
$$

$V_{r}=44.09 k N$

\section{A.2 Moment and Shear resisting capacity for UHPC beam and columns}

\section{A.2.1 Beam moment resisting capacity}

Using equations 2.6, 2.12 and 2.31 the resisting moment capacity of UHPC beam has been calculated based on the experimental values obtained from tested specimens.

$M_{n}=A_{s} f_{y}\left(d-\frac{a}{2}\right)+\sigma_{t} b(h-c)(h+c-a) / 2$

Where 
$a=\frac{\left(A_{s} f_{y}+\sigma_{t} b h\right)}{\left(\lambda f_{c}^{\prime} b+\sigma_{t} b\right)}$

$\sigma_{t}=2 \eta_{o} \eta_{b} \eta_{l} V_{f} \tau_{f}\left(l_{f} / d_{f}\right)$

$\eta o:$ Orientation factor $=0.41 ; \eta b$ : Bond efficiency factor $=0.5 ; \eta l:$ Length efficiency factor $=$

$0.86 ; \tau f=0.66 \sqrt{ } f_{c^{\prime}} ; f_{c^{\prime}}:$ Compressive strength of normal strength concrete $(\mathrm{MPa}) ; \mathrm{lf}=14 \mathrm{~mm} ; \mathrm{df}$ $=0.4 \mathrm{~mm} ; \mathrm{Vf}=0.021 \%$;

$\sigma_{t}=2 \times 0.41 \times 0.5 \times 0.86 \times 0.021 \times 0.66 \sqrt{136} \times\left(\frac{14}{0.4}\right)=1.99 M P a$

$a=\frac{(200 \times 527+1.99 \times 120 \times 160)}{(0.66 \times 136 \times 120+1.99 \times 120)}=13.04 \mathrm{~mm}$

$M_{n}=200 \times 527 \times\left(134.5-\frac{13.04}{2}\right)+1.99 \times 120 \times \frac{(160-90)(160+90-13.04)}{2}$

$M_{n}=15.47 \mathrm{kN} \cdot \mathrm{m}$

\section{A.2.2 Column moment resisting capacity}

$a=\frac{(400 \times 478+1.99 \times 120 \times 160)}{(0.66 \times 136 \times 120+1.99 \times 120)}=20.83 \mathrm{~mm}$

$M_{n}=400 \times 478 \times\left(136.5-\frac{20.83}{2}\right)+1.99 \times 120 \times \frac{(160-90)(160+90-20.83)}{2}$

$M_{n}=26.02 \mathrm{kN} \cdot \mathrm{m}$

\section{A.2.3 Beam shear resisting capacity}

The concrete shear resisting capacity without shear reinforcement for UHPC beam and column calculated from equations 2.21 and 2.22 as follow:

$V_{\text {shear }}=0.6 \times \frac{1+\sqrt{\frac{5.08}{d_{a}}}}{\sqrt{1+\frac{d}{25 d_{a}}}} \times \sqrt[3]{\rho_{s}(1+4 F)} \times\left[f_{c}^{0.44}+275 \sqrt{\frac{\rho_{s}(1+4 F)}{\left(\frac{a}{d}\right)^{5}}}\right] b d$ 
$F=\left(\frac{L_{f}}{D_{f}}\right) V_{f} d_{f}$

Where:

$\rho_{s}=0.01$

$F=\left(\frac{14}{0.4}\right) \times 0.021 \times 0.5=0.3675$

$d_{a}=1.05 \mathrm{~mm}$

a: shear span $=990 \mathrm{~mm}$

$V_{\text {shear }}=0.6 \times \frac{1+\sqrt{\frac{5.08}{1.05}}}{\sqrt{1+\frac{134.5}{25 \times 1.05}}} \times \sqrt[3]{0.01(1+4 \times 0.3675)} \times\left[136^{0.44}\right.$

$$
+275 \sqrt{\left.\frac{0.01 \times(1+4 \times 0.3675)}{\left(\frac{990}{134.5}\right)^{5}}\right]} \times 120 \times 134.5
$$

$V_{C}=32.79 k N$

\section{A.2.4 Column shear resisting capacity}

Where

a: shear span $=680 \mathrm{~mm}$

$\rho_{s}=0.021$

$V_{\text {shear }}=0.6 \times \frac{1+\sqrt{\frac{5.08}{1.05}}}{\sqrt{1+\frac{136.5}{25 \times 1.05}}} \times \sqrt[3]{0.021(1+4 \times 0.3675)} \times\left[136^{0.44}\right.$

$+275 \sqrt{\left.\frac{0.01 \times(1+4 \times 0.3675)}{\left(\frac{680}{136.5}\right)^{5}}\right]} \times 120 \times 136.5$ 
$V_{C}=44.56 k N$

\section{A.3 Moment and Shear resisting capacity for ECC beam and columns}

\section{A.3.1 Beam moment resisting capacity}

Using equations 2.14 and 2.20 the resisting moment capacity of ECC beam has been calculated based on the experimental values obtained from tested specimens.

$$
\begin{aligned}
& T_{\text {Steel }}=0.4 f_{y} A_{s} \\
& T_{\text {steel }}=0.4 \times 527 \times 200=42.16 \mathrm{KN} \\
& T_{E C C-1}=f_{t}[(1-n) d+c] b \\
& n=\frac{0.02 \%}{0.4 \times 0.00234}=0.214 \\
& C=160-134.5=25.5 \mathrm{~mm} \\
& T_{E C C-1}=3.45 \times[(1-0.214) d+25.5] \times 120=(321.058) d+10557 \mathrm{KN} \\
& T_{E C C-2}=0.5 f_{t} n d b \\
& T_{E C C-2}=0.5 \times 3.45 \times 0.214 \times d \times 120=46.2 d K N \\
& C_{E C C}=0.5 f_{t}\left(\frac{1}{n d}\right)\left(t_{s}-d-c\right)^{2} b \\
& C_{E C C}=0.5 \times 3.45\left(\frac{1}{0.214 d}\right)(160-d-25.5)^{2}(120) K N \\
& T_{\text {Steel }}+T_{E C C-1}+T_{E C C-2}=C_{E C C} \\
& 559.5 d^{2}-302177 d+1673404=0 \\
& d=62.64 \mathrm{~mm}
\end{aligned}
$$




$$
\begin{aligned}
& T_{\text {steel }}=42.16 \mathrm{kN} \\
& T_{E C C-1}=30.76 k N \\
& T_{E C C-2}=2.90 \mathrm{kN} \\
& C_{E C C}=75.82 \mathrm{kN} \\
& M_{r}=\left\{T_{\text {Steel }} d+T_{E C C-1}\left(\frac{(1-n) d+c}{2}+n d\right)+T_{E C C-2}\left(\frac{2}{3}\right) n d\right. \\
& \left.+C_{E C C}\left(\frac{2}{3}\right)\left(t_{s}-d-c\right)\right\}\left(\frac{1}{1000}\right) \\
& M_{r}=\left\{42.16 \times 62.64+30.76\left(\frac{(1-0.214) \times 62.64+25.5}{2}+0.214 \times 62.64\right)\right. \\
& \left.+2.9\left(\frac{2}{3}\right) 0.214 \times 62.64+75.82\left(\frac{2}{3}\right)(160-62.64-25.5)\right\}\left(\frac{1}{1000}\right) \\
& M_{r}=8.64 k N . m \\
& n=\frac{0.02 \%}{0.4 \times 0.00231}=0.216 \\
& c=160-136.5=23.5 \mathrm{~mm} \\
& T_{E C C-1}=3.45 \times[(1-0.216) d+23.5] \times 120=(324.38) d+9729 K N \\
& T_{E C C-2}=0.5 \times 3.45 \times 0.216 \times d \times 120=44.805 d K N \\
& C_{E C C}=0.5 \times 3.45\left(\frac{1}{0.214 d}\right)(160-d-23.5)^{2}(120) K N \\
& T_{\text {steel }}+T_{E C C-1}+T_{E C C-2}=C_{E C C} \\
& 587.12-347290 d+17742286=0
\end{aligned}
$$

\section{A.3.2 Column moment resisting capacity}




$$
\begin{aligned}
& d=78.06 \mathrm{~mm} \\
& T_{\text {steel }}=76.48 \mathrm{kN} \\
& T_{E C C-1}=28.88 \mathrm{kN} \\
& T_{E C C-2}=2.53 \mathrm{kN} \\
& C_{E C C}=103 \mathrm{kN} \\
& M_{r}=\left\{476.48 \times 56.48+28.88\left(\frac{(1-0.216) \times 78.06+23.5}{2}+0.216 \times 56.48\right)\right. \\
& \left.\quad+3.46\left(\frac{2}{3}\right) 0.216 \times 56.48+103.07\left(\frac{2}{3}\right)(160-56.48-23.5)\right\}\left(\frac{1}{1000}\right) \\
& M_{r}=11.7 \mathrm{kN} . \mathrm{m}
\end{aligned}
$$

\section{A.3.3 Beam shear resisting capacity}

The concrete shear resisting capacity and stirrups capacity for ECC beam and column calculated from equations 2.21 and 2.22 as follow:

$V_{\text {shear }}=0.6 \times \frac{1+\sqrt{\frac{5.08}{d_{a}}}}{\sqrt{1+\frac{d}{25 d_{a}}}} \times \sqrt[3]{\rho_{s}(1+4 F)} \times\left[f_{c}^{0.44}+275 \sqrt{\frac{\rho_{s}(1+4 F)}{\left(\frac{a}{d}\right)^{5}}}\right] b d$

$F=\left(\frac{L_{f}}{D_{f}}\right) V_{f} d_{f}$

Where

$\rho_{s}=0.01$

$F=\left(\frac{14}{0.4}\right) \times 0.021 \times 0.5=0.3675$ 
$d_{a}=1.05 \mathrm{~mm}$

a: shear $\operatorname{span}=990 \mathrm{~mm}$

$$
\begin{aligned}
& V_{\text {shear }=0.6} \times \frac{1+\sqrt{\frac{5.08}{1.05}}}{\sqrt{1+\frac{134.5}{25 \times 1.05}}} \times \sqrt[3]{0.01(1+4 \times 0.3675)} \times\left[63.5^{0.44}\right. \\
& +275 \sqrt{\left.\frac{0.01 \times(1+4 \times 0.3675)}{\left(\frac{990}{134.5}\right)^{5}}\right] \times 120 \times 134.5} \\
& V_{C}=23.76 \mathrm{kN}
\end{aligned}
$$

\section{A.3.4 Column shear resisting capacity}

Where

a: shear span $=680 \mathrm{~mm}$

$\rho_{s}=0.021$

$$
\begin{aligned}
& V_{\text {shear }}=0.6 \times \frac{1+\sqrt{\frac{5.08}{1.05}}}{\sqrt{1+\frac{136.5}{25 \times 1.05}}} \times \sqrt[3]{0.021(1+4 \times 0.3675)} \times\left[63.5^{0.44}\right.
\end{aligned}
$$

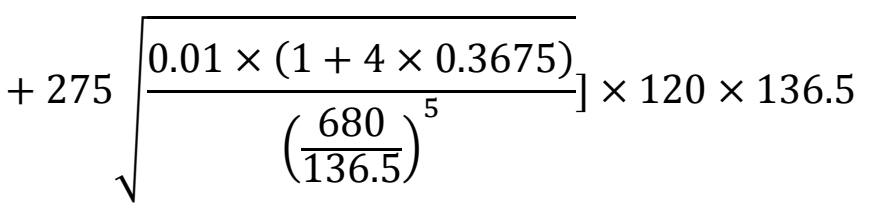

$$
\begin{aligned}
& V_{C}=32.92 \mathrm{kN}
\end{aligned}
$$

